\title{
Applying GIS to program performance measurement and evaluation: The case of children's community-based public health promotion programs
}

\section{by}

\author{
Kara Hayne, B.A. (Honours) 2000
}

A thesis submitted to the Faculty of Graduate and Postdoctoral Affairs in partial fulfillment of the requirements for the degree of

Master of Arts

In

Geography

Carleton University

Ottawa, Ontario

(C) 2012

Kara Hayne 
Library and Archives

Canada

Published Heritage

Branch

395 Wellington Street

Ottawa ON K1A ON4

Canada
Bibliothèque et

Archives Canada

Direction du

Patrimoine de l'édition

395 , rue Wellington

Ottawa ON K1A ON4

Canada
Your file Votre référence

ISBN: 978-0-494-94303-8

Our file Notre référence

ISBN: $978-0-494-94303-8$
NOTICE:

The author has granted a nonexclusive license allowing Library and Archives Canada to reproduce, publish, archive, preserve, conserve, communicate to the public by telecommunication or on the Internet, loan, distrbute and sell theses worldwide, for commercial or noncommercial purposes, in microform, paper, electronic and/or any other formats.

The author retains copyright ownership and moral rights in this thesis. Neither the thesis nor substantial extracts from it may be printed or otherwise reproduced without the author's permission.
AVIS:

L'auteur a accordé une licence non exclusive permettant à la Bibliothèque et Archives Canada de reproduire, publier, archiver, sauvegarder, conserver, transmettre au public par télécommunication ou par l'Internet, prêter, distribuer et vendre des thèses partout dans le monde, à des fins commerciales ou autres, sur support microforme, papier, électronique et/ou autres formats.

L'auteur conserve la propriété du droit d'auteur et des droits moraux qui protege cette thèse. $\mathrm{Ni}$ la thèse ni des extraits substantiels de celle-ci ne doivent être imprimés ou autrement reproduits sans son autorisation.
In compliance with the Canadian Privacy Act some supporting forms may have been removed from this thesis.

While these forms may be included in the document page count, their removal does not represent any loss of content from the thesis.
Conformément à la loi canadienne sur la protection de la vie privée, quelques formulaires secondaires ont été enlevés de cette thèse.

Bien que ces formulaires aient inclus dans la pagination, il n'y aura aucun contenu manquant. 


\section{ABSTRACT}

The application of spatial methods is notably absent from the program evaluation literature. To investigate the feasibility and utility of bridging the two disciplines, a spatial analytical approach was developed and applied in a practical case study of two federally-funded children's community-based public health promotion programs. With national coverage, small-area analysis was conducted on program delivery sites, target neighbourhoods based on a deprivation index, and service catchment areas as a means to examine program reach.

The central argument of this thesis is that spatial analysis can significantly improve and add value to existing approaches of measuring reach, thus contributing to program evaluation. The case study results validated the hypothesis and the principal conclusion was that neighbourhood level analysis through GIS is an achievable means of the development of new and meaningful evidence that is also useful for a host of further geographical inquiry at multiple scales including potential program gaps. 


\section{ACKNOWLEDGEMENTS}

First and foremost, I would like to thank my husband, Anil Hayne, for his incredible patience and support especially in the last few months of my thesis writing. Without his Superdad efforts, completing this thesis and therefore my Master's degree would not have been possible. Likewise, I thank my parents, Perry and Suzanne Linttell for their ongoing moral support. My sister, Jennifer Attridge, in-laws Derek and Heather Hayne, and other family and friends also deserve to be acknowledged for always believing in me.

Thank you, Dr. Fraser Taylor, for being so patient with my part time progress over the years. Your academic expertise, encouragement, and gentle ways of motivating me have been appreciated. I have much gratitude for Dr. David Bennett, who retired a little too soon to see the completion of this work, and Dr. Scott Mitchell who provided support in the last few phases of the thesis writing. Thank you, Aimee Barber, for your editorial support.

This educational endeavor would not have been possible without the generous support of the Public Health Agency of Canada. Colleagues who have encouraged me along the way include but are not limited to: Dr. Philip AbdelMalik, David A. Lewis, Dolon Chakravartty, Dr. Michael Goddard, Philip Ng, Clément Chabot, and Lauranne Matheson. A special thanks to Jay Barber and Kate-Lynn Duplessis for bringing forward such an interesting, challenging and relevant case study opportunity.

Lastly, I need to thank the person in the mirror for (finally) completing this while working full time and passing through major life milestones including getting married, becoming a home owner, birthing and mothering two young children, and undergoing career changes. Determination is how I reached my goal, despite obstacles and weaknesses. "In the confrontation between the stream and the rock, the stream always wins...not through strength but by perseverance" (H. Jackson Brown Jr).

I dedicate this thesis and my Master's degree to my two beautiful daughters, Eva and Carley, for whom l've strived to achieve this and teach through example to reach high and never give up, and that great things will come as a result. You are my sunshine.

In memory of my grandmother, Cecile Clement, who passed away just before my MA completion. 


\section{TABLE OF CONTENTS}

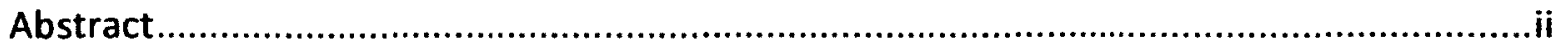

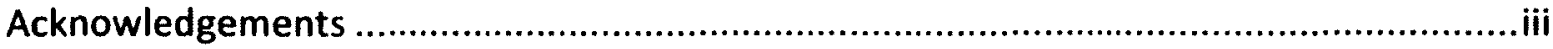

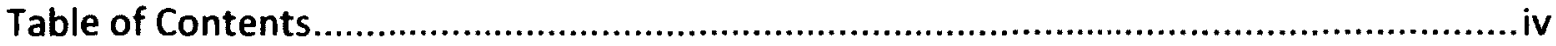

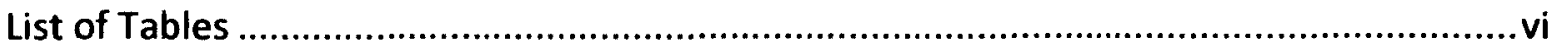

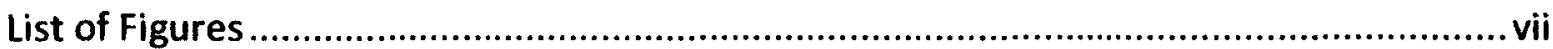

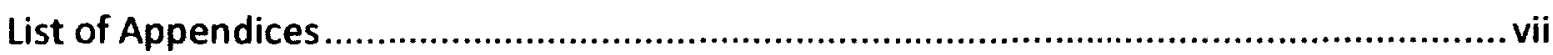

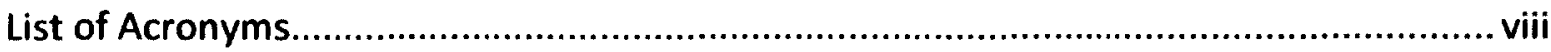

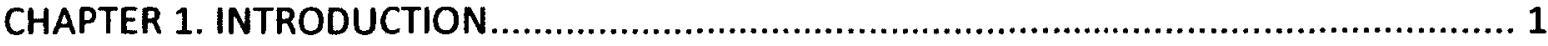

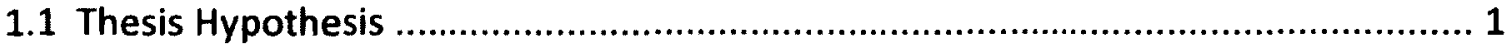

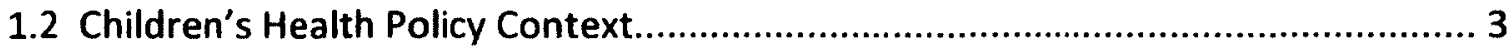

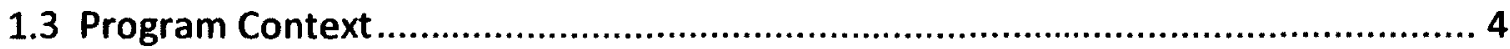

1.4 Challenge of Identifying Program Reach ................................................... 8

1.5 Current State of Identifying Program Reach................................................ 9

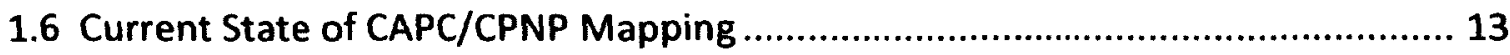

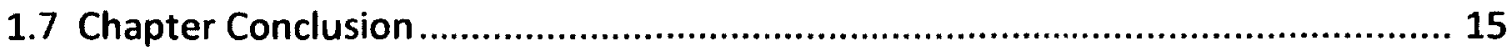

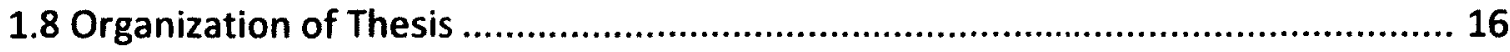

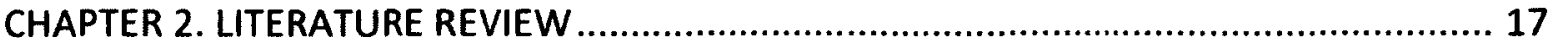

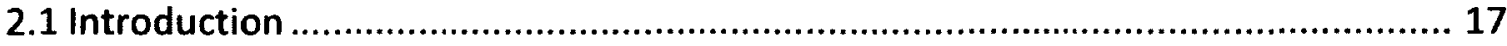

2.2 Population Health, Public Health and Medical Geography.............................. 17

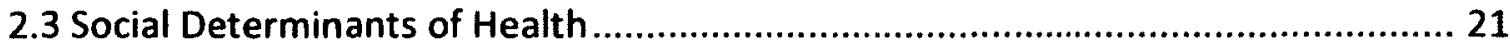

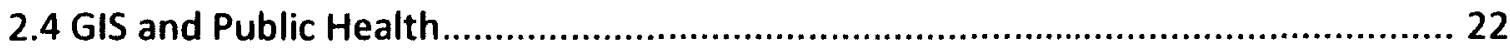

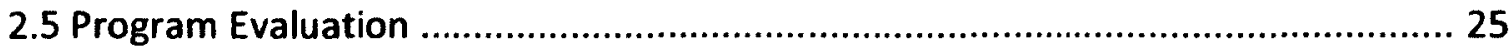

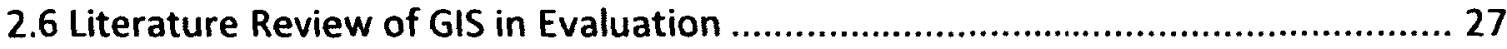

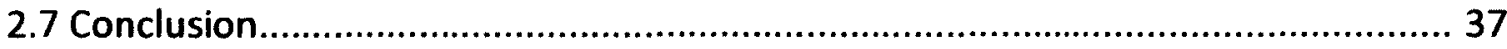

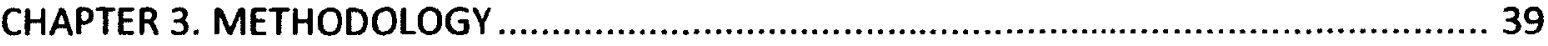

3.1 Site Locations and Catchment Areas ........................................................ 41

3.1.1 Site Address Collection .................................................................. 41

3.1.2 Site Address Geocoding ................................................................. 44

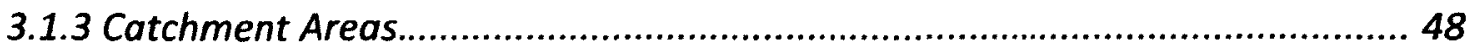

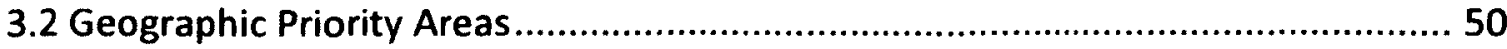


3.2.1 Literature Search of Deprivation Indices................................................. 52

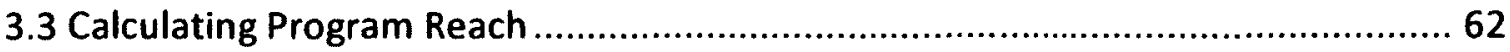

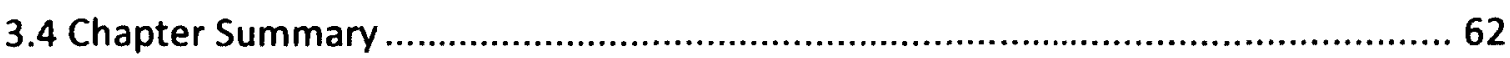

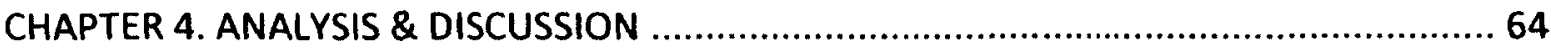

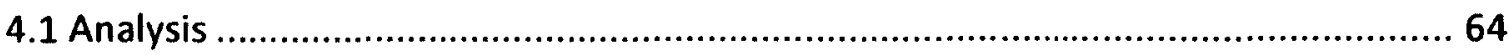

4.1.1 Locations of CAPC/CPNP Program Delivery Sites..................................... 64

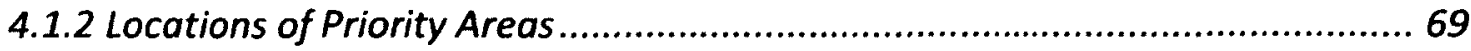

4.1.3 Program Reach of Priority Areas ....................................................... 73

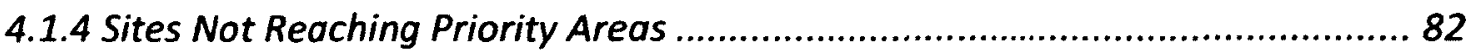

4.1.5 Program Underservice of Priority Areas ................................................. 82

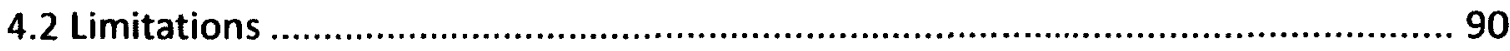

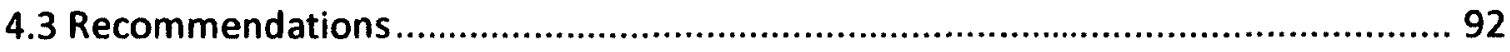

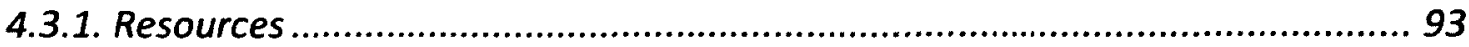

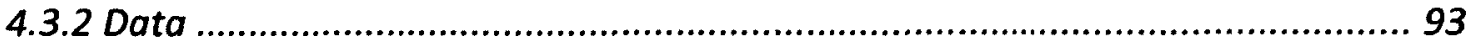

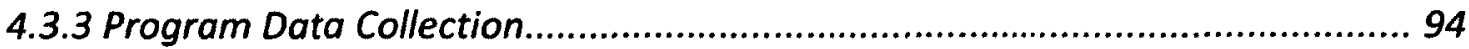

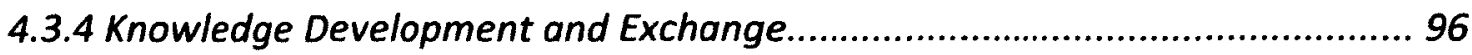

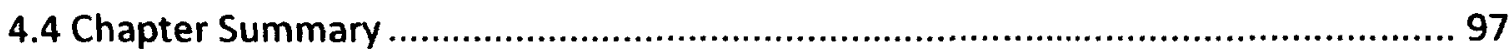

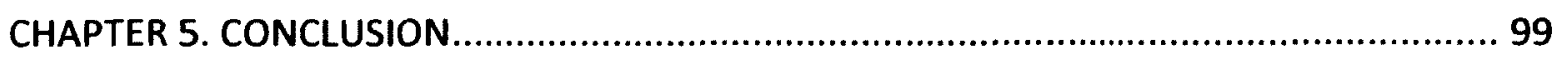

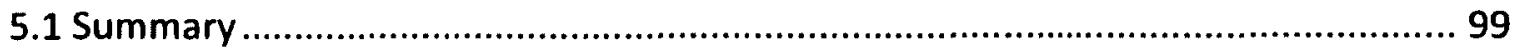

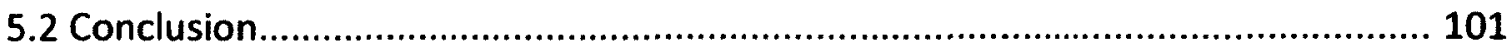

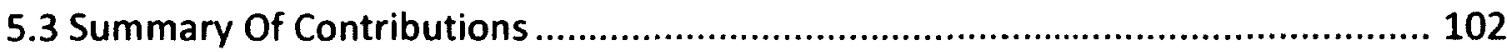

5.3.1 Significance to CAPC and CPNP Children's Programs .............................. 102

5.3.2 Significance to Federal Health Departments ....................................... 104

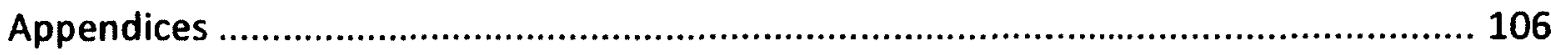

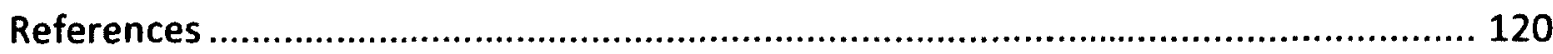




\section{LIST OF TABLES}

Table 1: CAPC \& CPNP Program Description ................................................................... 6

Table 2: Preliminary Search Key Words for Literature Review, 1990-2012 .................... 28

Table 3: Final Search Key Words for Evaluation Literature Review, 1990-2012 .............. 29

Table 4: GIS in Evaluation Literature Search Results ...................................................... 29

Table 5: Reference Details of Relevant Articles................................................................ 32

Table 6: Reference Details of Quasi-Relevant Articles ................................................... 33

Table 7: Number of Addresses Collected ........................................................................ 43

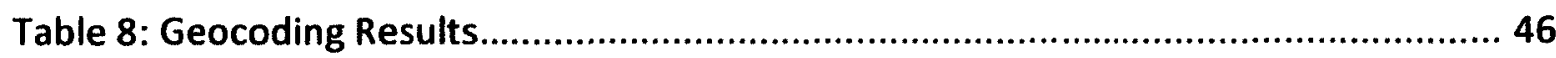

Table 9: Additional Geocoding Support Tools ................................................................ 47

Table 10: CAPC/CPNP Target Population.................................................................... 51

Table 11: Criteria for Deprivation Index Selection .......................................................... 53

Table 12: INSPQ Deprivation Index Components \& Variables ........................................ 55

Table 13: Priority Area Selection Criteria ..................................................................... 59

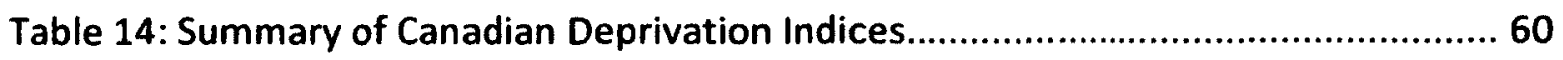

Table 15: CAPC/CPNP Sites by Province/Territory and Type of Community .................... 66

Table 16: Priority Areas by Province/Territory and Type of Community ......................... 72

Table 17: CAPC/CPNP Reach of Priority Areas within Various Driving Distances from

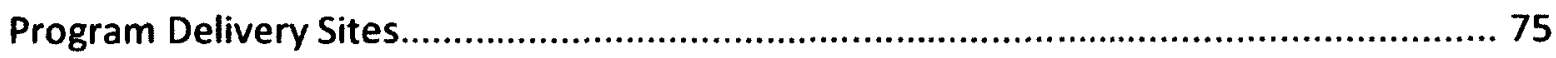

Table 18: CSDs with the Top 10 Most Populated Priority Areas, and the Extent of their

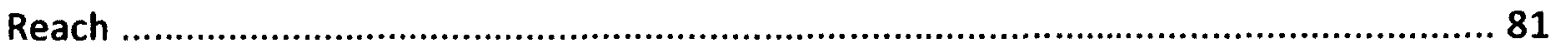

Table 19: Number of Potentially Underserviced Communities by Province/Territory .... 88

Table 20: Top 10 Most Populated Potentially Underserved Communities in Three

Program Reach Scenarios .......................................................................................... 89 


\section{LIST OF FIGURES}

Figure 1: CAPC Program Profile Geographic Reach Question ................................ 11

Figure 2: CAPC/CPNP Integrated Geographic Reach Question (1) .......................... 12

Figure 3: CAPC/CPNP Integrated Geographic Reach Question (2) ........................ 12

Figure 4: PHAC National Map of CAPC \& CPNP Projects ....................................... 14

Figure 5: Timeline of GIS in Evaluation Journals, 1990-2012, with country of origin ...... 31

Figure 6: Service Area Settings in ESRI ArcGIS ..................................................... 50

Figure 7: INSPQ Deprivation Index Map Legend .............................................. 56

Figure 8: INSPQ Deprivation Index and Health Issues .......................................... 57

Figure 9: Map of CAPC and CPNP Program Delivery Sites across Canada.................... 67

Figure 10: Map of Priority Areas across Canada.................................................. 71

Figure 11: Map of Comparison of Euclidean and Driving Distance Methods for

Calculating Program Reach, Using British Columbia CAPC Sites as a Sample ................. 76

Figure 12: Map of a Sample Community-Level Analysis of CAPC Program Delivery Site

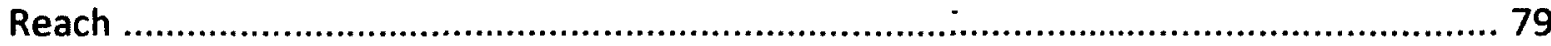

Figure 13: Map of Priority Area with the Greatest Number of Children Aged 0 to 6 in Canada: Dissemination Area \#35204567 within St. James Town, City of Toronto $(n=809)$

Figure 14: Map of Sample Regional-Level Analysis of Potentially Underserviced Communities

\section{LIST OF APPENDICES}

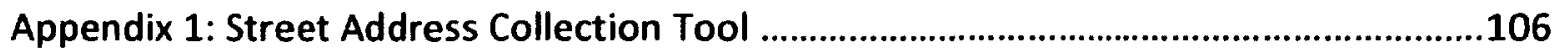

Appendix 2: Geocoding Results of Site Addresses .......................................................109

Appendix 3: List of Communities Potentially Not Reached by CAPC/CPNP Programs, by Province/Territory 


\section{LIST OF ACRONYMS}

CAPC Community Action Program for Children

CMA census metropolitan area

CPNP Canada Prenatal Nutrition Program

CSD census subdivision

CUMI Canadian Urban Marginalization Index

DA dissemination area

ECD early childhood development

EDI Early Development Instrument

FASD Fetal Alcohol Spectrum Disorder

GIS geographic information system

INET Integrated National Evaluation Tool

INSPQ Institut nationale de santé publique du Québec

LICO low income cut-off

MAUP modifiable areal unit problem

NPP National Program Profile performance measurement tool

$\mathrm{P} / \mathrm{T} \quad$ province/territory

PCA principal component analysis

PHAC Public Health Agency of Canada

RE-AIM reach, effectiveness, adoption, implementation, maintenance

SES socioeconomic status

UNCRC United Nations Convention on the Rights of the Child

WHO World Health Organization 


\section{CHAPTER 1. INTRODUCTION}

\subsection{THESIS HYPOTHESIS}

Geographic information systems (GIS) and spatial analytical methods have immense potential in the field of public health program evaluation as an innovative approach to the production of new and insightful evidence. Geospatial techniques are well documented in the geography and public health literatures, especially in the applications of disease ecology, epidemiology, and increasingly in health care service access and utilization. Evidence of geospatial applications to public health program evaluation, however, is notably absent in the evaluation literature. Its potential utility has been relatively unacknowledged, and when GIS is used, its capability is underutilized (Renger, Cimetta, Pettygrove \& Rogan, 2002; Koschinsky, 2012).

Performance measurement and evaluation comprise the analysis of a program's impact, relevance, cost-effectiveness and effectiveness in achieving desired results. One key evaluative element or indicator of program delivery is whether or not the program is reaching the intended target population, regardless of its efficacy. This is particularly critical for programs that deliver services in-person since they must physically reach their intended audience.

The central argument of this thesis is that spatial analysis can significantly improve and add value to existing approaches of measuring reach, thus contributing to program evaluation. Results from this research will be contrasted with the existing ways of measuring reach of community-based public health programs, which have some 
shortcomings. A spatial analytical approach will be developed in a practical case study of two well-established children's health promotion programs to test the validity of the central argument of the value added by spatial analysis. Small-area analysis will be applied while simultaneously maintaining national coverage to demonstrate that, even for federal government departments, neighbourhood level analysis is an achievable means for the development of new and meaningful evidence that is also useful for a host of further geographical inquiries.

The research question emerged from real performance measurement and evaluation needs of a Canadian federal government department, specifically the Public Health Agency of Canada (PHAC). The evaluation function within the department had no previous geomatics capacity, and in the past had only mapped program locations in a national visual representation for general reference, likely produced by a communication service. For the purpose of performance measurement and evaluation of two PHAC-funded children's health promotion programs, the department was interested in applying geographic approaches to answer two basic reach questions that had been otherwise unanswered over the programs' decade-long lifespans:

1. Where are the target children aged 0 to 6 located across Canada?

2. Are program delivery sites located within relative proximity to this population? 


\subsection{CHILDREN'S HEALTH POLICY CONTEXT}

In the early child development literature, there is significant evidence suggesting that healthy development during childhood strongly influences the health and wellbeing throughout the life course (Mustard, 2002), and that "investment in early childhood is the most powerful (public) investment a country can make, with returns over the life course many times the amount of the original investment" (Irwin, Arjumand Siddiqi \& Hertzman, 2007, p. 16).

In 1991, the Government of Canada became bound by provisions of the United Nations Convention on the Rights of the Child (UNCRC). The UNCRC has 54 articles $^{1}$ to establish the basic human rights of the child, founded on four core principles: nondiscrimination; devotion to the best interests of the child; the right to life, survival and development; and, respect for the views of the child. The Public Health Agency of Canada is responsible for coordinating federal implementation of the Convention in Canada through policies, legislation and programs.

Acting upon its commitment to the promotion and protection of children's health, PHAC implemented various programs and initiatives on Fetal Alcohol Spectrum Disorder (FASD), family violence prevention, Aboriginal children's school readiness, adolescent health, prenatal and postnatal care, and early child development, targeting vulnerable families and specific audiences such as health care practitioners. The case study within this work is based on two of these programs - the Canada Prenatal

\footnotetext{
' UNCRC Articles available online at: http://www2.ohchr.org/english/law/crc.htm
} 
Nutrition Program (CPNP) and the Community Action Program for Children (CAPC) which are further described in the following section.

\subsection{PROGRAM CONTEXT}

The CAPC and CPNP were initiated by the Liberal government in the early 1990s, with the Public Health Agency of Canada funding local coalitions and non-government community-based organizations through transfer payments (contributions) to the provinces and territories in the amount of $\$ 52.9 \mathrm{M}$ and $\$ 27.2 \mathrm{M}$ annually to each program, respectively (Public Health Agency of Canada, 2010). The purpose of the programs is to complement existing early childhood development (ECD) programs and services, and not to duplicate or reduce the responsibilities of other jurisdictions. The Public Health Agency of Canada therefore is not mandated to fund programs in every single community.

The designs of these community-based health promotion programs are grounded on well-established principles in the areas of health promotion, child development, early intervention, population health, and determinants of health. As such, the programs offer activities and services to children aged 0 to 6 , and pregnant women and their families who are living in conditions of risk which may impact their ability to reach optimal health. Vulnerability was considered by the programs as multiple conditions of risk including low income, teenage parents, recent immigrants, social or geographic isolation, substance abuse, family violence, Aboriginal children, lone parenting, and children with developmental problems. 
The CAPC and CPNP programs offer various in-person, culturally appropriate services including but not limited to nutritional support, child development activities and literacy, pre/postnatal support, and physical activities. Each contribution recipient organization must meet minimum requirements in order to obtain funding. The flexibility granted in the service delivery model, however, enables each communitybased organization to tailor their project's activities and services to the specific needs of the community. As a result, the activities and intervention strategies vary considerably between projects and across the country (e.g. services offered, language of service, type of community partnerships, type of community served, types of facilities used to deliver the services, volunteer capacity, cultural activities, etc.). Table 1 summarizes the CAPC and CPNP program descriptions. 
Table 1: CAPC \& CPNP Program Description

\begin{tabular}{|c|c|c|}
\hline & CAPC $^{\mathrm{a}}$ & CPNP ${ }^{b}$ \\
\hline $\begin{array}{l}\text { Year } \\
\text { Implemented }\end{array}$ & 1994 (announced in 1992) & 1994 (announced in 1994) \\
\hline $\begin{array}{l}\text { Number of } \\
\text { Projects }\end{array}$ & 441 & 330 \\
\hline $\begin{array}{l}\text { PHAC } \\
\text { Funding }\end{array}$ & $\begin{array}{l}\$ 52.9 \text { million ( } \$ 120 \mathrm{k} \text { per project) } \\
\text { annually }\end{array}$ & $\begin{array}{l}\$ 27.2 \text { million ( } \sim 82 \mathrm{k} \text { per project) } \\
\text { annually }\end{array}$ \\
\hline $\begin{array}{l}\text { Reported } \\
\text { Reach } \\
\end{array}$ & $\begin{array}{l}\text { More than } 3,000 \text { communities across } \\
\text { Canada }\end{array}$ & $\begin{array}{l}\text { Close to } 50,000 \text { women in over } 2,000 \\
\text { communities across Canada per year. }\end{array}$ \\
\hline $\begin{array}{l}\text { Services } \\
\text { Offered }\end{array}$ & $\begin{array}{l}\text {-drop-in childcare } \\
\text {-school readiness programs for } \\
\text { preschoolers } \\
\text {-outreach and home visiting } \\
\text {-nutritional support and collective } \\
\text { kitchens } \\
\text {-child development activities } \\
\text {-cultural programs } \\
\text { - healthy physical activities } \\
\text {-literacy development } \\
\text {-community capacity building }\end{array}$ & $\begin{array}{l}\text {-food/vitamin supplements or } \\
\text { vouchers } \\
\text {-nutrition counseling/education } \\
\text {-social support } \\
\text {-pre/postnatal information \& support } \\
\text {-breastfeeding information and } \\
\text { incentives } \\
\text {-transportation assistance/bus tickets } \\
\text {-culturally sensitive prenatal support } \\
\text { for off-reserve Aboriginal women. }\end{array}$ \\
\hline $\begin{array}{l}\text { Targeted } \\
\text { Population }\end{array}$ & $\begin{array}{l}\text {-Children living in low-income families; } \\
\text {-children living with teenage-parents; } \\
\text {-children experiencing developmental } \\
\text { delays, social, emotional or } \\
\text { behavioural problems; } \\
\text {-abused and neglected children. } \\
\text { - Métis, Inuit and off-reserve First } \\
\text { Nations children, } \\
\text {-children of recent immigrants and } \\
\text { refugees, } \\
\text {-children in lone-parent families, } \\
\text {-children who live in remote and } \\
\text { isolated communities. }\end{array}$ & $\begin{array}{l}\text { Children and their families living in } \\
\text { conditions of risk: } \\
\text {-Poverty } \\
\text {-teenage pregnancy } \\
\text {-social or geographic isolation with } \\
\text { poor access to services } \\
\text {-recent arrival to Canada } \\
\text {-alcohol or substance abuse } \\
\text {-family violence }\end{array}$ \\
\hline Objectives & $\begin{array}{l}\text {-Improve the health and social } \\
\text { development of children and their } \\
\text { families; } \\
\text {-Increase partnerships; } \\
\text {-Increase the number of effective } \\
\text { community resources and programs; } \\
\text {-Increase support for communities at- } \\
\text { risk, their needs, interests and rights; } \\
\text {-Increase empowerment and } \\
\text { knowledge of families and } \\
\text { communities; and } \\
\text {-Increase accessibility to culturally- } \\
\text { appropriate and linguistically- } \\
\text { sensitive programming. }\end{array}$ & $\begin{array}{l}\text {-Reduce the incidence of babies born } \\
\text { with birth weights that are too high } \\
\text { or too low } \\
\text {-Improve the health of pregnant } \\
\text { women and their infants } \\
\text {-Promote and support the initiation } \\
\text { and duration of breastfeeding } \\
\text {-Increase the accessibility of services } \\
\text { and community supports for } \\
\text { pregnant women } \\
\text {-Build partnerships, linkages and } \\
\text { collaboration within communities }\end{array}$ \\
\hline
\end{tabular}

Sources: ${ }^{a}$ PHAC 2010c, ${ }^{b}$ PHAC 2010b 
The Public Health Agency of Canada currently funds 441 CAPC projects, and 330 CPNP projects. Each project usually has one administrative site, which may also act as a main program delivery site, and one or more satellite sites within the community or area to increase participant reach and access to their services. Through the street address data collection process of the case study, it was determined that there is a total of almost 2,300 program delivery sites from these 771 projects combined across Canada. The CAPC and CPNP programs are evidently large, comprehensive and complex. The Treasury Board of Canada, the management body of the federal government, is responsible for financial and administrative management, regulation approval, policy implementation, and accountability and ethics. To satisfy Treasury Board reporting requirements as per its policy on evaluation ${ }^{2}$, the Public Health Agency of Canada is responsible for conducting a summative program evaluation of CAPC and CPNP every five years, which is supported by the annual collection and analysis of performance measurement data, and special infrequent studies including economic analysis and outcomes assessments.

\footnotetext{
${ }^{2}$ Treasury Board of Canada Policy on Evaluation, accessed August 24, 2012: http://www.tbs-sct.gc.ca/pol/doc-eng.aspx ?id=15024
} 


\subsection{CHALLENGE OF IDENTIFYING PROGRAM REACH}

Glasgow, Vogt and Boles (1999) argued that the then existing evaluation frameworks were insufficient for evaluating public health community-based interventions, and, as a result, they proposed their "RE-AIM" evaluation framework model. The RE-AIM model has five key components: reach, effectiveness, adoption, implementation, maintenance. As a strong indication that this framework is still relevant, it was later peer reviewed, tested, and endorsed by other health promotion researchers and organizations (McKenzie, Naccarella, Stewart \& Thompson, 2007; Centre for Disease Control, 2011).

As suggested in the RE-AIM model and for the sake of accountability of public expenditure, it is imperative to demonstrate that the program is at least reaching the intended audience or target population. Reporting on program participation counts is a rather straightforward measurable statistic to collect from projects and is an important indicator in program evaluation. From a program management and accountability perspective, however, the number of participants is insufficient as a stand-alone indicator for program reach. Ideally, dividing the participant count (numerator) by the overall target population (denominator) would indicate the magnitude of need and program uptake while also producing a proportion that can be analyzed over time to demonstrate program success and progress as either the numerator or denominator increases or decreases.

Identifying an explicit denominator and finding the data, due to the complexity of multiple conditions of risk that affect the CAPC and CPNP target population, as listed 
in Table 1, is a difficult task and has not been achieved by the evaluation function of PHAC, nor statistical entities like Statistics Canada. A socio-demographic index could be used as a proxy to assist with developing this indicator, and will be explored much further in the case study methodology and results.

\subsection{CURRENT STATE OF IDENTIFYING PROGRAM REACH}

It is important to note that CAPC and CPNP evaluation documents seem to treat "reach" and "access" synonymously. As indicated in the literature, "access" is a broad and complex concept involving many factors including population characteristics (e.g. attitudes towards healthcare, willingness to seek services, predisposing factors of population at risk), utilization rates, satisfaction scores, availability of resources (e.g. healthcare professionals, healthcare facilities), days or time of services, wait times, travel time, processing time, socio-organizational attributes (e.g. fees, sex of the healthcare provider, system navigation processes), and geographic attributes (e.g. physical distance) (Aday \& Anderson, 1974; Goddard \& Smith, 2001; Wilson \& Rosenburg, 2004). This case study focuses on geographic proximity to represent reach (or geographic access) and does not study the other factors of access.

As previously emphasized, reach is a key program measurement indicator. In a PHAC summary report of program evaluations on its population health contributions programs, it broadly states that "the expected outcomes are increasing program participants' access to resources, increased reach, improved processes, and a broader 
and deeper capacity and capability to influence or carry out policy development and program delivery" (Section 9.1, PHAC 2010).

Specifically, the Public Health Agency of Canada claimed that "programs such as CPNP make significant effort in identifying their target populations and locating/funding projects in close proximity to them so as to increase accessibility...The evaluations for ...CAPC and CPNP were also successful in providing quantitative indicators of reach" (Section 9.7, PHAC 2010).

For a few data collection years, PHAC collected demographic information from CAPC and CPNP participants in order to report on the socio-demographics of the population reached (e.g. number of Aboriginals, teen mothers, etc.). Although this demographic profile approach indicates to what degree the program is providing services to its intended audience, it does not indicate the degree to which the programs are fulfilling a need.

Historically, CAPC collected a geographic reach indicator through the following question, shown in Figure 1, in their annual National Program Profile performance measurement data collection tool, up until the 2005/06 reporting year after which the survey was cancelled. PHAC has published evaluation results and other program information products using the sum of responses to the question in Figure 1, as a representation of the total number of communities served by this program (e.g. "A total of 3,177 communities across Canada were reached through CAPC projects" (PHAC, 2010c, p.29)). Due to the inconsistent definition of 'community' (4 answer options) and the potential for duplication in reporting by individual projects serving overlapping 
communities, this indicator of 'reach' is flawed. The summative evaluation recognizes

this as a limitation and as a result, the number of communities reached is not

mentioned within the executive summary's key findings of program impact.

\section{Figure 1: CAPC Program Profile Geographic Reach Question}

2b. In this reporting period. how many different geographic communities were served by your (APC project? Please be careful not to double count communities. For example, if your project serves 5 neighbourhoods in 1 town, your answer should be "5 neighbourhoods," or" 1 town" nol "5 neighbourhoods and I lown."

This question is being asked to... determine the "reach" of the dollars invested in CAPC and to assess the difference in service delivery anong projects in urben, rural and renote areas.

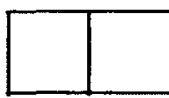

Neighbourhoods

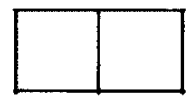

Villages or other rural communities

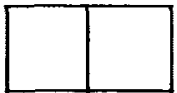

Towns or cities

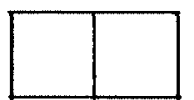

Other (please specify):

$\square$ Vot applicable given project stnucture (for example: if your project covers the whole province or territory)

Source: CAPC National Program Profile performance measurement tool (NPP) 2005/06

The CAPC/CPNP Integrated National Evaluation Tool (INET) is another standard

performance measurement data collection process conducted annually by the Public

Health Agency of Canada. A component of this tool is to assess the geographic reach of both CAPC and CPNP using the two key geography related questions shown in Figures 2 and 3, below. 
Figure 2: CAPC/CPNP Integrated Geographic Reach Question (1)

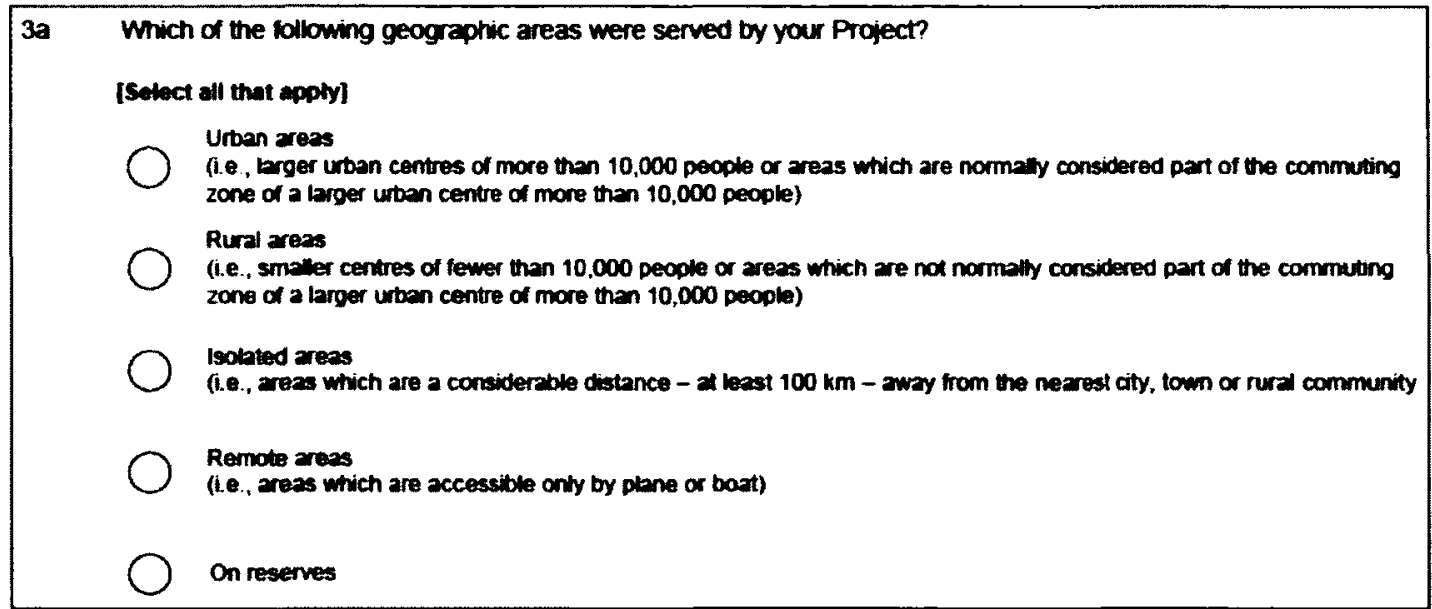

Source: PHAC Integrated National Evaluation Tool (INET) 2009/10

Figure 3: CAPC/CPNP Integrated Geographic Reach Question (2)

3b Which of the following best describes the location of participants who are served by your project?
[Seloct only one]
Located in one city, town or rural community
Located in more than one city, town or nural community
Located in the whole province or teritory
Other - specify

Source: PHAC Integrated National Evaluation Tool (INET) 2009/10

These three questions about number and type of communities served, type of geographic area served, and basic geographic distribution of participants, are attempting to determine the level of program reach, but are insufficient. The use of the quantitative results from the first question to reflect total number of communities served has been reflected in simplistic terms based on projects self-reporting the number of communities they serve.

Based on these questions alone, the key evaluation question of proportion of target population reached cannot be answered. Firstly, the structure of the questions in 
the performance measurement tools does not permit projects to list the communities they reach, but rather, they report a simple numerical count. As a noted limitation in the 2004-2009 CAPC summative evaluation, the sum of communities reached within each province could very easily represent double-counting. "A community definition could include geographical boundaries, neighbourhoods or specific sub-populations and is noted as a limitation as this may include double-counting at the project level" (Public Health Agency of Canada, 2010, p. 29).

\subsection{CURRENT STATE OF CAPC/CPNP MAPPING}

Prior to this work, PHAC had rarely and minimally applied geographic information systems to the CAPC and CPNP programs. In fact, only one instance was found throughout this research. In April 2008, the Public Health Agency of Canada had a national map created, identifying the cities or communities having at least one project, as shown in Figure 4. However, the purpose of this map is limited to general program promotion and communications through the medium of posters, presentations, websites and other graphic outputs for public consumption. The project locations on the map reflect the administrative sites of sponsored organizations (774 combined), and exclude geographical reference to the main and satellite program delivery sites (approximately 2,300 combined). Spatial analysis capabilities of GIS could be applied to identify program delivery locations in relation to the location of the target population using a population-based dataset. 
Figure 4: PHAC National Map of CAPC \& CPNP Projects

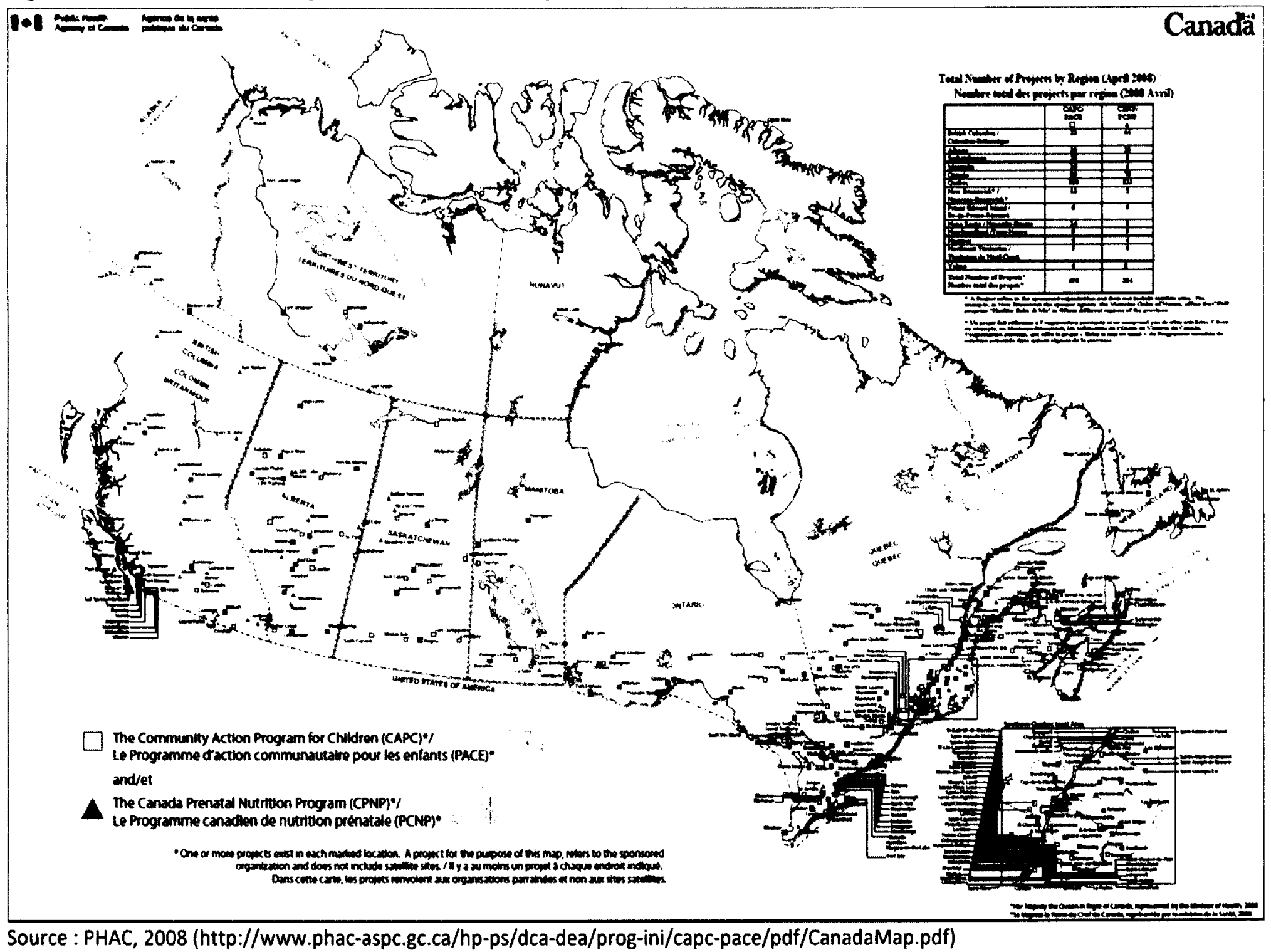




\subsection{CHAPTER CONCLUSION}

Applying GIS to add value to the current approach to assessing program reach, and therefore to the performance measurement and evaluation of the CAPC and CPNP programs according to the RE-AIM model for community-based public health interventions, could positively impact the national and international policies with which they are aligned. PHAC's role is to provide funding to projects selected through a solicitation process, regularly collect and analyze performance measurement data through process survey tools, develop additional lines of evidence including special research studies, and conduct summative program evaluations every five years. It is the primary goal of this research to develop and apply spatial methods and techniques to demonstrate their potential to support the organization in improving its analysis and reporting for evaluation purposes.

A secondary goal of this research is to open a new window of opportunity for further spatial investigation besides identifying reach of target population. The Government of Canada's Policy on Evaluation, introduced in April 2009, emphasises the role of federal departments' evaluation function in informing government expenditure decisions by providing neutral and credible evidence about the value for money of its programs (Treasury Board of Canada Secretariat, 2011). Especially under current economic times of deficit reduction, there is great interest in the utilization of evaluation recommendations to inform streamlining and priorities for government resources. As such, the secondary objective is to argue for the utility of GIS in identifying potential gaps in service and therefore supporting program strategic planning. 


\subsection{ORGANIZATION OF THESIS}

This chapter has introduced the central argument of the research and has briefly shed light on the importance of this work. The goal is to bridge the disciplines of geomatics and evaluation by arguing through demonstration the added value of spatial analytical methods in the production of new and meaningful evidence. By narrowing the gap between geomatics and evaluation, the expectation is a strengthened approach to evidence-building and decision-making support for public health program evaluation, as well as a model on which other departments and organizations with similar information needs may build.

Chapter 2 offers a critical discussion of the literature to situate this research and to reveal gaps and opportunities for GIS in program evaluation. Chapter 3 develops the chosen methodology with emphasis on the process of selecting the population-based data and the application of spatial analysis techniques. The resulting analysis, limitations and recommendations are discussed in Chapter 4 , followed by contributions of this research and concluding remarks in Chapter 5. 


\section{CHAPTER 2. LITERATURE REVIEW}

\subsection{INTRODUCTION}

This chapter first reviews the theoretical frameworks of the overarching disciplines of population health, public health and medical geography which act as the guiding epistemology of this research. The concept of social determinants of health is introduced to establish the context of the case study used to support the thesis hypothesis. The introduction of GIS to public health is then discussed, focussing on its progress and challenges. In order to prepare for the literature review, a summary of evaluation is offered in terms of definitions, its function and influences. An extensive literature review was conducted to gauge the evidence of GIS in the evaluation literature. This critical assessment draws particular attention to the lack of penetration despite advocacy from scholars recognizing the potential benefits of spatial inquiry. This chapter concludes with suggested explanations for evaluators' reluctance to use GIS, and potential solutions.

\subsection{POPULATION HEALTH, PUBLIC HEALTH AND MEDICAL GEOGRAPHY}

Population health, in which the core scientific discipline is epidemiology, is the conceptual framework for studying and describing the health condition of a given population, as measured by health determinants and health status indicators. Additionally, it forms the basis for studying policy development, research agendas, and resource allocation (Young 1998). Meanwhile, in the Dictionary of Epidemiology, John 
Last defines public health as "one of the efforts organized by society to protect, promote and restore the people's health" through the delivery of programs, services, and institutions (Last 2001, p.145). More specifically, the core functions of public health are health promotion, health protection, health surveillance, disease and injury prevention, and population health assessment. Although these definitions are not universal, it is clear in the literature that population health and public health are not separate topics but rather two intertwining disciplines that are integrated in the overall approach to health. Therefore, this study treats population health as the framework and discipline for studying and describing the condition of a population's health, and public health as the set of practices, policies and organized action for protecting, promoting and improving a population's health.

In the social sciences, the concept of health has usually been viewed from a biomedical model based on modern Western medicine, using disease aetiology as a means to classify diseases based on symptoms, syndromes and the presence of disease vectors. This biomedical model has several drawbacks caused by some of the assumptions it makes, including that diseases are generic and universal over time across different cultures and societies (Eyles and Woods 1983). In addition, the biomedical model does not consider that "disease only usually results when natural resistances have been undermined by the stresses and strains of life....thus, the doctrine of specific aetiology provides a simple cause and effect model which cannot adequately explain why specific individuals in specific places are sick or ill" (Eyles and Woods 1983, p.16). These authors criticize the Western biomedical model as the "bearer of an urban, male, 
technological, hospital-based, cosmopolitan, curative, individualistic world view" (Eyles and Woods 1983, p.187). In a more current perspective, Gatrell concludes that the biomedical model is a positivist approach, which seeks to generalize, and search for laws and order (reflecting Enlightenment) because in mapping, it focuses on what is observable and measurable, and strives to explain spatial distribution (Gatrell 2002). According to Jones and Moon (1987), there have been two clear schools of thought in medical geography. The first notion outlines the disease ecology tradition, which has focused primarily on the cause and spread of diseases, reflecting the positivist and biomedical model described by Gatrell. This approach has been rejected by many large public health organizations including the World Health Organization (WHO). In the Constitution of the World Health Organization, 'health' is defined as "a state of complete physical, mental and social well-being and not merely the absence of disease or infirmity" (WHO 2006). This definition has not changed since 1948 (Jones and Moon, 1987). Health is therefore not just a state of negative biological circumstances of suffering, from disease, disability or death (Evans and Stoddart, 1990).

The second notion about medical geography suggested by Jones and Moon is the provision and consumption of health care, focusing on accessibility and drawing from economics and sociology (Jones and Moon, 1987). Consumption of health care entails the behavioural approach, which explores the decisions made by individuals to seek health care or not based on factors like distance, as well as the welfare approach, which seeks to understand the location and type of service an individual receives. These attempts are made to ensure those who require the health care service have equitable 
access (Jones and Moon, 1987). This strongly resembles the economic and social inclusion approach to health promotion and population health, which both focus attention on inequalities in health and social justice (Public Health Agency of Canada, 2006c).

Sharing a similar viewpoint and dating back to 1974, the Lalonde Report is a significant marker in the establishment of population health theory and conceptual framework in Canada. Today, it is still fully supported and advocated by large public health bodies like the Public Health Agency of Canada ${ }^{3}$. Former Minister of National Health and Welfare Marc Lalonde argues that a balanced investment in social and physical environments would lead to more improvement in health in terms of raising the general standard of living, than an increased investment in health care delivery (Lalonde, 1974). Further, he moves the population health agenda forward in Canada by challenging the tradition of medical service provision and cure (health care organization), and proposes a new approach of breaking down the 'health field' into concepts of human biology, environment, lifestyle and health care organization, giving equal importance to all four elements, and not just health care organization as in the traditional perspective (Lalonde, 1974).

In 1994, the Strategies for Population Health report and the population health framework was published and adopted by the federal, provincial and territorial Ministers of Health. This report argues that "investing in a population health approach offers benefits in three main areas: increased prosperity, because a healthy population

\footnotetext{
${ }^{3}$ Accessed September 6, 2012: http://www.phac-aspc.gc.ca/ph-sp/pube-pubf/perintrod-eng.php
} 
is a major contributor to a vibrant economy; reduced expenditures on health and social problems; and overall social stability and well-being for Canadians" (Minister of Supply and Services Canada, 1994, p.1). The population health approach endorses the postmedical approach to health, which focuses on preventive care instead of curative or intervention care.

\subsection{SOCIAL DETERMINANTS OF HEALTH}

An underlying assumption of a population health approach is that "reductions in health inequities require reductions in material and social inequities" (Public Health Agency of Canada \#2, 2006). Population health looks 'upstream', toward the root causes in social structures and processes in which ill-health originates (Young 1998). These refer to the social determinants of health, including behavioural issues (like nutrition and substance abuse) and structural issues (like unemployment and infrastructure). In the report of the Commission on Social Determinants of Health 2005-2008, the World Health Organization published global indicators within a comprehensive surveillance framework that includes health behaviours (e.g. smoking, substance use, nutrition), physical and social environments (e.g. water, housing), working conditions (e.g. hazards, stress), health care (e.g. infrastructure), social protection, gender, social inequities (e.g. exclusion, education, income), and sociopolitical context (e.g. governance, economy) (CSDH 2008, p.182). Echoing this in Canada, the federal Public Health Agency of Canada has identified twelve factors of social determinants of health: income and social status, social support networks, education and literacy, employment/working conditions, social 
environments, physical environments, personal health practices, healthy child development, genetic endowment, health services, gender and culture ${ }^{4}$.

\subsection{GIS AND PUBLIC HEALTH}

ESRI, the corporation holding one of the highest proportions of the global GIS market, states that a GIS "integrates hardware, software, and data for capturing, managing, analyzing, and displaying all forms of geographically referenced information." ${ }^{5}$ Geographic information systems are more than just desktop mapping software. They also involve data exploration, data visualization and hypothesis generation, and are broadly used in many applications including environmental studies, natural resources, marketing, utilities, real estate management, emergency preparedness and response, criminology, military defence, and public health.

There is evidence that various forms of maps and GIS have been used in public health since the mid-1800s. The earliest piece of evidence comes from Dr. John Snow, known as the 'Father of Epidemiology', who mapped the locations of cholera cases and water sources in London. Snow hypothesised that cholera was a waterborne disease, and by mapping the cases discovered that the majority surrounded one particular water pump (the Broad Street pump). Purportedly when that pump's handle was removed, no new cholera cases were reported. Although the story and role of Snow's map has been contested in health geography, epidemiology and public health (McLeod 1998), it is still often cited by much of the literature (Eyles and Woods 1983; Young 1998).

\footnotetext{
${ }^{4}$ Accessed September 6, 2012: http://www.phac-aspc.gc.ca/ph-sp/determinants/indexeng.php\#key_determinants

${ }^{5}$ Accessed September 13, 2012: http://www.esri.com/what-is-gis/overview.html\#overview_panel
} 
With the introduction of more robust computers and early GIS software, GIS applications in public health slowly evolved in the 1980s. Along with the evolution of the Internet and a greater availability of spatial data, GIS software became widely available to non-experts in the 1990s, thus allowing spatial epidemiologic studies and mapping of health data to become commonplace for analysing and presenting data (Friis \& Sellers, 2009).

In the background of the applications of GIS in public health over the past few decades has been a long debate. GIS have been labelled 'scientific', 'positivistic' and primarily a visual form of communication (Taylor 2005). Due to the inherent nature of Boolean algorithms and databases with abstract variables, postpositivists have criticised GIS and spatial analysis since the early 1990 s for deductive logic, truth-seeking, hypothesis testing and value neutrality (Sheppard 2001). However, the GIS scholars have largely dismissed the debate of their positivistic versus postpositivistic critics. There is voluminous literature on the epistemologies of GIS and the reader is referred elsewhere for the historical accounts of such deliberation (see Schuurman, 2000; Sheppard, 2001). Sheppard asserts that the quantitative/positivist and qualitative/postpositivist debate is not settled, but argues that scholars can progressively move towards a strengthened critical thought by practicing both quantitative and qualitative geography, and by respecting complex relationships between methods, philosophy, and social theory (Sheppard 2001). Indeed, the parallel discussion by Michael Goodchild on the scholarly perspectives of GIS in human geography suggests that, in less extreme forms, the positivistic tools of geographic analysis can be balanced with interpretation placed in 
a wider, less rigid context (Goodchild, 1992). Some scholars of the 1990 s and early 2000 s therefore advocate that GIS is poly-epistemological, embracing science and social science - a significant position given scholars like Goodchild have great influence in the field of public health GIS.

As demonstrated in Snow's example, people, time and place make a triad in public health and epidemiology, which emphasizes a critical role for geography and spatial-temporal analysis. Public health is the professional discipline of organized efforts for delivery of programs and services with the core functions of health promotion, health protection, health surveillance, disease and injury prevention, and population health assessment (Last 2001). All these functions involve geography such as program or population locations, distance and access to the nearest health facility, disease patterns over space and time, health service catchment delineation, location-allocation of resources, and cost-benefit analysis of a fixed location versus a mobile service.

Spatial analysis is most commonly used within a biomedical framework for disease incidence (Gatrell and Löytönen 1998). Although GIS is increasingly used in other public health applications, its benefits are underestimated in public health policy, planning and evaluation: "Although the potential benefits of spatial information and analysis are immediately apparent in the communicable disease and environmental health fields, there are major and not fully recognized benefits to be gained in relation to policy and planning....[including] health needs assessment, planning and implementation, and monitoring and evaluation" (Maheswaran and Craglia 2004, p.2). The ability of GIS to integrate, overlay, and merge disparate data sources within a single 
automated information system has been recognised as providing an important new evidence base for health care planning (Gatrell and Löytönen, 1998; Boulos 2004).

Furthermore, Boulos insists that GIS can "promote creative problem solving and sound decisions with lasting, positive impacts on people's lives" (Boulos 2004, p.2). It is therefore recognized that a gap in the application of GIS to public health program planning and evaluation is evident, but the reasons for this are not well documented. To validate this statement, the focus of the remainder of this chapter will consider and analyse journal articles demonstrating the application and utility of GIS as a measure of the penetration of GIS into the evaluation discipline.

\subsection{PROGRAM EVALUATION}

Program evaluation is "the use of social research methods to systematically investigate the effectiveness of social intervention programs in ways that are adapted to their political and organizational environments and are designed to inform social action to improve social conditions" (p.16, Rossi, Lipsey \& Freeman, 2004). The discipline of evaluation research evolved post World War II when federal agencies made major commitments to international programs including family planning, health and nutrition, demanding an accompanied analysis of results. Evaluation was commonplace by the end of the 1950s when social science research methods had further developed, and by the 1970s, evaluation emerged as a distinct speciality field in the social sciences. Today, it is seen as an integral part of the social policy and public administration movements (Rossi, Lipsey \& Freeman, 2004). 
While Lee Cronbach, a highly influential scholar in the field, suggests that evaluation is more of an art than a science (1980), Rossi, Lipsey and Freeman (2004) advocate scientific methods and argue that a balance must be struck where high standards of scientific methods are met as much as possible, without sacrificing the resources, funding, time and information needs of the program decision-makers. For example, mixed-methods evaluation designs employing both qualitative and quantitative methods can effectively provide a strong approach that offers benefits of triangulation, but relative costs and benefits of their sequential or concurrent implementation need to be considered (Greene \& McClintock, 1985).

Program evaluation is powerfully shaped by management needs in reaction to political trends, such as liberal government spending or conservative cutbacks due to recessions or deficits that impose intensive scrutiny. Evaluators therefore must design and conduct evaluations in a way that are sensitive to the political context.

Nevertheless, evaluators should apply professional codes of conduct through neutrality, avoidance of conflict of interest, and objectivity.

The degree to which evidence based decision making is supported through the uptake of evaluation findings and recommendations is partly dependent on the strength of the evaluator's stakeholder engagement skills. Indeed the literature suggests that the uptake of evidence is very much a social process that is shaped by trust and the quality of the link between the evaluator and the program manager, as well as the knowledge translation and distribution method of the evidence (Nutley et al., 2007). 
Without this mechanism to support evidence based decision making, program managers and policy makers may fall back on intuition, ideology or conventional wisdom.

Through regular collection and analysis of program performance measurement data including inputs (e.g. staff, funds, equipment), outputs (e.g. services, products), and outcomes (e.g. desired change expected from program), evaluation makes a judgement about a program's value, effectiveness and efficiency, need and quality. The objectives of evaluation are to assess the program's progress toward a desired endresult, what and how to improve the program (in terms of administration, implementation, or program design and delivery), best practices and lessons learned, as well as to inform program policy and planning, and stimulate client advocacy. In the context of federal government, the evaluation function is also for program management and accountability to the Canadian tax-payers' value for dollar.

\subsection{LITERATURE REVIEW OF GIS IN EVALUATION}

As previously stated, the purpose of this section is to analyse published journal articles demonstrating the application and utility of GIS as a measure of the penetration of GIS into the discipline of evaluation. This literature review in its entirety draws on published peer-reviewed literature, and excludes grey literature to keep it to both manageable size and trusted content. Seven journals were identified as devoted primarily to program and policy evaluation, and formed the basis for the literature search (1 Canadian, 3 American, and 3 international). 
Although the case study is established in a Canadian context, research in any country was included in the literature review in order to obtain a broad perspective of the penetration of GIS in evaluation. With greater availability and accessibility of GIS emerging in the 1990s in general, it was considered unlikely that much literature would be published prior to that decade and therefore this review considers a publication period from 1990 to 2012.

A preliminary search was first conducted using four sets of key words related to GIS, deprived population, reach and health (Table 2) to identify whether or not similar work to the application and approach of the case study in this thesis had been carried out. This search produced virtually no evidence of this, which may be partially due to the multidisciplinary nature of evaluation. It quickly became evident that the search key words were too narrow. As a result, only the set of geography and GIS-related search key words were used in the final evaluation literature search, listed in Table 3 . The results are listed in Table 4, and to identify any possible trends in the publication of GIS and evaluation, the numbers of relevant and quasi-relevant articles are included together with their years of publication.

Table 2: Preliminary Search Key Words for Literature Review, 1990-2012 [geo* or "GIS" or map* or spatial] AND [vulnerable or target or deprived or deprivation or marginalized or marginalization] AND [access or utilization or utilisation or reach or reaching or catchment] AND

[performance or performance measurement or evaluation or assess*]

Source: Compiled by author 
Table 3: Final Search Key Words for Evaluation Literature Review, 1990-2012 [geo* or "GIS" or map* or spatial]

Source: Compiled by author

Table 4: GIS in Evaluation Literature Search Results

\begin{tabular}{|c|c|c|c|c|c|}
\hline ( & $\therefore$ & $\begin{array}{l}\text { Impact factor } 8 \\
\text { Renkins }\end{array}$ & $\begin{array}{l}\text { Results for } \\
\text { ["Cis" or } \\
\text { seo" or } \\
\text { spetial or } \\
\text { map'] } \\
\text { (in all fieids) }\end{array}$ & $\begin{array}{c}\text { Number of } \\
\text { Aulevant } \\
\text { Articles } \\
\text { (putblication } \\
\text { period) } \\
\text { (i of times } \\
\text { cited) }\end{array}$ & $\begin{array}{c}\text { Number of } \\
\text { Quast Relevant } \\
\text { Articles } \\
\text { (publication } \\
\text { perlod) } \\
\text { (1 of times } \\
\text { cited })\end{array}$ \\
\hline $\begin{array}{l}\text { 1. American Journal of } \\
\text { Evaluation } \\
\text { (US) }\end{array}$ & $\begin{array}{l}\text { PHAC } \\
\text { subscription } \\
\text { with Sage }\end{array}$ & $\begin{array}{l}1.157 \\
\text { Ranked: } 17 / 83 \text { in } \\
\text { Social Sciences, } \\
\text { Interdisciplinary }\end{array}$ & $\begin{array}{l}395 \\
\text { (34 initially } \\
\text { screened) }\end{array}$ & $\begin{array}{l}1 \\
(2002) \\
\text { (cited 13) }\end{array}$ & $\begin{array}{l}3 \\
(1996-2003) \\
\text { (cited 4-16) }\end{array}$ \\
\hline $\begin{array}{l}\text { 2. Canadian Journal of } \\
\text { Program Evaluation } \\
\text { (CA) }\end{array}$ & $\begin{array}{l}\text { Google } \\
\text { Scholar }\end{array}$ & (cannot locate) & 5 & $\begin{array}{l}1 \\
(2000)\end{array}$ & 0 \\
\hline $\begin{array}{l}\text { 3. Evaluation and } \\
\text { Program Planning } \\
\text { (International) }\end{array}$ & $\begin{array}{l}\text { Carleton } \\
\text { Scholars } \\
\text { Portal }\end{array}$ & 0.711 & 51 & $\begin{array}{l}2 \\
\text { (2012) } \\
\text { (unknown) }\end{array}$ & $\begin{array}{l}2 \\
\text { (2009-2011) } \\
\text { (cited unknown) }\end{array}$ \\
\hline $\begin{array}{l}\text { 4. Evaluation and the } \\
\text { Health Professions } \\
\text { (US) }\end{array}$ & Scopus & $\begin{array}{l}1.208 \\
\text { Ranked: } 49 / 72 \text { in } \\
\text { Healthcare Sciences \& } \\
\text { Services; } 33 / 58 \text { in } \\
\text { Health Policy \& } \\
\text { Services } \\
\end{array}$ & 32 & $\begin{array}{l}1 \\
\text { (2007) } \\
\text { (unknown) }\end{array}$ & 0 \\
\hline $\begin{array}{l}\text { 5. Practical Assessment, } \\
\text { Research, and } \\
\text { Evaluation } \\
\text { (International) } \\
\end{array}$ & Scopus & (cannot locate) & 5 & 0 & 0 \\
\hline $\begin{array}{l}\text { 6. Evaluation Review: A } \\
\text { Journal of Applied } \\
\text { Social Research } \\
\text { (US) }\end{array}$ & $\begin{array}{l}\text { Carleton } \\
\text { Scholars } \\
\text { Portal }\end{array}$ & $\begin{array}{l}0.84 \\
\text { Ranking: } 29 / 84 \text { in } \\
\text { Social Sciences, } \\
\text { Interdisciplinary }\end{array}$ & 6 & $\begin{array}{l}3 \\
\text { (2008-2011) } \\
\text { (unknown-1) }\end{array}$ & $\begin{array}{l}2 \\
(1997-2000) \\
(6-54)\end{array}$ \\
\hline $\begin{array}{l}\text { 7. Evaluation: The } \\
\text { International Journal } \\
\text { of Theory, Research } \\
\text { and Practice } \\
\text { (International) }\end{array}$ & Scopus & (cannot locate) & 3 & 0 & $\begin{array}{l}1 \\
\text { (2011) } \\
\text { (unknown) }\end{array}$ \\
\hline Total & & & 497 & $\begin{array}{l}8 \\
\text { (2000-2012) } \\
\text { (unknowin-13) }\end{array}$ & $\begin{array}{l}8 \\
\text { (1996-2011) } \\
\text { (unknown-54) }\end{array}$ \\
\hline
\end{tabular}

${ }^{1}$ Number of Times Cited is the range of citations based on the article's search results within Google Scholar.

${ }^{2}$ Quasi-Relevant Articles include articles with reference to geographical analysis or maps in general, or articles where GIS/maps/geographical analysis was not substantially emphasized or discussed.

Source: Compiled by author 
For all seven journals, the final key word search produced 497 articles, which were then screened for their title and abstract content relevance. Ninety-seven percent of those articles were screened out, mostly due to some of the search engines lacking facilities for exact text match queries. Consequently, "GIS" resulted in irrelevant articles mentioning words like "sociologists", "logistical", and "psychologists". A mere total of 8 articles were considered relevant, and 8 more were quasi-relevant in that one of the key words was mentioned, but was not the focus of the article. The journal producing the highest number of relevant and quasi-relevant articles combined was the Evaluation Review (US). The relevant articles were published only in the past twelve years (20022012), and the quasi-relevant articles dated a little further back, between 1996 and 2011.

Renger, Cimetta et al. (2002) conducted a similar literature search for GIS in evaluation journals, published in the American Journal of Program Evaluation, concluding that only one relevant article was published, in the Canadian Journal of Program Evaluation in 2000. In the Journal of Evaluation and Program Planning, Koschinsky (2012) showed the distinct spiking path of the number of spatial articles in health journals compared to the low lying flat line trend of that in the evaluation journals, between 1995 and 2009. The literature search conducted for this thesis found the same results in a slightly extended timeframe of 1990 to 2012 . Using the results from Table 4, a sequential timeline was developed to visually interpret the twenty-year trend of year of publication, country of origin, and the article's degree of relevance. Figure 5 shows that studies originating in the US represent a dominating three quarters 
of the articles, with Canada having the first relevant article. Despite almost half of the journals being international, only 3 foreign countries have contributed to the conversation, namely Italy, Iran and Australia, although with less emphasis on spatial analysis in evaluation. The references of relevant and quasi-relevant articles applied in this discussion are found in Tables 5 and 6, respectively.

Figure 5: Timeline of GIS in Evaluation Journals, 1990-2012, with country of origin

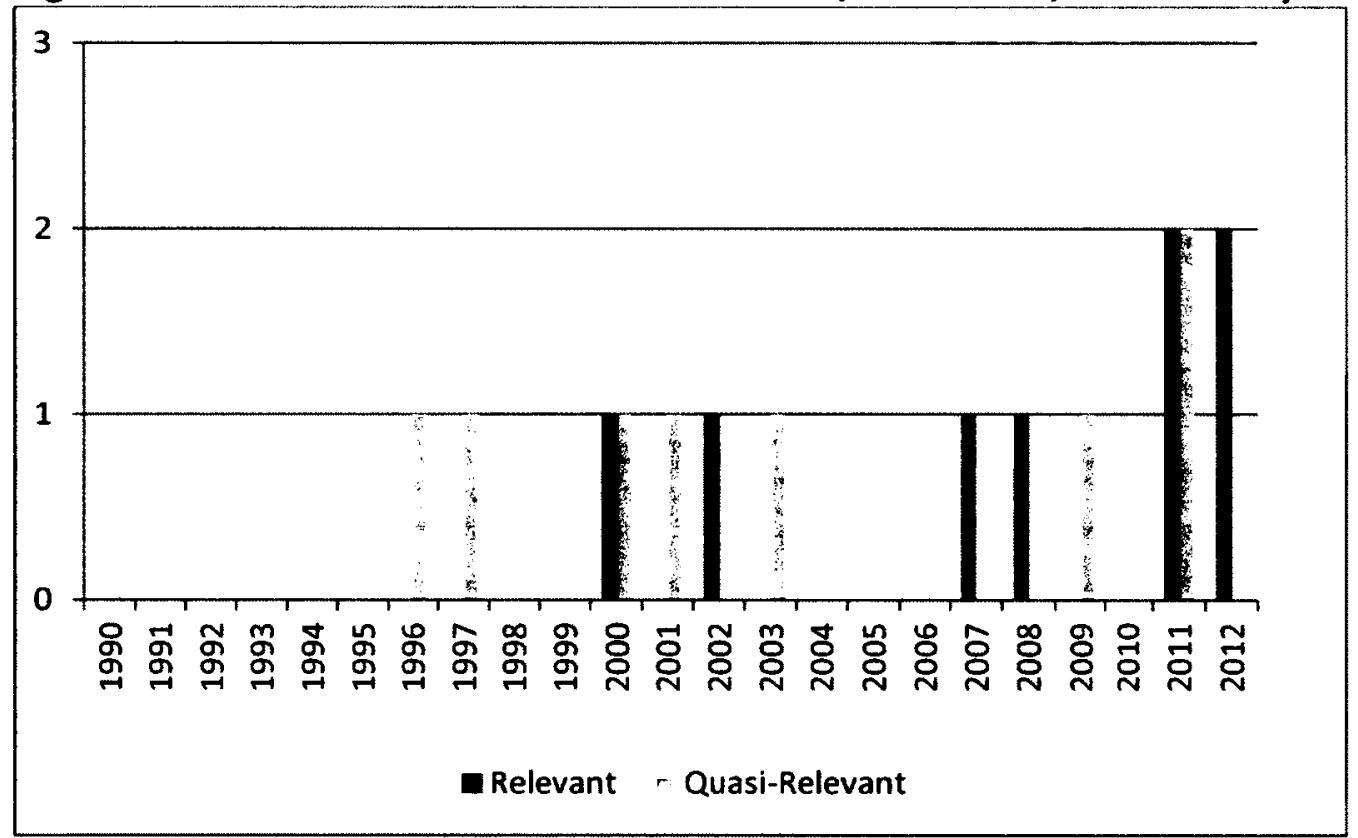

Source: Compiled by author 
Table 5: Reference Details of Relevant Articles

1. Renger R, Cimetta A, Pettygrove S and Rogan S. 2002. "Geographic Information Systems (GIS) as an Evaluation Tool". American Journal of Evaluation. 23:469-479.

2. Suggett, B.,\&Larsen, P. 2000. "Prenatal education class attendance with additional insights provided by a geographic information system". Canadian Journal of Program Evaluation Special Issue, 177183.

3. Batsche $\mathrm{CJ}$ and Reader S. 2012. "Using GIS to enhance programs serving emancipated youth leaving foster care". Evaluation and Program Planning. 35(1):25-33.

4. Koschinsky J. 2012. "The case for spatial analysis in evaluation to reduce health inequities". Evaluation and Program Planning, doi:10.1016/j.evalprogplan.2012.03.004 In Press, Corrected Proof. Last accessed September 14, 2012.

5. Myers J, Bernstein M, Morin SF and Reyes M. 2007. "Targeting HIV clinical training with maps: Lessons from the Pacific AIDS Education and Training Center". Evaluation and the Health Professions. 30(4):322-338.

6. Craun S and Freisthler B. 2008. "Using Tax Parcels to Select a Location-Based Sample: An Illustration That Examines Residents' Awareness of Sex Offenders in Neighbourhoods". Evaluation Review. 32(4):315-334.

7. Braga A, Hureau D and Papachristos A. 2011. "An Ex Post Facto Evaluation Framework for PlaceBased Police Interventions". Evaluation Review. 35(6):592-626.

8. Nunn S and Newby W. 2011. "The Geography of Deterrence: Exploring the Small Area Effects of Sobriety Checkpoints on Alcohol-Impaired Collision Rates Within a City". Evaluation Review. 35(4):354-378.

Source: Compiled by author 
Table 6: Reference Details of Quasi-Relevant Articles

1. Renger R, Passons $O$ and Cimetta A. 2003. "Evaluating Housing Revitalization Projects: Critical Lessons for all Evaluators". American Journal of Evaluation. 24:51-64.

2. Greene JC. 2001. "Evaluation Extrapolations". American Journal of Evaluation. 22:397-402.

3. Holian J. 1996. "Client and Birth Record Linkage: A Method, Biases, and Lessons". American Journal of Evaluation. 17:227-235.

4. Borzacchiello MT, Torrieri V and Nijkamp P. 2009. “An operational information systems architecture for assessing sustainable transportation planning: principles and design". Evaluation and Program Planning. 32(4):381-389.

5. Hashemi SM and Hedjazi Y. 2011. "Factors affecting members' evaluation of agri-business ventures' effectiveness". Evaluation and Program Planning. 34(1):51-59.

6. Jaeger E, Shlay A and Weinraub M. 2000. "Child Care Improvement on a Shoestring: Evaluating a LowCost Approach to Improving the Availability of Quality Child Care". Evaluation Review. 24(5):484-515.

7. Anderton D, Oakes J and Egan K. 1997. "Environmental Equity in Superfund: Demographics of the Discovery and Prioritization of Abandoned Toxic Sites". Evaluation Review. 21(1):3-26.

8. Jacobon C, Carter RW, Hockings M and Kelman J. 2011. "Maximizing Conservation Evaluation Utilization". Evaluation. 17(1):53-71.

Source: Compiled by author

In these few articles, the themes of the discourse are rather diverse, ranging from basic data visualisation and communication of evaluation results, to more advanced spatial methods for applied program planning and evaluation, as well as innovation uptake, theoretical debates and promotion of GIS in evaluation. These are discussed in more detail below.

In a theoretical discourse, Greene discusses the proliferation and diversification of evaluation methods in more recent years (2001). The repertoire of tools has expanded to include various types of analyses, software and GIS. Just like the GIS advocates, "most members of the evaluation community currently support the coexistence of quantitative and qualitative methods, if not their rapprochement" 
(Greene, 2001, p.399). Although the author claims that GIS is part of the evaluators' and social scientists' methods, this is not substantiated with references to their application. Greene concludes that in the near future, it is the "adventuresome evaluator [who] will take up contemporary challenges such as alternative reporting approaches and develop creative new methods for collecting, analyzing, and reporting data" and that "this is a good thing" (Greene, 2001, p.399).

In the only Canadian example found in the literature search, Suggett and Larsen (2000) applied GIS to program evaluation specifically to identify the location of, and reasons for, pregnant women's participation and non-participation in prenatal classes within the Regina Health District. The evaluation question was a response to an observed sharp decrease in participation over a short 3-year period. The resulting spatial associations in their data concluded that although they were reaching their target population (i.e. women living in vulnerable conditions), there were geographic clusters of target population they were not reaching. This new knowledge allowed the program to reallocate resources and enhance their services in order to break down the barriers experienced by the non-participants (e.g. lack of childcare, hours of service, etc.). With regards to program promotion, the GIS results informed the program about the specific means that worked (word of mouth, doctor's referral, pamphlets), and what did not work (TV, radio and newspaper ads), leading to a more efficient way of raising awareness of their program and reaching its target population. Without a spatial approach, such insight would have been extremely unlikely. This study is an excellent 
example of how GIS, when used to its full potential, can inform program planning and evaluation, resulting in improved program efficiencies, effectiveness and outcomes.

In a recent study conducted in Florida, Batsche and Reader (2012) demonstrated the power of GIS through its integration and analysis of disparate data (e.g. public transportation, types of housing, service locations, grocery stores, crime rates) to support the planning and evaluation of a transition housing service supporting emancipated youth leaving foster care. The GIS prototype was developed using inclusion, exclusion and weighted selection criteria based on evidence in the literature to identify safe, accessible and affordable housing that would support the transition of youth with various types of needs to independent living. This study is particularly important for demonstrating the capacity of GIS to modify the outcomes based on various scenarios of interest to evaluators, and takes GIS to the next level of providing an interactive GIS prototype for both the social worker and youth end-users in finding appropriate housing.

A public health evaluation study in the US showed that a GIS approach had a highly positive impact on the spatial distribution analysis of HIV care providers and clinical training program locations (Myers et al., 2007). The analysis and resulting maps were not only used for the federal agency and its program evaluation, but customized maps were also shared with the training centres to share the information with them in terms of their own trainee participants and local reach. The agency provided their training centres with data tables and maps representing data over a 3 year period, which, according to self-rated surveys, had a great impact on the training centres' ability 
to visualize geographic change over time and reallocate resources and focus services where needed. This study proved that collaboration between public health professionals and spatial analysts can create mutually beneficial results, both expected and unexpected.

In their promotion of and intentionally simplified demonstration of GIS applied to evaluation, Renger et al. (2002) hypothesise that the reasons for evaluators not recognizing the potential of GIS is two-fold. First, a strong interest of evaluators is change over time to a desired outcome state. Evaluators may see the use of GIS for cross-sectional studies only and it may not be obvious how it can be used for showing change. Second, underlying GIS databases produced for other purposes may be overlooked by evaluators as they do not include relevant outcomes, and as a result "evaluators have failed to realize the potential of using GIS by adding the results of primary data collection to an existing secondary database" (Renger et al., 2002, p.471).

Placed in the context of health inequities, Koschinsky (2012) has offered the evaluation community a way forward in the "spatial revolution" that seems to address the issues raised by Renger et al. (2002). First, spatial analysis can be placed within a broader framework of applying spatial concepts, tools and processes in evaluation. The argument is that since the very nature of health inequities "are usually concentrated in space, programs and evaluations that explicitly take spatial dimensions into account are likely to improve in regards to insights and impacts compared to spatially agnostic approaches" (Koschinsky, 2012, p.4). Second, an increase in collaboration between 
evaluation researchers and spatial analysts can help bridge the gap between evaluation and the "spatial revolution".

Additional relevant articles detailed the use of GIS for various planning and evaluation purposes: a spatial technique for selecting samples of residents that are geographically representative (Craun and Freisthler, 2008); a more rigorous evaluation and strategically place police interventions to reduce crime (Braga, Hureau and Papachristos, 2011); the selection of best-placed sobriety checkpoints which reduced the number of impaired collisions by $19 \%$ (Nunn and Newby, 2011); the detection of geography's role in daycare provider service utilization (Jaeger et al., 2000); the dissemination of evaluation results in an interactive format to increase communication and ease of data interpretation (Jacobson et al., 2011).

Articles of quasi-relevance seem to briefly mention GIS for a particular function, such as its facilitation for joining records of disparate health databases (Holian, 1996) or conducting national tract-level analysis of environmental hazards on vulnerable populations (Anderton et al., 1997), and are generally applied to various disciplines including transportation (Borzacchiello, 2009) and agri-business (Hashemi and Hedjazi, 2011).

\subsection{CONCLUSION}

As suggested in the literature and confirmed by the systematic literature search, GIS and spatial approaches applied to program evaluation are still in their infancy. The examples have shown that for the most part, GIS are underutilized considering their 
capability. The literature therefore demonstrates the timeliness and need for this current work. The author's vision, and forecast if she dares, is that one day in the future, GIS will become a common tool and geospatial approaches a common mindset in the evaluator's toolkit and practice, as it has become for spatial epidemiology, and that lastly, the disciplines of spatial epidemiology, evaluation of place-based programs and geomatics will inevitably collide into a focussed specialty of "spatial evaluation". It is hoped that this thesis will make a contribution towards this process. 


\section{CHAPTER 3. METHODOLOGY}

The validity of the central argument - that the value added by spatial analysis significantly improves performance measurement - is evaluated via a case study, using the requirements of two well established federally-funded community-based children's public health programs - the Canada Action Program for Children (CAPC) and the Canada Prenatal Nutrition Program (CPNP). As discussed in Chapter 1, the Public Health Agency of Canada (PHAC) funds these two children's health promotion programs and is responsible for both the routine collection and reporting of performance measurement indicators and conducting the programs' evaluation every 5 years as per the Treasury Board policy ${ }^{6}$. The primary objective of applying a geographic information system approach to these programs was to identify the size and location of the target population across Canada, and to evaluate to what extent the children's health promotion programs are within a geographic reach of this population.

Given that the programs are intended to deliver face-to-face services to vulnerable children aged 0 to 6 years of age and their families, physical proximity of the program sites to the target population is of great importance. Many of these families do not have access to personal transportation and rely on either walk-ability or public transportation. Many program sites offer a pick-up and drop-off transportation service or offer their services at multiple public facility sites (e.g. schools, churches, community centres) on a rotational basis to increase their reach.

\footnotetext{
${ }^{6}$ http://www.tbs-sct.gc.ca/pol/doc-eng. aspx?id=15024\&section=text
} 
Due to the proximity requirements of sites to the target population, this analysis required a small area spatial analytical approach, using the most accurate location data possible for both site locations and target areas. Multiple steps were taken to obtain/collect, prepare and analyze the data, with each step having its own set of decisions, procedures, and challenges. As such, the methodology developed for this case study is technical, using an applied approach to have the greatest value and direct impact on the case study organization with complete national and sub-national results.

This case study uses an ecological and cross-sectional approach. The methodology consists of primary data collection, secondary data collection from multiple sources, a literature search on deprivation indices, and spatial analysis using ESRI ArcGIS v.10 GIS software and its Spatial Analyst extension. Cleaning, preparing, integrating and analyzing these disparate data sources was time consuming but an essential task. This chapter discusses the methodology of each component of the study.

It is important to note that the author had the geomatics role in the Public Health Agency of Canada's Division of Childhood and Adolescence throughout this study. Treating PHAC as the "client", an advisory committee of key PHAC employees was established as a participatory mechanism for needs-gathering, feedback, engagement and buy-in, and consisted of children's program managers, evaluation analysts, program consultants, and the performance measurement unit manager. Throughout the study, the author provided technical expertise based on a decade of public health geomatics experience in the federal government. The organization trusted and relied on the technical decision-making of the author. Where appropriate during the methodology 
development, options and recommendations were generated for the committee's input and approval. Some of the methodological choices were influenced, therefore, by the program knowledge, timelines and concurrence of this advisory committee.

This chapter has three parts. The first discusses the methodology for representing the site locations and their geographic extent of service delivery, in other words site street address collection, geocoding, and the production of catchment areas at various driving distances. The second develops an approach to identifying geographic priority areas most likely containing a concentration of CAPC and/or CPNP target population, independent of the site locations. The third applies spatial analysis to the geographic overlap of program site catchment areas and priority areas to assess the extent to which CAPC/CPNP are reaching their target population. The results are presented in Chapter 4.

\subsection{SITE LOCATIONS AND CATCHMENT AREAS}

\subsubsection{Site Address Collection}

Through contribution agreements, PHAC provides funding to coalitions and nongovernment organizations to operate the CAPC and CPNP community-based programs. The recipient organizations could receive CAPC and/or CPNP funding, and each program they run is then considered a 'project' with a project name, such as Building Brighter Futures (CAPC) or Buns in the Oven (CPNP). These projects run one or multiple program delivery site locations, operating out of church basements, schools, public libraries, and other public places. As part of the management and administration of CAPC/CPNP, 
PHAC has historically collected only the administration mailing address for each funding recipient organization, and not the street addresses of the program's actual delivery sites.

As McLafferty, Freeman, Barrett, Luo and Shockley (2012) demonstrated, it is imperative to conduct spatial analysis based on service delivery addresses and not mailing addresses. For their study area, results found that geocoding physicians by their mailing address placed them on an average of $8.8 \mathrm{~km}$ away from their actual address of service delivery - a significant error for service delivery within walking distance. The socio-demographics of the population within the address catchment area differed between the two types of addresses, producing systematic biases of overestimating physician accessibility in high income suburban areas and underestimating it in low to medium income central areas. In essence, their study shows that resulting "errors affect local measures of spatial accessibility to primary care, biasing statistical analyses of the associations between spatial access to care and health outcomes" (McLafferty, Freeman, Barrett, Luo \& Shockley, 2012, p.31).

In order to assess the program's reach of the target population, the street addresses of where the programs are physically delivered at all the projects' multiple sites were essential to collect and utilize for the analysis. These had never been collected prior to this research.

Many sites offer home visits to participants for one-on-one support, however this type of service is excluded from the reach analysis for many reasons including participants' privacy. This analysis, rather, focuses on program reach strictly based on 
the location of drop-in sites, which provide services to the public, usually in group settings.

Within the PHAC Regional offices across the country are Program Consultants whose role is to provide an official oversight of the project stakeholders, and of particular importance to this work, to implement and monitor the collection of performance measurement data. As a result of their intimate knowledge of the projects, the Program Consultants played a key role in assisting with the collection of street address data.

To encourage reporting of addresses in a standard, organized way most helpful in preparation for geocoding, a street address collection tool was developed in Microsoft Excel and was verified with the regional Program Consultants for its user friendliness and clarity. The tool had three worksheet components: instructions; street address template; submission verification questions. The submission questions were to verify whether or not the addresses being submitted represented $100 \%$ of the sites within the Program Consultant's region and to allow for any contextual comments about the addresses (see Street Address Collection Tool in Appendix 1). The Program Consultants filled in the template with both CAPC and CPNP street addresses for every location of service delivery. All the responses were collected in the fall of 2010 and were collated into one national file. Table 7 shows the number of addresses collected.

Table 7: Number of Addresses Collected

\begin{tabular}{|lc|}
\hline Program & $n$ \\
\hline CAPC & 1,413 \\
CPNP & 853 \\
\hline Total & $2,266^{*}$ \\
\hline
\end{tabular}

*Approximately $18 \%$ of these sites are co-located with CAPC and CPNP. Source: Compiled by author 


\subsubsection{Site Address Geocoding}

Despite the attempt to impose standard formatting of addresses during collection, the street addresses required cleaning to increase matching results. For example, the street type abbreviations had to be standardized (e.g. Drive to Dr).

To minimize computer processing time, geocoding was completed in chunks by province/territory instead of nationally. This process was repeated thirteen times, and then merged to create a national file. Some provinces took longer to geocode than others due to varying number of addresses, and particular address challenges (e.g. missing or incomplete road directional identifiers, particularly prevalent in Alberta).

DMTI's CanMap Streetfiles v.2011.1 product was used as the address locator for geocoding. Although Statistics Canada produces a road network file, which aligns with census geographies, it lacks attribute information such as address ranges that are absolutely critical for accurate geocoding.

Three geocoding threshold settings were used to produce highly accurate results. Spelling sensitivity, the degree to which a geocoding service must match the spelling of one address element in the address data to the address element in the reference data, was set at $80 \%$ (the software default, which only allows minor spelling variations). The minimum candidate score, which determines which address candidates are presented in the results, was set at $80 \%$ (the software default is $30 \%$, but for the volume of addresses in this case study, it was desirable to filter out as much as possible). The minimum match score, the degree to which a match candidate needs to be considered in the geocoding search, was set at $85 \%$ (a score between 80 and 99 is 
generally considered a good match). This latter setting was set at an even higher score than the first two settings because a higher minimum match score is necessary when the analysis demands that addresses be located with a high level of confidence ${ }^{7}$.

In total, 1306 (58\%) addresses matched the CanMap Streetfiles reference data, and 960 (42\%) did not. Table 8 summarizes the geocoding results by province, the number of addresses, and some commentary on the effort required.

The unmatched addresses were run through a second attempt at geocoding with a lower spelling sensitivity, and if still unsuccessful, those remaining were identified through other publicly available reference tools and search engines (Table 9) and manually located or matched to the next best address. For rural or remote communities in the territories where street number ranges are largely non-existent in the CanMap Streetfiles, these reference tools were heavily relied upon to determine the best point location of the address.

${ }^{7}$ ESRI ArcGIS online help resource. Accessed August 13, 2012 : http://webhelp.esri.com/arcgisdesktop/9.3/body.cfm?id=6741\&pid=6740\&topicname=Defining\% 20 the\% 20address\%20locator\%20components\&tocVisable $=0$ 
Table 8: Geocoding Results

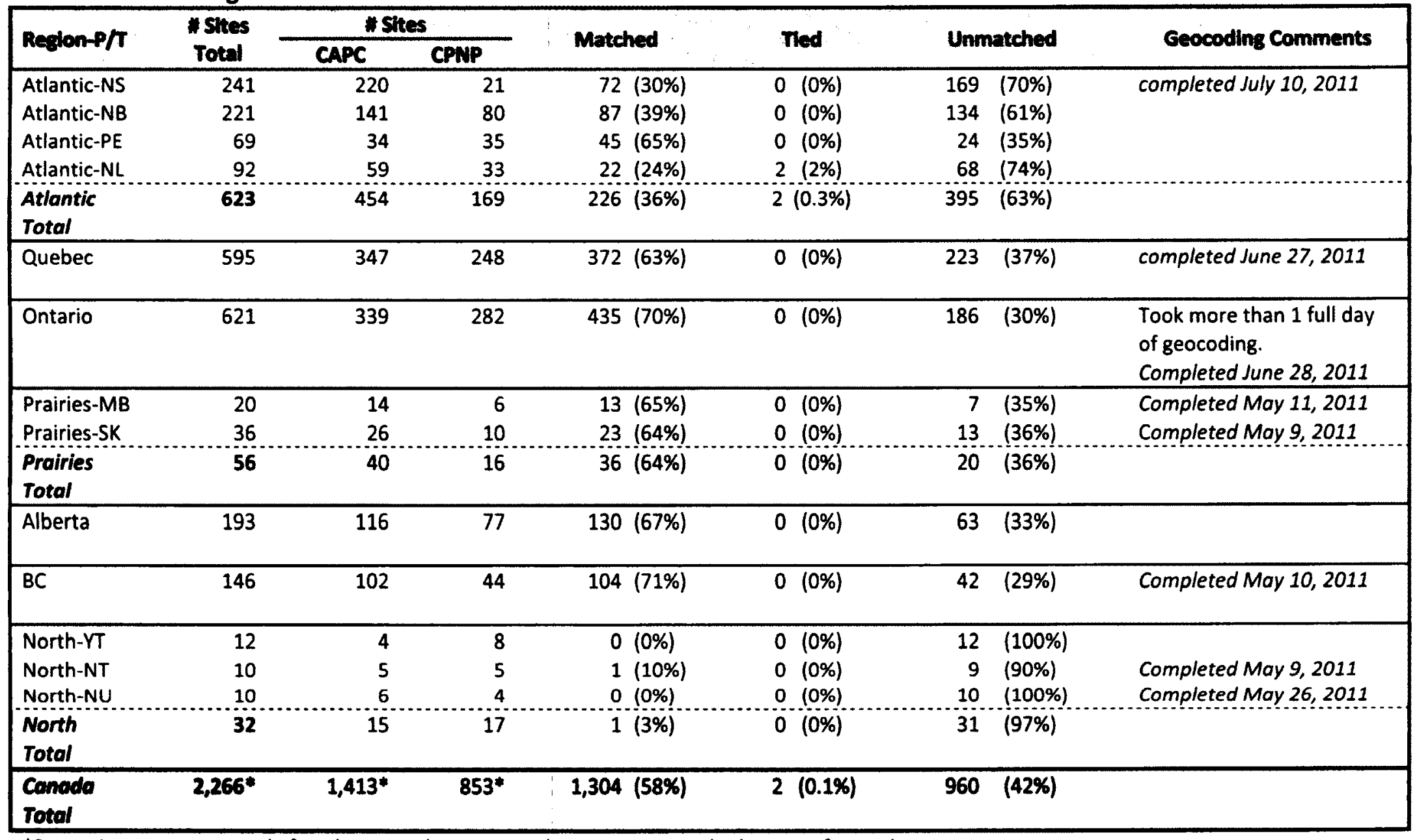

* Some sites were removed after the geocoding process due to erroneous duplication of records.

The final number of sites was: 2,223 (total), 1,399 (CAPC), 824 (CPNP). Source: Compiled by author 
Table 9: Additional Geocoding Support Tools

\begin{tabular}{|l|l|}
\hline Search Engine & Location and Description \\
\hline Google Earth & $\begin{array}{l}\text { Freeware (requires Internet access to operate). Used to obtain } \\
\text { latitude/longitude of addresses not successfully geocoded. } \\
\text { Available: www.earth.google.com }\end{array}$ \\
\hline Google Maps & $\begin{array}{l}\text { Used for address search of addresses not successfully geocoded. } \\
\text { StreetView often used to verify precision of address location, } \\
\text { especially in rural areas. } \\
\text { Available: www.maps.google.com }\end{array}$ \\
\hline $\begin{array}{l}\text { Canada Post- Find an } \\
\text { Address }\end{array}$ & $\begin{array}{l}\text { Used to verify street address with postal code. } \\
\text { Available: } \\
\text { http://www.canadapost.ca/cpotools/apps/fpc/personal/findAnAd } \\
\text { dress?execution=e3s1 }\end{array}$ \\
\hline Canada 411 & $\begin{array}{l}\text { Used Canada 411 and general Internet searches to verify street } \\
\text { address by searching host facility name. } \\
\text { Available: www.canada411.ca }\end{array}$ \\
\hline $\begin{array}{l}\text { Statistics Canada - } \\
\text { Community Profiles }\end{array}$ & $\begin{array}{l}\text { Used to verify community name of address, particularly for PEI } \\
\text { where the CanMap geolocator uses the Lot number instead of } \\
\text { community name, or parts of Ontario where the official } \\
\text { municipality name is used. } \\
\text { Available: http://www12.statcan.ca/census- } \\
\text { recensement/2006/dp-pd/prof/92-591/index.cfm?Lang=E }\end{array}$ \\
\hline
\end{tabular}

Source: Compiled by author

The geocoding process was an incredibly lengthy exercise, demanding a

disproportionate amount of effort and time compared to the other analysis components of the study. The data collection process required approximately 2 months in duration, and the geocoding process required approximately 3 months, for a total of approximately 5 months in duration. The number of days of effort was neither tracked nor estimated. Having the addresses geocoded, however, permitted the analysis and discussion of Chapter 4, making the investment in time and effort in the geocoding process highly useful. For a detailed discussion of the methodology and challenges of geocoding, the reader is referred to Appendix 2. 


\subsubsection{Catchment Areas}

With the purpose of analyzing the program delivery sites' reach of the target population, catchment areas (or service areas) had to be created around each address location. Since the CAPC and CPNP projects are dispersed across the country in both urban and rural settings, alongside variability in both projects' level of transportation services and sites' accessibility via public transportation, a variety of driving distances were chosen: $1 \mathrm{~km}, 5 \mathrm{~km}, 10 \mathrm{~km}$, and $20 \mathrm{~km}$. Catchment areas based on four different distances would allow for multiple scenarios and result in a reach analysis for each.

The availability and level of transportation service offered by each project (e.g. maximum distance that each site offers pick-up/drop-off services) has never been collected as part of federal program performance measurement. Although it is possible that projects or regions may have taken such analysis upon themselves at a local or regional scale, a national perspective would not be available. In the future, this could be captured in annual national performance measurement collection and could be analyzed again with a custom distance for each site, instead of applying a universal distance across all sites.

The simple crow-fly (Euclidian or straight-line distance) approach to creating a buffer or catchment area would be time-saving. However, given the variability in physical landscapes and between rural and urban settings, the assumption of barrierfree access to a site address from 360 degrees is not appropriate in this case. Although more time consuming for the number of sites in this case study, using travel distance is a more sophisticated and more effective approach (Martin, Wrigley, Barnett \& Roderick, 
2002). The level of error due to a crow-fly approach is tested and discussed further in Chapter 4 . The results justify the time and resources invested in developing catchment areas based on a road network.

In preparation for calculating catchment areas, network datasets for each province and territory first had to be built using the CanMap Streetfiles dataset in ESRI ArcMap v.10 and the accompanying Network Analyst extension. Using the newly created network datasets, catchment $\operatorname{areas}^{8}$ were created in incremental distances of 1 , 5, 10, and 20 kilometres from each unique CAPC and CPNP project site address. The four distances were calculated simultaneously in one service area request for each province, and therefore this process was performed 26 times (13 provinces $\times 2$ programs). The resulting 13 service area layers were then merged to produce a national layer of service areas for each program.

As a result of the service areas subsequently being used for small area analysis to determine programs' reach of priority areas, it was important to produce as detailed service areas as possible. Therefore, "detailed polygons" was selected in the service area calculation settings, rather than "generalized polygons", as shown in Figure 6.

\footnotetext{
${ }^{8}$ ESRI software uses the term "service areas". This term will be used for the purpose of this technical section, however it is interchangeable with "catchment areas".
} 


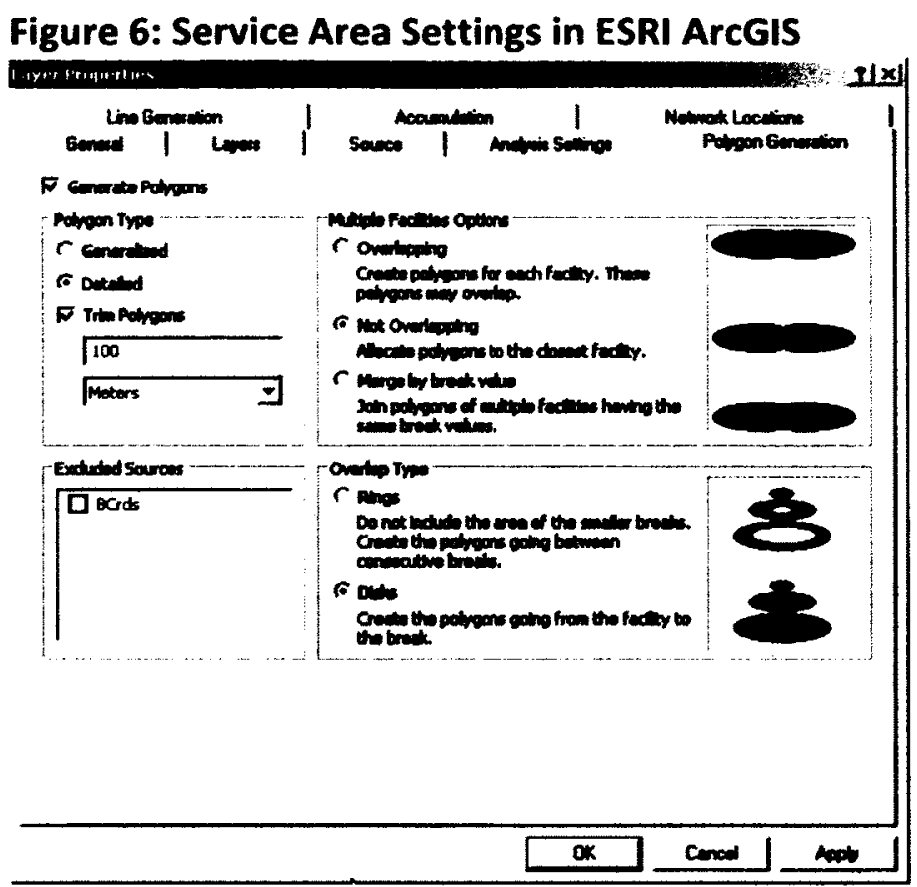

Source: ArcGIS v.10

\subsubsection{Catchment Area Calculation Challenges}

Due to software and hardware limitations in producing detailed polygons with multiple distances concurrently, two large metropolitan areas (Toronto and Montreal) were broken into sub-regions and only generalized polygons could be applied.

Additionally, larger provinces were broken into sub-regions with detailed polygons, and the results were merged.

\subsection{GEOGRAPHIC PRIORITY AREAS}

This section develops an approach to identifying geographic priority areas most likely containing a concentration of CAPC and/or CPNP target population, independent of the site locations, in order to target program funding and services where they will have the greatest impact. 
The CAPC and CPNP programs intend to reach vulnerable children, who are at

risk of not reaching their potential, and pregnant women and their babies living in conditions of risk. Vulnerability and risk can be defined in various ways, but PHAC enumerates their target population as defined in Table 10, below.

Table 10: CAPC/CPNP Target Population

\begin{tabular}{|c|c|}
\hline $\begin{array}{l}\text { Community Action Program for Children } \\
\text { (CAPC) }\end{array}$ & $\begin{array}{l}\text { Canada Prenatal Nutrition Program } \\
\text { (CPNP) }\end{array}$ \\
\hline $\begin{array}{l}\text { - children living in low-income families; } \\
\text { - children living with teenage-parents; } \\
\text { - children experiencing developmental delays, } \\
\text { social, emotional or behavioural problems; } \\
\text { - abused and neglected children; } \\
\text { - Métis, Inuit and off-reserve First Nations } \\
\text { children; } \\
\text { - children of recent immigrants and refugees; } \\
\text { - children in lone-parent families; and } \\
\text { - children who live in remote and isolated } \\
\text { communities. }\end{array}$ & $\begin{array}{l}\text { Pregnant women living in conditions of risk } \\
\text { including: } \\
\text { - poverty, } \\
\text { - teenage pregnancy, } \\
\text { - social or geographic isolation with poor } \\
\text { access to services, } \\
\text { - recent arrival to Canada, } \\
\text { - alcohol or substance abuse, and } \\
\text { - family violence }\end{array}$ \\
\hline
\end{tabular}

Source: PHAC 2010b, 2010c

To define the number of people living under such conditions of risk is nearly impossible with Canadian data primarily due to privacy legislation. Various government bodies collect data for some of these conditions, for different purposes. However, integrating such data would greatly increase error because the conditions of risk are not mutually exclusive. Moreover, they are either not collected nationally, or are reported at the provincial or national level and therefore do not lend themselves to national small-area analysis. Lastly, population-based data for some conditions of risk are not tracked. Some have vague definitions, or sometimes go unreported (such as 
developmental delays or social/emotional/behavioural problems among children, or abuse, family violence, and alcohol and substance abuse among caregivers). This challenge could also explain the lack of national reporting against baselines and targets.

On the other hand, population-based data that is readily available for some of these conditions of risk, and for national small-area geography, comes from the Canadian census which includes sex, age, low-income, Aboriginal status, recent immigration, and lone-parenting. As these categories are not mutually exclusive, it is necessary to use an index based on such variables to define where vulnerability has the greatest concentration.

\subsubsection{Literature Search of Deprivation Indices}

A literature search of deprivation indices was conducted to identify options for representing areas of vulnerability or deprivation which reflects the program target population of CAPC and CPNP. Conceptualized in the 1960s, deprivation is distinguished from poverty in that it denotes a state of social and material disadvantage relative to the local community or the wider society or nation to which an individual, family or group belongs, including conditions such as lack of access to employment, recreation, education or basic household amenities (Townsend, 1987, p.125).

Experts from several countries, including England, Canada, and Ireland, have been working on this issue for years and there is no consensus on what depicts the golden standard index. Cognisant of this immediate limitation, the goal for this case study is to select an index that adequately reflects the target population of the 
CAPC/CPNP programs (Table 10), and that is based on Canadian data, along with other criteria shown in Table 11.

The modifiable areal unit problem (MAUP) is a persistent consideration in the mapping of socio-demographic and health data, whereby the aggregation of data to different geographic units can exhibit completely different patterns. A second and related problem is the ecological fallacy which assumes that the statistics for the whole population apply equally to each individual in that population. As the areal unit increases in size, such as neighbourhoods to municipalities, data variance also increases and the relationship weakens between the individual and the geographical unit, resulting in sociodemographic heterogeneity. To improve the homogeneity of a population, the availability of data for the smallest aerial unit possible is one of the important criteria for the deprivation index selection.

Table 11: Criteria for Deprivation Index Selection

1. Variables reflective of CAPC/CPNP target population
2. Based on Canadian data
3. Data available nationally
4. Data available for standard census geographies
5. Data available for the lowest level geography possible
6. Data freely available
7. Data currency - as current as possible (e.g. 2006 census)

Source: Compiled by author

Fifteen Canadian deprivation indices resulted in the literature search and are summarized in Table 14. At the time of this literature search, twelve of those were not available nationally (most only for metropolitan areas) and were therefore eliminated from the index selection. The Statistics Canada Social Risk Index was further considered, 
however the methodology and related information was unobtainable within the case study time frame and therefore was also excluded for its lack of peer review and references. Although of high interest and relevance to CAPC/CPNP, the Early Development Instrument (EDI) at the time of this research had not been conducted nationally and was based on inconsistent geographies across the regions (e.g. school board districts, municipalities).

The Institut nationale de santé publique du Québec (INSPQ) Deprivation Index, developed by Pampalon and Raymond (2000), was the last remaining index for further research, and was selected for its best fit. Originally produced for Quebec and subsequently for all of Canada, the index is readily available for the census years 1991, 1996, 2001 and 2006, at the dissemination area level (formerly enumeration area in 1996 and earlier). The dissemination area (DA) is a standard census geography covering $100 \%$ of Canada's land mass, split into small areas composed of one or more neighbouring dissemination blocks, with a population of 400 to 700 persons $^{9}$, and is the smallest level of geography for which census data is available.

Principal component analysis (PCA) is the statistical technique used in the INSPQ Deprivation Index to reduce large datasets to manageable groupings of variables with collinearity. Although the PCA approach has been criticized for removing variance exhibited in the original data structure (Bell, Schuurman, Oliver \& Hayes, 2007), significant Canadian literature on small-area estimation of socioeconomic status draws

\footnotetext{
${ }^{9} \mathrm{http}: / /$ www12.statcan.ca/census-recensement/2006/ref/dict/geo021-eng.cfm
} 
from PCA (Frohlich and Mustard 1996; Pampalon and Raymond 2000; Langlois and Kitchen 2001).

For the INSPQ Deprivation Index, the PCA produced two major dimensions: material deprivation and social deprivation, each based on three census variables as shown in Table 12. The components scores of each dimension were ranked and split into quintiles, producing a matrix of 25 values sub-grouped into 9 classes for representing dissemination areas from low to high deprivation, as shown in the legend in Figure 7. Although the Canadian Urban Marginalization Index (CUMI) has great potential and applicability to CAPC/CPNP if it were ever to become a national dataset, one of its weaknesses at the time is that it had 4 factors (matrix of 625 values) $\left(5^{4}\right)$ and would require the development of a mapping technique and a sub-grouping methodology.

Table 12: INSPQ Deprivation Index Components \& Variables

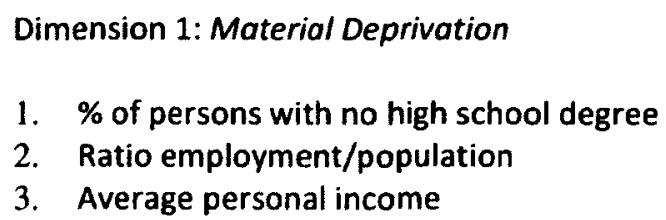

3. Average personal income

Dimension 2: Social Deprivation

1. $\%$ of persons living alone

2. \% of persons separated, divorced or widowed

3. \% of single-parent families

Source: Pampalon R \& Raymond G. (2000) 
Figure 7: INSPQ Deprivation Index Map Legend

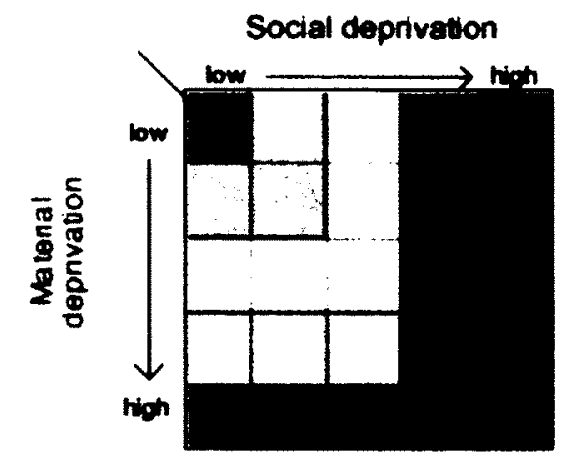

Source: Reprinted, with permission, from www.inspq.qc.ca/pdf/evenements/1754_anglais.pdf

Although the variables used directly in the INSPQ Deprivation Index do not include child abuse/neglect or family violence, studies conducted over a wide period of time such as that by Wolock and Horowitz (1979) as well as Sidebotham, Heron and Golding (2002) have indicated that child maltreatment was strongly associated with social and material deprivation. For example, "families in which maltreatment occurred live under poorer material circumstances, had more socially and materially deprived childhoods, are more socially isolated, and have more children" (Wolock \& Horowitz, 1979, p.175).

In a study conducted subsequently by the authors of the INSPQ Deprivation Index, it was found that a high proportion of child maltreatment occurs in areas of high deprivation, even more so when the two dimensions of social and material deprivation coexist (Pampalon and Raymond, 2003). Furthermore, areas of high deprivation in large cities across Canada highlighted by this very index have also been shown to have a high proportion of low birth weights, injuries and asthma in children, and hospitalization for mental health, anxiety disorders, and substance-related disorders (e.g. alcohol binging) 
(CIHI, 2008) which are mostly highly related to the CAPC/CPNP target population. Figure 8 demonstrates these differences by socioeconomic status groups, where "Low SES" is equivalent to "high social and material deprivation".

Figure 8: INSPQ Deprivation Index and Health Issues

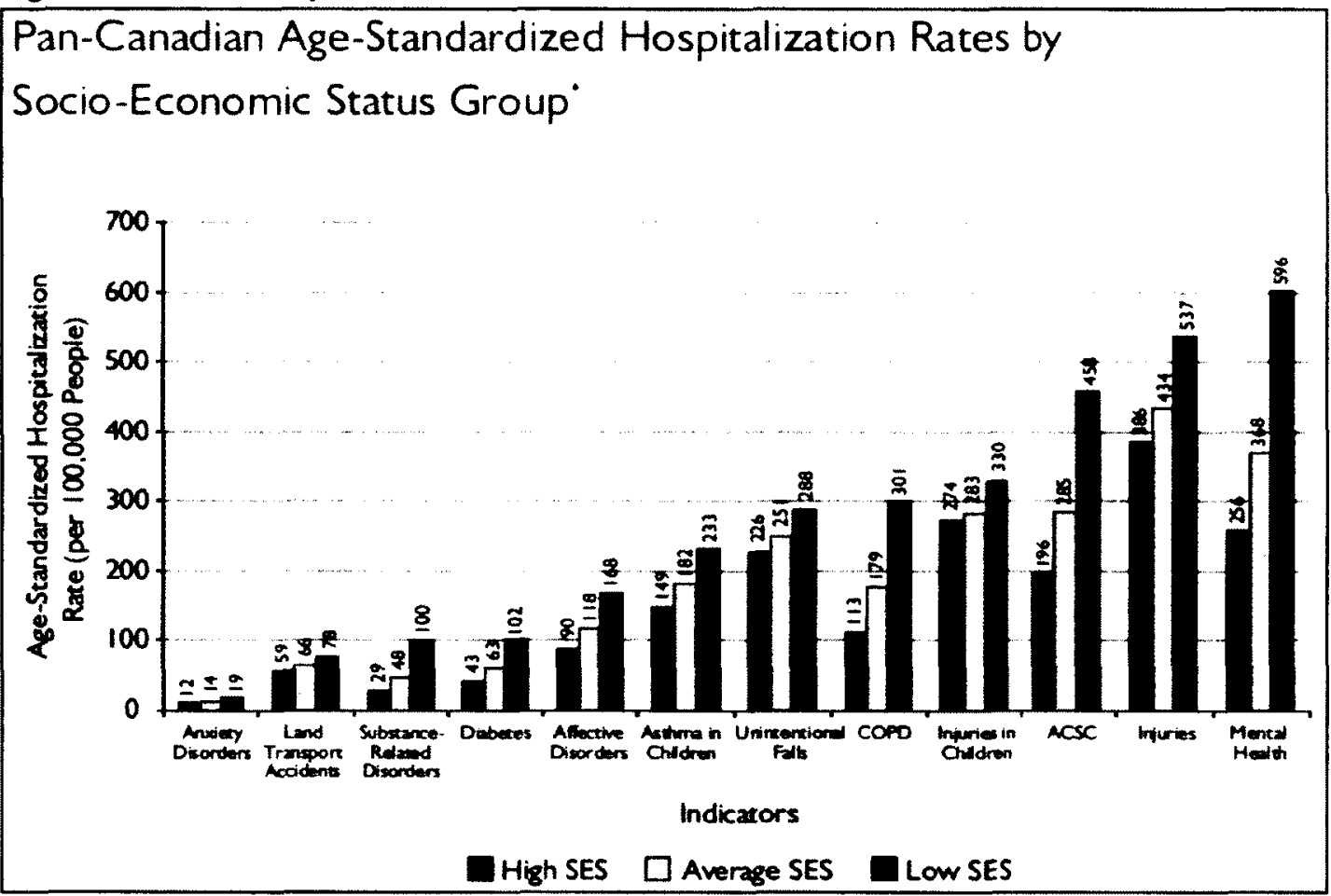

Source: Reprinted, with permission, from CIHI 2008, Figure 2, p.29.

Lastly, the teen pregnancy rate has been shown to be significantly higher in areas of high social and material deprivation. In Alberta, Predy (2008) showed that a steep gradient of the teen birth rate was associated with areas of high deprivation. Pampalon and Raymond (2003) demonstrated this association as well for Quebec, especially where the two components of deprivation coexist.

In summary, the INSPQ Deprivation Index is a powerful indicator of health and well-being outcomes. The multiple studies cited demonstrate strong associations 
between deprivation and negative health outcomes or behaviours, and substantiates the use of the INSPQ Deprivation Index as a model for appropriately identifying target areas for the CAPC and CPNP programs including conditions of vulnerability not directly included in the census variables of the index. Furthermore, the amplification of negative health outcomes or behaviours in areas where both forms of deprivation coexist is the justification for using a selection criterion of dissemination areas in the $4^{\text {th }}$ and $5^{\text {th }}$ quintiles for both components.

In the criteria selection for establishing priority areas, it was also important to the case study organization to target areas where there are many families or adults with young children and avoid identifying retirement communities. The census variable "adults 15 years and older with at least 1 child under the age of 6" was considered an appropriate target group since it represented the target age group of the program, and would help identify concentrations of families the programs need to target. Table 13 shows the final dissemination area selection criteria to represent priority areas of target CAPC and CPNP population for the remainder of the reach analysis.

Census Subdivisions (CSDs) are an additional standard census geography and represent municipalities or their equivalent, and are classified by type (e.g. town, hamlet, city, rural municipality). All DAs falling within areas classified as reserves, as per the criteria established by Aboriginal Affairs and Northern Development Canada ${ }^{10}$, were excluded from the analysis since Health Canada's First Nations and Inuit Health Branch funds CAPC and CPNP sister programs for on-reserve populations (e.g. Indian reserve,

\footnotetext{
${ }^{10} \mathrm{http}: / /$ www12.statcan.ca/census-recensement/2006/ref/dict/geo012a-eng.cfm
} 
Indian settlement, Terres réservées aux Cris ). Results are discussed in the following chapter.

\section{Table 13: Priority Area Selection Criteria}

High Social Deprivation $\left(4^{\text {th }}\right.$ and $5^{\text {th }}$ quintiles)

AND

High Material Deprivation ( $4^{\text {th }}$ and $5^{\text {th }}$ quintiles)

AND

High proportion of adults with at least 1 child under the age of $6\left(4^{\text {th }}\right.$ and $5^{\text {th }}$ quintiles)

Source: Compiled by author 


\begin{tabular}{|c|c|c|c|c|c|}
\hline Index Neme & Authors & $\begin{array}{l}\text { Small drea a standard } \\
\text { ophy }\end{array}$ & Netional date & Indicators & $\begin{array}{l}\text { Data } \\
\text { currency }\end{array}$ \\
\hline 1. INSPQ Deprivation Index & $\begin{array}{l}\text { Pampalon and } \\
\text { Raymond, } 2000\end{array}$ & $\begin{array}{l}\text { Census Dissemination } \\
\text { Area }\end{array}$ & Yes & Most reflective & 2006 \\
\hline $\begin{array}{l}\text { 2. Canadian Urban Marginalization } \\
\text { Index (CUMI) }\end{array}$ & $\begin{array}{l}\text { Matheson, } \\
\text { Moineddin et al. } \\
2006\end{array}$ & $\begin{array}{l}\text { Census Tract (exist only in } \\
\text { metropolitan areas) }\end{array}$ & $\begin{array}{l}\text { No. Metropolitan } \\
\text { areas only. }\end{array}$ & $\begin{array}{l}\text { Too many } \\
\text { components to map } \\
\text { (4) }\end{array}$ & 2001 \\
\hline 3. [partial CUMI] & $\begin{array}{l}\text { Matheson, } \\
\text { Moineddin and } \\
\text { Glazier, } 2008\end{array}$ & $\begin{array}{l}\text { Census Tract (exist only in } \\
\text { metropolitan areas) }\end{array}$ & $\begin{array}{l}\text { No. Metropolitan } \\
\text { areas only. }\end{array}$ & & \\
\hline 4. Socioeconomic Factor Index (SEFI) & $\begin{array}{l}\text { Frohlich and } \\
\text { Mustard, } 1996\end{array}$ & $\begin{array}{l}\text { Enumeration Areas } \\
\text { (aggregated to } \\
\text { Municipality, Health } \\
\text { Region) }\end{array}$ & $\begin{array}{l}\text { No. Produced only } \\
\text { for Manitoba }\end{array}$ & 23 into 6 domains & 1986 \\
\hline 5. Early Development Instrument (EDI) & $\begin{array}{l}\text { Hertzman and } \\
\text { Bertrand, } 2007\end{array}$ & $\begin{array}{l}\text { No. Uses inconsistent } \\
\text { geographies (school } \\
\text { districts, municipalities, } \\
\text { etc) }\end{array}$ & Not yet. & & \\
\hline 6. Composite Learning Index (CLI) & & $\begin{array}{l}\text { not available at a small } \\
\text { enough geography }(\mathrm{P} / \mathrm{T} \text {, } \\
\text { Region, metropolitan area) }\end{array}$ & & $\begin{array}{l}\text { complex, not all } \\
\text { variables relevant to } \\
\text { CAPC/CPNP }\end{array}$ & \\
\hline 7. Urban Deprivation Indicators & $\begin{array}{l}\text { Broadway \& } \\
\text { Jetsy, } 1998\end{array}$ & $\begin{array}{l}\text { Census Tract (exist only in } \\
\text { metropolitan areas) }\end{array}$ & $\begin{array}{l}\text { No. Only available } \\
\text { in metropolitan } \\
\text { areas }\end{array}$ & $\begin{array}{l}\text { very few indicators, } \\
\text { analyzed individually } \\
\text { instead of grouped } \\
\text { into dimensions }\end{array}$ & $\begin{array}{l}\text { outdated } \\
\text { (data based } \\
\text { on } 1981- \\
1991 \text { years) }\end{array}$ \\
\hline 8. Social Risk Index (SRI) & $\begin{array}{l}\text { Human } \\
\text { Resources } \\
\text { Development } \\
\text { Canada, } 2003 \\
\end{array}$ & & & $\begin{array}{l}\text { Unobtainable } \\
\text { methodology within } \\
\text { case study time } \\
\text { frame. }\end{array}$ & \\
\hline
\end{tabular}




\begin{tabular}{|c|c|c|c|c|c|}
\hline Index lame (coned) & Authors & stondond ephy & metional dote & nillentors & $\begin{array}{l}\text { Data } \\
\text { currency }\end{array}$ \\
\hline 9. General Deprivation Index (GDI) & $\begin{array}{l}\text { Langlois \& } \\
\text { Kitchen, } 2001\end{array}$ & & $\begin{array}{l}\text { No. Only available } \\
\text { in metropolitan } \\
\text { areas }\end{array}$ & $\begin{array}{l}\text { complex, difficult to } \\
\text { understand }\end{array}$ & $\begin{array}{l}\text { last } \\
\text { conducted } \\
\text { in } 1996 \\
\end{array}$ \\
\hline 10. Nova Scotia Multiple Deprivation Index & $\begin{array}{l}\text { M. Tershima - } \\
\text { Dalhousie } \\
\text { University GIS } \\
\text { Centre, } 2009\end{array}$ & & $\begin{array}{l}\text { No. Only available } \\
\text { for Nova Scotia - } \\
\text { urban and rural }\end{array}$ & & \\
\hline $\begin{array}{l}\text { 11. Vancouver Area deprivation index } \\
\text { (VANDIX) }\end{array}$ & $\begin{array}{l}\text { Bell, Shurman, } \\
\text { Oliver and Hayes, } \\
2007\end{array}$ & & $\begin{array}{l}\text { No. Only available } \\
\text { for Vancouver. }\end{array}$ & $\begin{array}{l}\text { influenced by } \mathrm{MOH}^{\prime} \mathrm{s} \\
\text { ranked socio- } \\
\text { economic indicators } \\
\text { by relative influence } \\
\text { on health outcomes } \\
\text { throughout BC. }\end{array}$ & \\
\hline 12. Ontario Deprivation Index & $\begin{array}{l}\text { Matern, } \\
\text { Mendelson and } \\
\text { Oliphant, } 2009\end{array}$ & $\begin{array}{l}\text { not small enough level } \\
\text { of geography }\end{array}$ & $\begin{array}{l}\text { No. Only available } \\
\text { for Ontario, based } \\
\text { on a custom survey }\end{array}$ & & \\
\hline 13. Neighbourhood Well-being Indices (NWI) & Krepicz, 2010 & & $\begin{array}{l}\text { No. Only available in } \\
\text { Toronto }\end{array}$ & & \\
\hline $\begin{array}{l}\text { 14. Indices of Community Well-being, } 2006 \\
\text { (Calgary) }\end{array}$ & & & $\begin{array}{l}\text { No. Only available in } \\
\text { Calgary }\end{array}$ & $\begin{array}{l}\text { data not only from } \\
\text { Census, but other } \\
\text { municipal departments } \\
\text { (eg. Calgary Police } \\
\text { Service) }\end{array}$ & \\
\hline $\begin{array}{l}\text { 15. Community Well-Being (CWB) Index, } 2006 \\
\text { (Calgary) }\end{array}$ & & Census Subdivisions & & $\begin{array}{l}\text { not a complete list of } \\
\text { dimensions of well- } \\
\text { being }\end{array}$ & \\
\hline
\end{tabular}




\subsection{CALCULATING PROGRAM REACH}

In ArcGIS, a query was performed for each province on the spatial intersection of the priority areas with the catchment areas (service areas) of each of the four distances $(1 \mathrm{~km}, 5 \mathrm{~km}, 10 \mathrm{~km}, 20 \mathrm{~km})$. This produced a table of the number of priority areas within or intersecting the catchment areas for each program, by province. The results are presented in the following chapter.

\subsection{CHAPTER SUMMARY}

This chapter discussed in detail the methodologies for each component for identifying program reach. Site address collection was gathered in collaboration with the case study organization using a data collection tool developed by the researcher, followed by an extensive period of address geocoding which was by far the most tedious, manual and time consuming aspect of the process. Catchment areas were created based on driving distance to improve the accuracy over a less advanced method of Euclidian distance (straight-line). Four distances were calculated to provide the case study organization with multiple scenarios, including $1 \mathrm{~km}$ for walking distance, $5 \mathrm{~km}$, $10 \mathrm{~km}$ and $20 \mathrm{~km}$ for public transportation or driving distances. This chapter included a lengthy discussion and justification for the selection of a deprivation index used to identify small areas with likely concentrations of CAPC and CPNP target population. The chapter concluded with a brief summary of the technical method for selecting dissemination areas of target population and their intersection of the catchment areas. 
The following chapter examines the results with a discussion and interpretation of findings. 


\section{CHAPTER 4. ANALYSIS \& DISCUSSION}

This chapter applies the research methodology discussed in previous chapters to assess the usefulness of the approach and methods presented for measuring program reach for the purpose of performance measurement and evaluation. The results are presented primarily through descriptive statistics.

The first section presents the analysis results, with particular emphasis on the CAPC and CPNP address geocoding, which provides a rich context and foundation for the remainder of the analysis. Locations and reach of priority areas are examined, as well as potential program gaps. Following the analysis is a discussion on data and methodology limitations. The chapter concludes with recommendations for similar future work based on lessons learned through this case study.

\subsection{ANALYSIS}

\subsubsection{Locations of CAPC/CPNP Program Delivery Sites}

The collection and geocoding of CAPC and CPNP program delivery sites' street addresses have enabled the descriptive analysis of their geographic distribution. As previously noted, some site addresses were removed following the geocoding process due to the identification of erroneous duplicates. The final number of program delivery sites used in the study's analysis is illustrated in Table 15, by program and province/territory, as well as the type of community in which they are located.

Identifying the type of community was accomplished by a spatial join between the geocoded address point file and the CSD census geography polygon file. CSDs are 
also classified as belonging, or not, to higher order Census Metropolitan Areas (CMAs).

CMAs are areas having a population of at least 100,000 , and are formed by one or more adjacent CSDs that have a high degree of integration with the urban area as measured by commuting flows derived from the census place of work ${ }^{11}$. Not all CSDs classified as a city or town are included in CMAs for this reason. Identifying the locations of sites by various types of communities allows for the descriptive analysis of the proportion of sites within highly urban areas compared with smaller cities, towns and rural areas. Figure 9 exhibits the locations of CAPC, CPNP, and CAPC/CPNP co-located sites across Canada for general reference.

${ }^{11}$ Statistics Canada CMA Definition: http://www12.statcan.gc.ca/censusrecensement/2006/ref/dict/geo009-eng.cfm 
Table 15: CAPC/CPNP Sites by Province/Territory and Type of Community

\begin{tabular}{|c|c|c|c|c|c|}
\hline \multicolumn{6}{|c|}{ CAPC } \\
\hline \multirow[t]{2}{*}{$P / T$} & \multirow{2}{*}{$\begin{array}{c}\text { Total } \\
\text { Number } \\
\text { of Sites }\end{array}$} & \multirow{2}{*}{$\begin{array}{l}\text { Sites within } \\
\text { CMAs }\end{array}$} & \multicolumn{3}{|c|}{ Sites outside of CMAs } \\
\hline & & & & city/towns & $\begin{array}{l}\text { type: } \\
\text { villages / } \\
\text { municipalities }\end{array}$ \\
\hline BC & 102 & $73(71.6 \%)$ & $29(28.4 \%)$ & 12 & 17 \\
\hline$A B$ & 116 & $59(50.9 \%)$ & $56(48.3 \%)$ & 35 & 21 \\
\hline SK & 26 & $18(69.2 \%)$ & $9(34.6 \%)$ & 5 & 4 \\
\hline $\mathrm{MB}$ & 14 & $10(71.4 \%)$ & $4(28.6 \%)$ & 3 & 1 \\
\hline ON & 339 & $209(61.7 \%)$ & $130(38.3 \%)$ & 51 & 79 \\
\hline QC & 338 & $226(66.9 \%)$ & $112(33.1 \%)$ & 55 & 57 \\
\hline NB & 141 & $36(25.5 \%)$ & $105(74.5 \%)$ & 39 & 66 \\
\hline NS & 215 & $68(31.6 \%)$ & $147(68.4 \%)$ & 52 & 95 \\
\hline PEI & 34 & $20(58.8 \%)$ & $14(41.2 \%)$ & 4 & 10 \\
\hline NL & 59 & $17(28.8 \%)$ & $42(71.2 \%)$ & 36 & 6 \\
\hline YT & 4 & $3(75.0 \%)$ & $1(25.0 \%)$ & 1 & 0 \\
\hline NT & 5 & $2(40.0 \%)$ & $3(60.0 \%)$ & 1 & 2 \\
\hline NU & 6 & $N / A^{*}$ & $6(100 \%)$ & 1 & 5 \\
\hline TOTAI & 1,399 & $\begin{array}{r}741 \\
(53.0 \%)\end{array}$ & $\begin{array}{r}658 \\
(47.0 \%)\end{array}$ & $\begin{array}{r}295 \\
(44.8 \%)\end{array}$ & $\begin{array}{r}363 \\
(55.2 \%)\end{array}$ \\
\hline
\end{tabular}

\begin{tabular}{|c|c|c|c|c|c|}
\hline \multicolumn{6}{|c|}{ CPNP } \\
\hline \multirow[t]{3}{*}{$P / T$} & \multirow{3}{*}{$\begin{array}{c}\text { Total } \\
\text { Number } \\
\text { of Sites }\end{array}$} & \multirow{3}{*}{$\begin{array}{l}\text { Sites within } \\
\text { CMAs }\end{array}$} & \multicolumn{3}{|c|}{ Sites outside of CMAs } \\
\hline & & & & \multicolumn{2}{|c|}{ by type: } \\
\hline & & & & city/towns & $\begin{array}{c}\text { villages / } \\
\text { municipalities }\end{array}$ \\
\hline BC & 44 & $27(61.4 \%)$ & $17(38.6 \%)$ & 10 & 7 \\
\hline$A B$ & 77 & $33(42.9 \%)$ & $44(57.1 \%)$ & 37 & 7 \\
\hline SK & 10 & $4(40 \%)$ & $5(50 \%)$ & 2 & 3 \\
\hline MB & 6 & $3(50 \%)$ & $4(66.7 \%)$ & 2 & 2 \\
\hline ON & 268 & $183(68.3 \%)$ & $85(31.7 \%)$ & 36 & 49 \\
\hline QC & 233 & $118(50.6 \%)$ & $115(49.4 \%)$ & 61 & 54 \\
\hline NB & 80 & $31(38.8 \%)$ & $49(61.3 \%)$ & 25 & 24 \\
\hline NS & 21 & $9(42.9 \%)$ & $12(57.1 \%)$ & 6 & 6 \\
\hline PEI & 35 & $21(60 \%)$ & $14(40 \%)$ & 4 & 10 \\
\hline NL & 33 & $13(39.4 \%)$ & $20(60.6 \%)$ & 19 & 1 \\
\hline YT & 8 & $4(50 \%)$ & $4(50 \%)$ & 2 & 2 \\
\hline NT & 5 & $1(20 \%)$ & $4(80 \%)$ & 3 & 1 \\
\hline NU & 4 & N/A & $4(100 \%)$ & 1 & 3 \\
\hline Total & 824 & $\begin{array}{r}447 \\
(54.2 \%)\end{array}$ & $\begin{array}{r}377 \\
(45.8 \%)\end{array}$ & $\begin{array}{r}208 \\
(55.2 \%)\end{array}$ & $\begin{array}{r}169 \\
(44.8 \%)\end{array}$ \\
\hline
\end{tabular}

* Note: In the 2006 Census, there were no areas classified as CMA in Nunavut.

Source: Compiled by author 
Figure 9: Map of CAPC and CPNP Program Delivery Sites across Canada

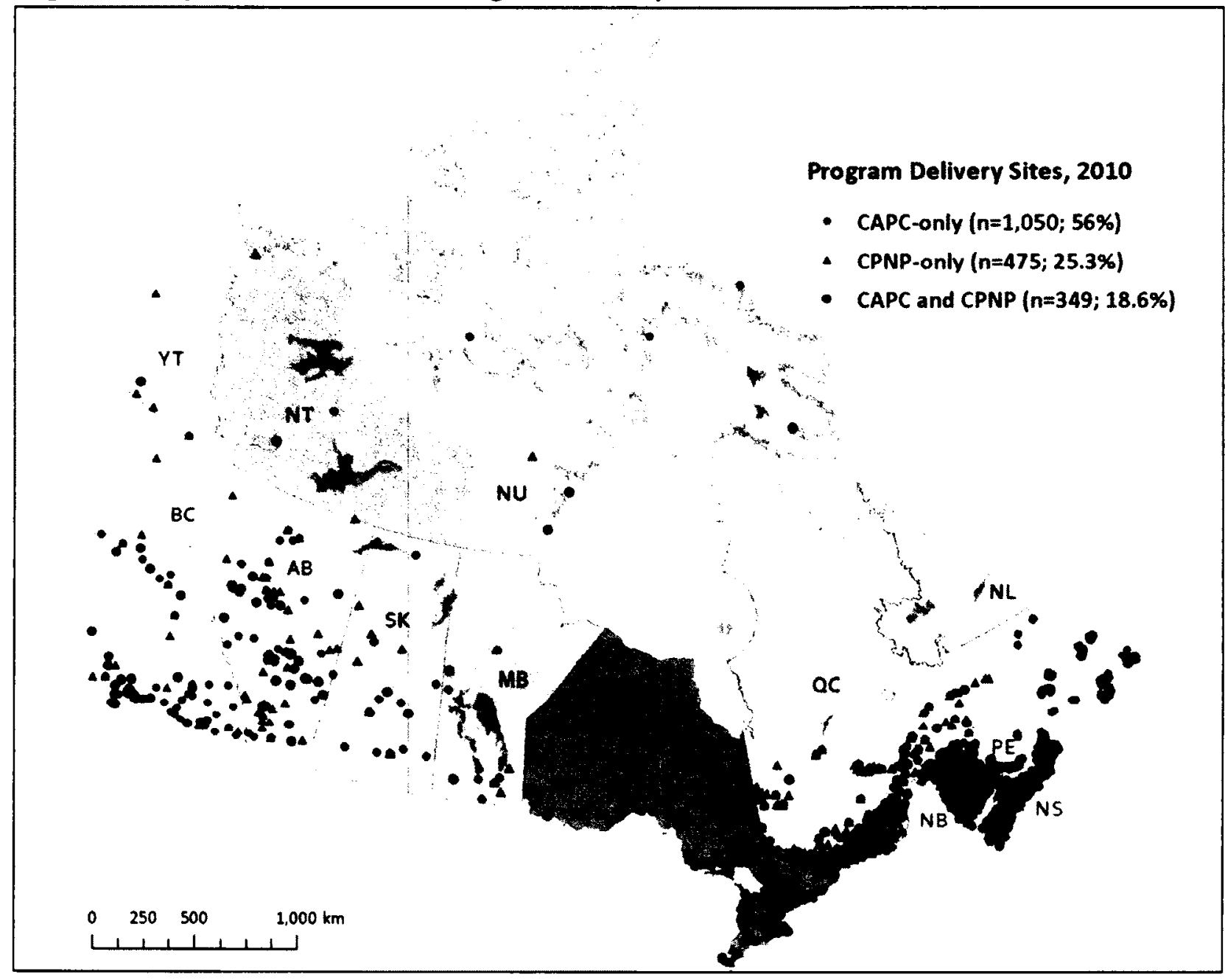

Source: Compiled by author 
In total, there are 1,399 CAPC sites and 824 CPNP sites across Canada, located in 657 and 523 communities, respectively. The 5 provinces with the highest number of CAPC sites are: Ontario (339), Quebec (338), Nova Scotia (215), New Brunswick (141), and Alberta (116). For a small province, Nova Scotia has a large number of CAPC program delivery sites. The 5 provinces with the highest number of CPNP sites are: Ontario (268), Quebec (233), New Brunswick (80), Alberta (77), and British Columbia (44). It is surprising that British Columbia has only half the number of sites as that in New Brunswick, yet has a much larger general population. Reasons for this discrepancy are unclear; however one could speculate that it could be caused by an underreporting of $\mathrm{BC}$ delivery sites during the address collection process.

In terms of distribution between types of communities, the national distribution shows that slightly more than half of both CAPC and CPNP sites are located in CMAs. Of those sites located outside CMAs, CAPC has slightly more than half of its sites in rural areas such as villages and municipalities, whereas CPNP has slightly more than half of its non-CMA sites in urban areas like cities and towns.

Regionally speaking, the Atlantic provinces tend to have a higher proportion of their sites in non-CMA areas for both programs, with the exception of PEI. Although they have fewer sites, the three territories also illustrate the same pattern, with the exception of the Yukon. Meanwhile, although Quebec, Ontario, the Prairies and the West coast all have a higher proportion of their CAPC sites in CMAs (51-72\%), their CPNP sites have a greater variability. 


\subsubsection{Locations of Priority Areas}

The importance of identifying priority areas is to determine where the program target population is most likely to be concentrated, which permits any subsequent analysis of the extent to which programs are reaching such areas. The analysis of priority areas, as per the selection criteria discussed in the methodology chapter, produced 1,263 Dissemination Areas in 595 communities across Canada. Figure 10 exhibits the locations of priority areas across Canada in relation to CMAs. Less urban types of communities are not shown due to the map scale and the consequential lack of visibility.

In terms of distribution, as seen in Table 16, each province/territory has at least one priority area. Although Ontario has the greatest number of priority areas $(n=448)$, followed by Quebec $(n=393)$, the proportion of dissemination areas classified as priority areas is the greatest in Nunavut (11.9\%), followed by Manitoba (3.7\%), compared to other provinces/territories across the country.

With respect to distribution of priority areas across types of communities, a high proportion (86\%) of the priority areas are in CMAs $(n=1088$ of 1263). While there are 151 CMAs across Canada, $93(61.6 \%)$ of those contain priority areas and are located across all the provinces with the majority in Ontario (31 CMAs), British Columbia (21 CMAs), and Quebec (14 CMAs).

Priority areas outside of CMAs are almost equally split between smaller cities or towns and more rural areas including northern villages, villages, municipalities and parishes $(6 \%$ ( $n=76$ of 1263$) ; 8 \%$ ( $n=99$ of 1263$)$, respectively), according to the type of 
census subdivision within which the priority areas are contained. These non-CMA priority areas are distributed across each province and territory, with the majority located in Quebec. 
Figure 10: Map of Priority Areas across Canada

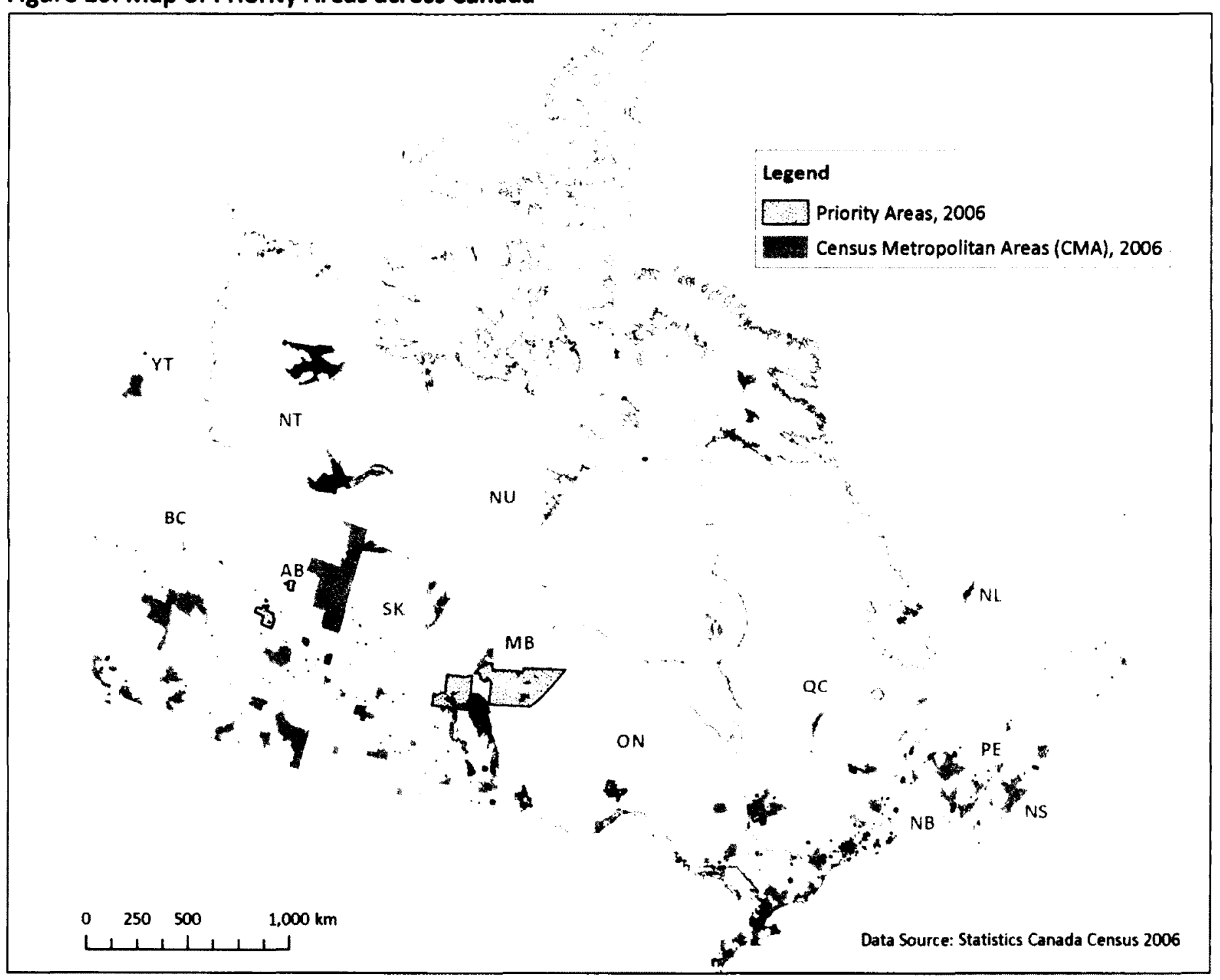


Table 16: Priority Areas by Province/Territory and Type of Community

\begin{tabular}{|c|c|c|c|c|c|c|}
\hline \multirow[t]{2}{*}{$\mathrm{P} / \mathrm{T}$} & \multirow[t]{2}{*}{ \# D.A.'s } & \multirow{2}{*}{$\begin{array}{c}\text { Priority } \\
\text { Area D.A.'s }\end{array}$} & \multirow{2}{*}{$\begin{array}{l}\text { \# Priority } \\
\text { Areas within } \\
\text { CMAs }\end{array}$} & \multicolumn{3}{|c|}{ \# Priority Areas outside of CMAs } \\
\hline & & & & & city/towns & $\begin{array}{l}\text { villages / } \\
\text { municipalities }\end{array}$ \\
\hline BC & 7,469 & $84(1.1 \%)$ & $77(92 \%)$ & $7(8 \%)$ & $1(14 \%)$ & $6(86 \%)$ \\
\hline$A B$ & 5,357 & $109(2.0 \%)$ & $84(77 \%)$ & $25(23 \%)$ & $13(52 \%)$ & $12(48 \%)$ \\
\hline SK & 2,431 & $82(3.4 \%)$ & $56(68 \%)$ & $26(32 \%)$ & $12(46 \%)$ & $14(54 \%)$ \\
\hline MB & 2,152 & $80(3.7 \%)$ & $67(84 \%)$ & $13(16 \%)$ & $9(69 \%)$ & $4(31 \%)$ \\
\hline ON & 19,177 & $448(2.3 \%)$ & $427(95 \%)$ & $21(5 \%)$ & $9(43 \%)$ & $12(57 \%)$ \\
\hline QC & 13,408 & $393(2.9 \%)$ & $344(88 \%)$ & $49(12 \%)$ & $15(31 \%)$ & $34(69 \%)$ \\
\hline NB & 1,439 & $18(1.3 \%)$ & $10(56 \%)$ & $8(44 \%)$ & $3(38 \%)$ & $5(62 \%)$ \\
\hline NS & 1,633 & $25(1.5 \%)$ & $17(68 \%)$ & $8(32 \%)$ & $3(38 \%)$ & $5(62 \%)$ \\
\hline PE & 292 & $3(1.0 \%)$ & $1(33 \%)$ & $2(67 \%)$ & $1(50 \%)$ & $1(50 \%)$ \\
\hline NL & 1,062 & $12(1.1 \%)$ & $5(42 \%)$ & $7(58 \%)$ & $7(100 \%)$ & $0(0 \%)$ \\
\hline$Y T$ & 78 & $1(1.3 \%)$ & $0(0 \%)$ & $1(100 \%)$ & $0(0 \%)$ & $1(100 \%)$ \\
\hline NT & 84 & $3(3.6 \%)$ & N/A & $3(100 \%)$ & $1(33 \%)$ & $2(67 \%)$ \\
\hline NU & 42 & $5(11.9 \%)$ & $N / A$ & $5(100 \%)$ & $2(40 \%)$ & $3(60 \%)$ \\
\hline \multirow[t]{2}{*}{ TOTAL } & 54,624 & 1,263 & 1,088 & 175 & 76 & 99 \\
\hline & & $(2.3 \%)$ & $(86.1 \%)$ & $(13.9 \%)$ & $(43.4 \%)$ & $(56.6 \%)$ \\
\hline
\end{tabular}

Source: Compiled by author

In 2006, there were an estimated ${ }^{12} 93,892$ children aged 0 to 6 living in the priority areas, $91 \%$ of whom resided in CMAs. Based on a natural break in the data, the ten priority areas $(0.8 \%$ of total priority areas) of the quintile with the highest count of children 0 to 6 , ranging from 377 to 809 children each, were all located in the CSDs of Brampton and City of Toronto, both located within the CMA of Toronto, Ontario. These two CSDs will be of particular interest in the program reach analysis, included in the following section.

\footnotetext{
${ }^{12}$ An estimate based on the sum of children $0-4$ plus $40 \%$ of children $5-9$.
} 


\subsubsection{Program Reach of Priority Areas}

Since the programs do not have a standard distance for their catchment areas, multiple distances were applied in the analysis, including a $1 \mathrm{~km}$ distance to represent walking distance, as well as a $5 \mathrm{~km}, 10 \mathrm{~km}$, and $20 \mathrm{~km}$ distance to represent driving distance, whether public or private transportation. The last distance category applied in the analysis is more than $20 \mathrm{~km}$ to represent the potential gap in service to priority areas. Table 17 exhibits the results of spatial analysis on the intersection of priority areas and driving distance catchment areas to represent program reach.

In advance of discussing the results of program reach based on driving distance, it is at this point appropriate to briefly discuss and demonstrate the importance of the chosen catchment area methodology. As discussed in Chapter 3, both the Euclidean distance and driving distance were considered for creating catchment areas surrounding all program delivery sites. Using British Columbia as a good example given its obvious physical features imposing barriers, both methodologies were tested for CAPC sites' reach of priority areas, and as expected, the Euclidean distance produced error.

As Figure 11 demonstrates, the Euclidean distance produced errors for three of the four distances, with the greatest impact on the $1 \mathrm{~km}$ distance with $8.3 \%$ error. There was reduced error at $5 \mathrm{~km}$, and the $10 \mathrm{~km}$ and $20 \mathrm{~km}$ had no error or very little error $10 \%$ and $1.2 \%$ respectively). If the results for British Columbia are reflective of those for other provinces/territories, then the Euclidean distance would have minimal impact on the potential gap analysis (priority areas beyond $20 \mathrm{~km}$ ) across Canada. However, the primary purpose of this study's analysis is to determine reach, and an error of $8.3 \%$ was 
considered too great. As a result, the driving distance was the most appropriate method for this study even though it was more demanding on resources and time. Turning attention back to the final program reach results shown in Table 17, the driving distance results can be discussed considering the method's demonstrated superior accuracy. 
Table 17: CAPC/CPNP Reach of Priority Areas within Various Driving Distances from Program Delivery Sites

\begin{tabular}{|c|c|c|c|c|c|c|c|}
\hline \multicolumn{8}{|c|}{ CAPC } \\
\hline PR & $\begin{array}{c}\# \\
\text { sites }\end{array}$ & $\begin{array}{c}\text { \# } \\
\text { Priority } \\
\text { Areas }\end{array}$ & & & $10 \mathrm{~cm}$ & & $\begin{array}{c}\text { Beyond } \\
20 \mathrm{~km} \\
\text { (Gap?) }\end{array}$ \\
\hline BC & 102 & 84 & $33(39.3 \%)$ & $68(81.0 \%)$ & $74(88.1 \%)$ & $76(90.5 \%)$ & $8(9.5 \%)$ \\
\hline AB & 116 & 109 & $24(22.0 \%)$ & $75(68.8 \%)$ & $79(72.5 \%)$ & $79(72.5 \%)$ & $30(27.5 \%)$ \\
\hline SK & 26 & 82 & $28(34.1 \%)$ & $55(67.1 \%)$ & $56(68.3 \%)$ & $56(68.3 \%)$ & $26(31.7 \%)$ \\
\hline \multirow[t]{2}{*}{ MB } & 14 & 80 & $21(26.3 \%)$ & $56(70.0 \%)$ & $66(82.5 \%)$ & $70(87.5 \%)$ & $10(12.5 \%)$ \\
\hline & & & 131 & 338 & 393 & & \\
\hline \multirow[t]{2}{*}{ ON } & 339 & 448 & $(29.2 \%)$ & $(75.4 \%)$ & $(87.7 \%)$ & $410(91.5 \%)$ & $38(8.5 \%)$ \\
\hline & & & 177 & 323 & 350 & & \\
\hline $\mathbf{Q C}$ & 338 & 393 & $(45.0 \%)$ & $(82.2 \%)$ & $(89.1 \%)$ & $373(94.9 \%)$ & $20(5.1 \%)$ \\
\hline NB & 141 & 18 & $5(27.8 \%)$ & $13(72.2 \%)$ & $16(88.9 \%)$ & $17(94.4 \%)$ & $1(5.6 \%)$ \\
\hline NS & 215 & 25 & $14(56 \%)$ & $19(76 \%)$ & $24(96 \%)$ & $24(96 \%)$ & $1(4 \%)$ \\
\hline PEI & 34 & 3 & $1(33.3 \%)$ & $1(33.3 \%)$ & $2(66.7 \%)$ & $2(66.7 \%)$ & $1(33.3 \%)$ \\
\hline NL & 59 & 12 & $4(33.3 \%)$ & $7(58.3 \%)$ & $7(58.3 \%)$ & $7(58.3 \%)$ & $5(41.7 \%)$ \\
\hline $\mathbf{Y T}$ & 4 & 1 & $0(0 \%)$ & $0(0 \%)$ & $0(0 \%)$ & $0(0 \%)$ & $1(100 \%)$ \\
\hline NT & 5 & 3 & $0(0 \%)$ & $0(0 \%)$ & $0(0 \%)$ & $0(0 \%)$ & $3(100 \%)$ \\
\hline NU & 6 & 5 & $2(40 \%)$ & $2(40 \%)$ & $2(40 \%)$ & $2(40 \%)$ & $3(60 \%)^{*}$ \\
\hline & & & 440 & 957 & 1069 & 1116 & 147 \\
\hline Total & 1399 & 1,263 & $(34.8 \%)$ & $(75.8 \%)$ & $(84.6 \%)$ & $(88.4 \%)$ & (11.6\%) \\
\hline
\end{tabular}

\begin{tabular}{|c|c|c|c|c|c|c|c|}
\hline \multicolumn{8}{|c|}{ CPNP } \\
\hline PR & $\begin{array}{c}\# \\
\text { sites }\end{array}$ & $\begin{array}{c}\# \\
\text { Priority } \\
\text { Areas }\end{array}$ & & & & & $\begin{array}{c}\text { Beyond } \\
20 \mathrm{~km} \\
\text { (Gap?) }\end{array}$ \\
\hline BC & 44 & 84 & $17(20.2 \%)$ & $49(58.3 \%)$ & $71(84.5 \%)$ & 74 (88.1\%) & $10(11.9 \%)$ \\
\hline $\mathbf{A B}$ & 77 & 109 & $17(15.6 \%)$ & $61(56.0 \%)$ & $77(70.6 \%)$ & $85(78.0 \%)$ & $24(22.0 \%)$ \\
\hline SK & 10 & 82 & $21(25.6 \%)$ & $52(63.4 \%)$ & $54(65.9 \%)$ & $54(65.9 \%)$ & $28(34.1 \%)$ \\
\hline \multirow[t]{2}{*}{ MB } & 6 & 80 & $10(12.5 \%)$ & $48(60.0 \%)$ & $59(73.8 \%)$ & $65(81.3 \%)$ & $15(18.8 \%)$ \\
\hline & & & 147 & 386 & 420 & & \\
\hline \multirow[t]{2}{*}{ ON } & 268 & 448 & $(32.8 \%)$ & $(86.2 \%)$ & (93.8\%) & $436(97.3 \%)$ & $12(2.7 \%)$ \\
\hline & & & & 310 & 347 & & \\
\hline QC & 233 & 393 & $88(22.4 \%)$ & $(78.9 \%)$ & $(88.3 \%)$ & $374(95.2 \%)$ & $19(4.8 \%)$ \\
\hline NB & 80 & 18 & $6(33.3 \%)$ & $13(72.2 \%)$ & $13(72.2 \%)$ & $15(83.3 \%)$ & $3(16.7 \%)$ \\
\hline NS & 21 & 25 & $2(9.5 \%)$ & $4(19 \%)$ & $15(71.4 \%)$ & $21(100 \%)$ & $0(0 \%)$ \\
\hline PEI & 35 & 3 & $1(33.3 \%)$ & $1(33.3 \%)$ & $2(66.7 \%)$ & $2(66.7 \%)$ & $1(33.3 \%)$ \\
\hline NL & 33 & 12 & $5(41.7 \%)$ & $7(58.3 \%)$ & $7(58.3 \%)$ & $7(58.3 \%)$ & $5(41.7 \%)$ \\
\hline$r T$ & 8 & 1 & $0(0 \%)$ & $0(0 \%)$ & $0(0 \%)$ & $0(0 \%)$ & $1(100 \%)$ \\
\hline NT & 5 & 3 & $1(33.3 \%)$ & $1(33.3 \%)$ & $1(33.3 \%)$ & $1(33.3 \%)$ & $2(66.7 \%)$ \\
\hline NU & 4 & 5 & $2(40 \%)$ & $2(40 \%)$ & $2(40 \%)$ & $?$ & $3(60 \%)^{* *}$ \\
\hline & & & 317 & 934 & 1068 & 1134 & 129 \\
\hline Total & 824 & 1,263 & $(25.1 \%)$ & $(74.0 \%)$ & $(84.6 \%)$ & $(89.8 \%)$ & $(10.2 \%)$ \\
\hline
\end{tabular}

* NU roads have maximum road distance of $16.5 \mathrm{~km}$ from sites. 3 remaining priority areas beyond $16.5 \mathrm{~km}$ are not accessible by road from current sites.

** NU roads have maximum road distance of $7.3 \mathrm{~km}$ from sites. 3 remaining priority areas beyond $20 \mathrm{~km}$ are not accessible by road from current sites.

Source: Compiled by author 
Figure 11: Map of Comparison of Euclidean and Driving Distance Methods for Calculating Program Reach, Using British Columbia CAPC Sites as a Sample

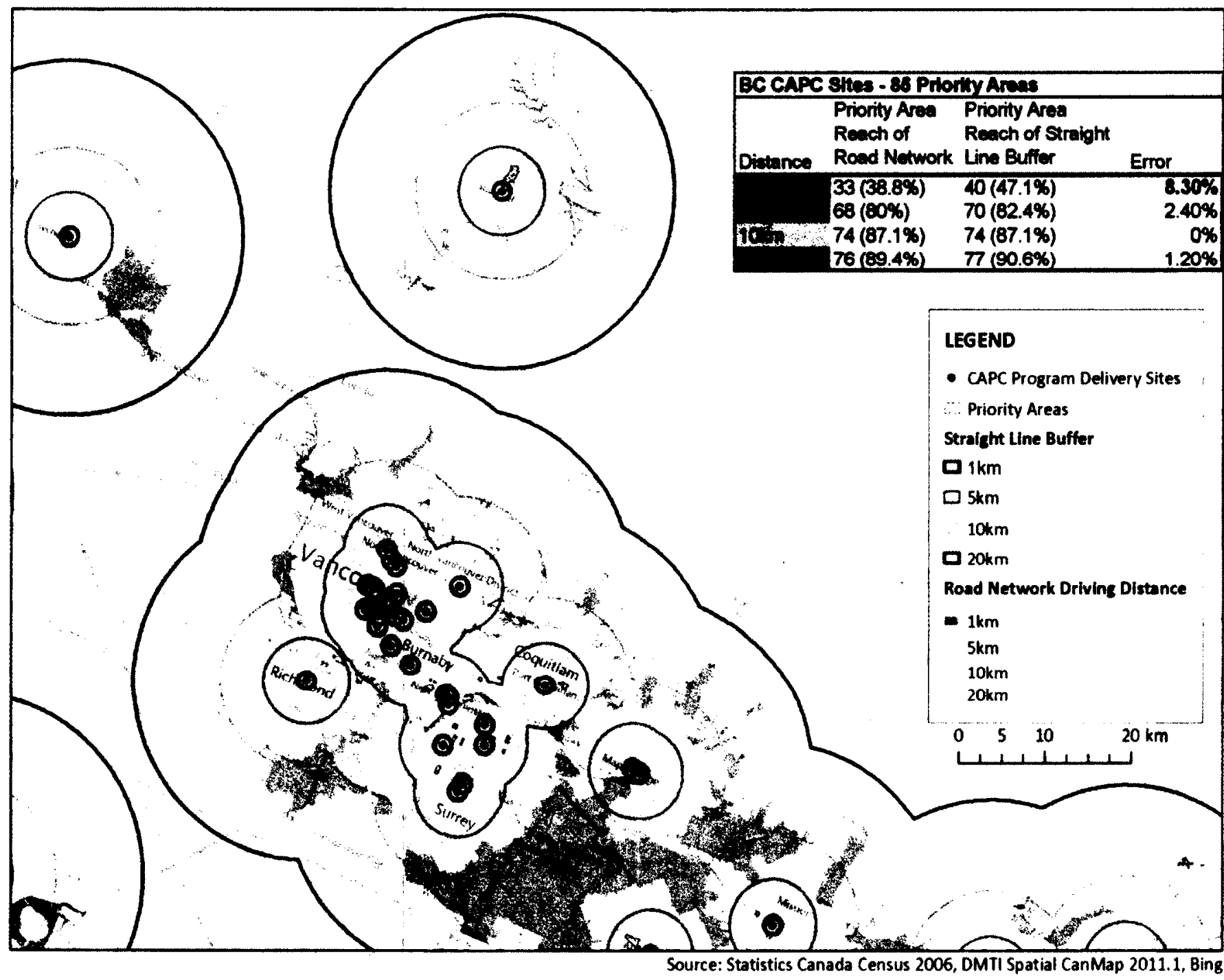

Source: Compiled bv author 
Within a $1 \mathrm{~km}$ driving distance, 1,399 CAPC sites across Canada reach $35 \%$ of priority areas, and 824 CPNP sites presumably reach fewer priority areas (25\%). The majority of priority areas reached within $1 \mathrm{~km}$ are located in CMAs (90\% for CAPC; $87 \%$ for CPNP). This is not surprising given that highly populated dissemination areas are smaller in surface area and therefore an urban area contains more DAs than rural areas. In these instances, multiple DAs are more likely to be captured in a $1 \mathbf{k m}$ driving distance than in a rural area where DAs tend to be geographically larger.

The provincial level roll-up analysis shows interesting results. Compared to other provinces' CAPC reach within $1 \mathrm{~km}$, Nova Scotia reaches the highest proportion of its priority areas (56\% of 25 priority areas), although it has a high number of CAPC sites (215), almost equivalent to the number of sites in the other three Atlantic provinces combined. By contrast, New Brunswick CAPC has only a $28 \%$ reach within $1 \mathrm{~km}$ even though it has fewer priority areas (18) and a substantial number of sites (141).

Within a $5 \mathrm{~km}$ driving distance, CAPC sites reach a greatly improved $76 \%$ of priority areas nationally. Quite remarkably, however, CPNP has an equally good reach as CAPC within this same distance, yet with just less than $60 \%$ of the number of CAPC sites! As shown earlier in Figure 9 , only $18.6 \%$ of unique program delivery sites have both CAPC and CPNP. Therefore, program co-location does not serve as an explanation. CPNP sites therefore are well situated for reaching a high proportion of priority areas with many fewer sites compared to CAPC. This finding is an intriguingly sharp contrast warranting further investigation beyond the scope of this study. 
This particular finding of CPNP's great success in reaching a high proportion of priority areas triangulates with the findings in the PHAC summary report of program evaluations on its population health contribution programs; thereby, also, indicating the strength of this case study's data and methodology: "programs such as CPNP make significant effort in identifying their target populations and locating/funding projects in close proximity to them so as to increase accessibility" (PHAC, 2010a, Section 9.7).

The $10 \mathrm{~km}$ and $20 \mathrm{~km}$ reach are incrementally better, with the $20 \mathrm{~km}$ catchment area having the best Canada-wide reach of priority areas ( $88 \%$ for CAPC, $90 \%$ for CPNP) using these distances. Most notably for CPNP, Nova Scotia is the only province/territory to reach $100 \%$ of its priority areas within a $20 \mathrm{~km}$ catchment area. Likewise, Nova Scotia CAPC has the greatest reach of priority areas (96\%).

Not only do the results of this study's analysis lend themselves to national and provincial/territorial comparisons, they are also useful for community-level analyses. In a sample city, shown in Figure 12, seven CAPC program delivery sites are situated in the downtown area while the majority of the city's priority areas are over $1 \mathrm{~km}$ but less than $5 \mathrm{~km}$ away (within the light green polygon). Although the sites are beyond a $1 \mathrm{~km}$ walking distance from these priority areas, the population living in those priority areas most likely have reasonable access given their proximity to the public transportation line. An eighth site in the northwest end of the city is located right in the heart of the larger priority areas. 
Figure 12: Map of a Sample Community-Level Analysis of CAPC Program Delivery Site Reach

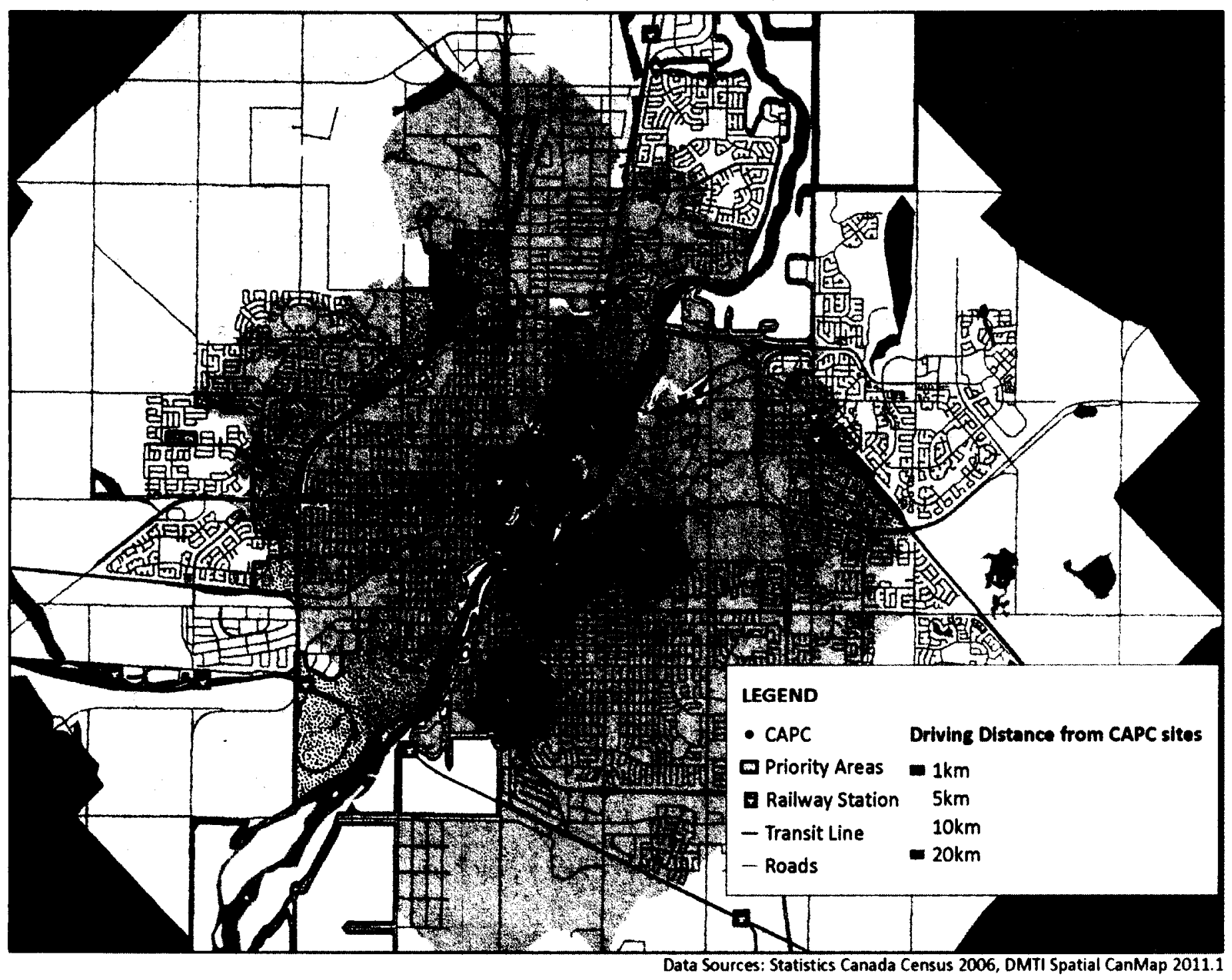


At this community-level scale, further analysis can be conducted on communities of particular interest. As highlighted in the previous section, priority area analysis results revealed that the CSDs Brampton and City of Toronto contained the top 10 priority areas most populated with children aged 0 to 6 . Upon further investigation, it was confirmed that CAPC reaches 8 of the 10 priority areas within a $5 \mathrm{~km}$ distance $(2 / 2$ in Brampton, $6 / 8$ in Toronto), and fully reaches $100 \%$ of the top 10 priority areas within $10 \mathrm{~km}$. CPNP fully reaches $100 \%$ of the top 10 priority areas within $5 \mathrm{~km}$. The results are shown in Table 18.

It must be noted that the priority area with the single greatest number of children aged 0 to 6 of all priority areas is a block within the St. James Town neighbourhood, as shown in Figure 13, located in the City of Toronto, with 809 children. Wikipedia describes St. James Town as one of the most densely populated neighbourhoods in North America, the largest high-rise community in Canada, one of Toronto's most economically deprived neighbourhoods, and composed primarily of immigrants, most of which arrived in the $1990 \mathrm{~s}^{13}$. This provides added reassurance that the INSPQ Deprivation Index and chosen criteria for priority areas in this study are indeed detecting target dissemination areas. Both CAPC and CPNP reach this particular dissemination area with multiple program delivery sites within $1 \mathrm{~km}$.

${ }^{13}$ Accessed August 8, 2012: http://en.wikipedia.org/wiki/St._James_Town 
Table 18: CSDs with the Top 10 Most Populated Priority Areas, and the Extent of their Reach

\begin{tabular}{|c|c|c|c|c|c|c|}
\hline \multirow{2}{*}{$\begin{array}{l}\text { CSD } \\
\text { Name }\end{array}$} & \multirow{2}{*}{$\begin{array}{l}\text { Number of } \\
\text { Priority Areas } \\
\text { within top } 10\end{array}$} & \multirow{2}{*}{$\begin{array}{l}\text { Population 0-6 } \\
\text { within those } \\
\text { Priority Areas }\end{array}$} & \multirow{2}{*}{$\begin{array}{l}\text { Number } \\
\text { of Sites* }\end{array}$} & \multicolumn{3}{|c|}{ Top 10 Priority Areas Reached } \\
\hline & & & & & & \\
\hline \multirow[t]{2}{*}{ Brampton } & 2 & 1,007 & 1 CAPC & 0 & $2(100 \%)$ & \\
\hline & & & 3 CPNP & 0 & $2(100 \%)$ & \\
\hline City of & 8 & 4,703 & $61 \mathrm{CAPC}$ & $1(12.5 \%)$ & $6(75 \%)$ & $8(100 \%)$ \\
\hline Toronto & & & 42 CPNP & $5(62.5 \%)$ & $8(100 \%)$ & \\
\hline
\end{tabular}

*Priority areas within these communities may be reached by additional sites in adjacent CSDs. Source: Compiled by author

Figure 13: Map of Priority Area with the Greatest Number of Children Aged 0 to 6 in Canada: Dissemination Area \#35204567 within St. James Town, City of Toronto $(n=809)$

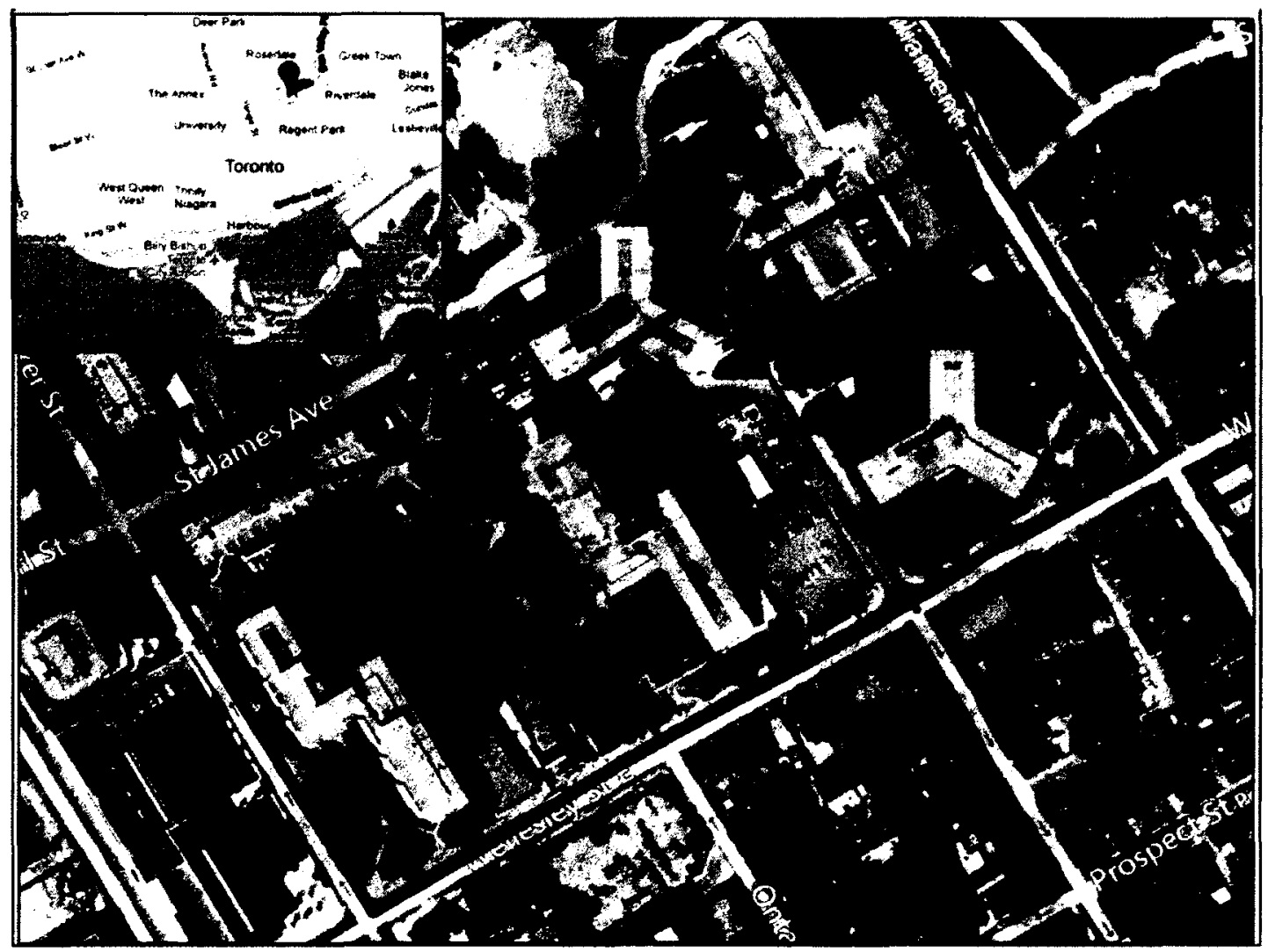

Source: Compiled by author

Inset Map Source: Google Maps (http://maps.google.com) 


\subsubsection{Sites not Reaching Priority Areas}

Having adequately answered the question of program reach of priority areas, the analysis could turn to a more sensitive and critical assessment of individual sites reaching no priority areas. This is not to say such sites are not reaching target population since there are most definitely pockets scattered across other areas. Instead, this approach would act as a mechanism to validate the location of sites, ensuring their best placement given that population demographics may have shifted since the program's inception over a decade ago. Any identified sites could be flagged for further investigation and follow-up for explanation or verification. This type of site by site analysis was an afterthought following the primary analysis and unfortunately the catchment areas were merged upon their creation and therefore individual site by site analysis of reach is not possible (see Figure 6 in Chapter 3, section 3.1.3). However, if this type of analysis was of interest, it is technically possible for the catchment areas to be created in a way that would allow for this.

\subsubsection{Program Underservice of Priority Areas}

Having the program reach calculated based on the intersection of catchment areas and priority areas, the opposite query can render a broad geographic analysis of potential gap in service: priority areas beyond $20 \mathrm{~km}$, as previously shown in Table 17. Since locations of home visits were not collected for this study, it is possible that these priority areas may or may not be serviced through such one-on-one services. However, it is the CAPC participants receiving home visits and one-on-one services that are the 
most at risk and require the most support (McMurchy \& Palmer, 2012), and, as such, program sites could presumably be offered in their area. Therefore, priority areas beyond $20 \mathrm{~km}$, for the sake of this study, are considered "potentially underserviced" and flagged for further investigation and assessment of their reach. Reiterating from a previous discussion, the CAPC and CPNP programs are not mandated to reach all communities, but rather to complement existing ECD programs offered by other jurisdictions. The purpose of flagging areas as potentially underserviced is to suggest specific locations where the program may assess their reach and the availability of ECD programs in general, with the support of the local intelligence from projects. If the level of service delivery is weak in a high need area, the CAPC/CPNP programs could creatively expand reach or identify possible partnerships and collaboration with other ECD programs to improve the equitable access of public health services to those in need. The remainder of the analysis and discussion utilises the term "underserviced areas" or "underservices", but in actual fact this term more precisely means "potentially underserviced areas" or "potentially underservices". This case study alone cannot make such judgements. Figure 14 exhibits a visual example of the geographic analysis identifying priority areas beyond $20 \mathrm{~km}$. 
Figure 14: Map of Sample Regional-Level Analysis of Potentially Underserviced Communities

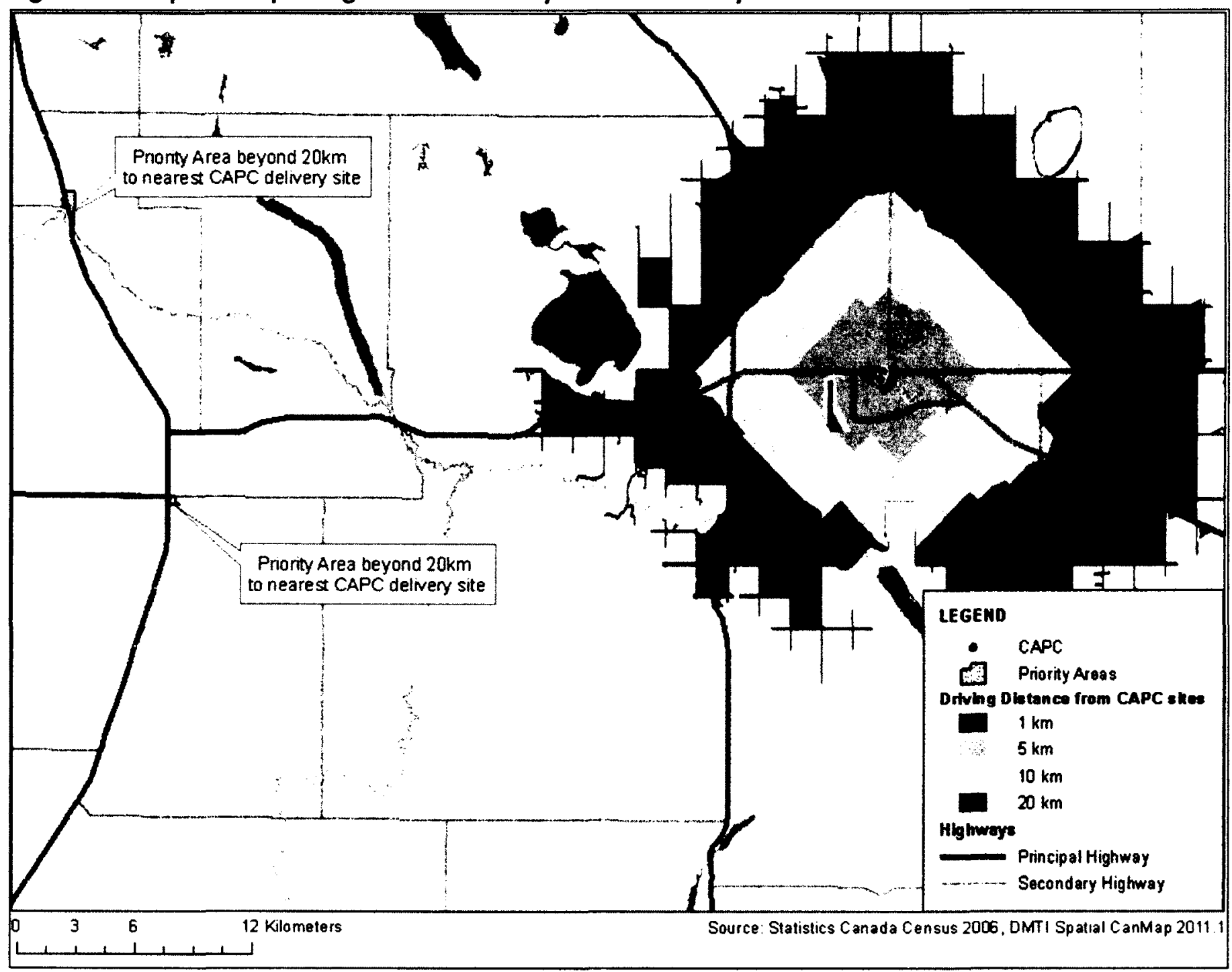

* Program staff requested the communities in this map remain unlabelled due to potential program sensitivities.

Source: Compiled bv author 
Nationally, CAPC underservices 147 priority areas within 113 census subdivisions (from this point forward referred to as "communities"). The national and provincial breakdown is shown below in Table 19. Half of the underserviced CAPC communities are in villages/municipalities, $30 \%$ in cities/towns, and $20 \%$ in CMAs. The province with the greatest number of underserviced communities is Alberta $(n=24)$. However, the province with the greatest number of children aged 0 to 6 living in underserviced priority areas is Ontario $(n=2,409)$, representing a third of the national total. The top three communities with the greatest number of underserviced priority areas are in Ontario (Chatham-Kent, Guelph, Cornwall), and they also have the greatest 0 to 6 population ( 368 to 500 each).

CPNP underservices 129 priority areas within 113 communities, although when compared, it was confirmed that they are not the exact same as those 113 underserviced CAPC communities. The distribution of these communities by community type is very similar to that of CAPC, a difference of only a couple percentage points. The range in the number of priority areas per underserviced community is from 1 to 3 , which is less than that of CAPC (1-7). The province with the greatest number of underserviced communities is Saskatchewan $(n=24)$, also having the greatest number of children aged 0 to $6(n=1,279)$, representing a fifth of the national total.

CAPC and CPNP, combined, underserve a total of 145 communities (113 each, but not all are mutually exclusive). Appendix 3 lists these potentially underserviced communities by province, sorted by descending number of children aged 0 to 6 living in priority areas. The communities are attributed with community name, community type 
(according to their CSD Type), Census Division name (counties or regional districts), CMA name, if applicable, and, population aged 0 to 6 . The table also provides the number of priority areas beyond $20 \mathrm{~km}$ for each CAPC and CPNP.

Of the 145 communities, 32 are reached by CAPC, but not by CPNP. The top three of these underserved communities with the greatest number of children are Mirabel, QC (196 children), Chilliwack, BC (153 children), and Portage la Prairie, MB (147 children). The communities identified could represent an opportunity for the program to increase capacity at the CAPC sites to include CPNP services.

Similarly, 33 of the 145 communities are reached by CPNP, but not by CAPC. The top three of these underserved communities with the greatest number of children are Chatham-Kent, Guelph and Cornwall, ON (500, 410, and 368 children, respectively). These are the same top three communities previously identified as underserviced by CAPC. Furthermore, this comparison of CAPC and CPNP by CSD confirms that although those communities are underserved by CAPC, they are indeed served by CPNP. This represents a significant opportunity, given the number of children, for the program to increase capacity at the CPNP sites to expand services by offering CAPC activities.

Significantly, over half of the 145 underserved communities are not reached by either CAPC or CPNP $(n=80)$, and addressing this could be a program consideration. The top three of these underserved communities with the greatest number of children are Pinehouse, SK, Belleville, ON, and Sarnia, ON (205, 195 and 155 children, respectively). Table 20 identifies the top 10 underserved communities for each of the three presented program reach scenarios. The population counts provided represent the sum 
of children living in the deprived areas within the communities, and do not reflect the entire population aged 0 to 6 of the CSD. The scenario with the greatest number of children residing in the top 10 communities is that for communities reached by CPNP but not CAPC (a total of 2,114 children). This corresponds to the previous finding that CPNP has just as good a reach as CAPC within a $5 \mathrm{~km}$ driving distance yet with just $60 \%$ of the number of CAPC sites and only $18.6 \%$ of programs being co-located. This intriguing finding is suggested for further investigation beyond the scope of this study; however, the listed communities reached by CPNP but not CAPC has shed light on the reason. If CAPC provided services in these particular communities, the program could indeed improve its reach, according to these results. 
Table 19: Number of Potentially Underserviced Communities by Province/Territory

\begin{tabular}{|c|r|r|r|}
\hline \multicolumn{1}{|c|}{ P/T } & $\begin{array}{c}\text { Number of Priority } \\
\text { Areas Beyond 20km }\end{array}$ & $\begin{array}{c}\text { Number of CSDs with } \\
\text { underserviced Priority } \\
\text { Areas }\end{array}$ & $\begin{array}{c}\text { Population 0-6 in } \\
\text { "Underserviced" Priority } \\
\text { Areas }\end{array}$ \\
\hline BC & 8 & 5 & 372 \\
AB & 30 & 24 & 1,326 \\
SK & 26 & 23 & 1,352 \\
MB & 10 & 10 & 582 \\
ON & 38 & 17 & 2,409 \\
QC & 20 & 19 & 918 \\
NB & 1 & 1 & 37 \\
NS & 1 & 1 & 49 \\
PEI & 1 & 1 & 26 \\
NL & 5 & 5 & 138 \\
YT & 1 & 1 & 57 \\
NT & 3 & 3 & 179 \\
NU & 3 & 3 & 365 \\
\hline TOTAL & 147 & 113 & 7,810 \\
\hline
\end{tabular}

\begin{tabular}{|l|r|r|r|}
\hline \multicolumn{1}{|c|}{ P/T } & $\begin{array}{c}\text { Number of Priority } \\
\text { Areas Beyond 20km }\end{array}$ & $\begin{array}{c}\text { Number of CSDs with } \\
\text { underserviced Priority } \\
\text { Areas }\end{array}$ & $\begin{array}{c}\text { Population 0-6 in } \\
\text { "Underserviced" Priority } \\
\text { Areas }\end{array}$ \\
\hline BC & 10 & 7 & 464 \\
AB & 24 & 20 & 1,077 \\
SK & 28 & 24 & 1,279 \\
MB & 15 & 14 & 962 \\
ON & 13 & 12 & 746 \\
QC & 18 & 17 & 950 \\
NB & 3 & 3 & 109 \\
NS & 4 & 3 & 157 \\
PEI & 1 & 1 & 26 \\
NL & 5 & 5 & 138 \\
YT & 1 & 1 & 57 \\
NT & 2 & 2 & 120 \\
NU & 5 & 4 & 446 \\
\hline TOTAL & 129 & 113 & 6,531 \\
\hline
\end{tabular}

Source: Compiled by author 
Table 20: Top 10 Most Populated Potentially Underserved Communities in Three Program Reach Scenarios

\begin{tabular}{|c|c|c|c|c|c|c|}
\hline & \multicolumn{2}{|c|}{$\begin{array}{l}\text { Reached by CAPC, but not } \\
\text { CPNip }\end{array}$} & \multicolumn{2}{|c|}{$\begin{array}{c}\text { Reached by CPNP, but not } \\
\text { CAPC }\end{array}$} & \multicolumn{2}{|c|}{$\begin{array}{l}\text { Not resched by either } \\
\text { program }\end{array}$} \\
\hline & Community & $\begin{array}{c}\text { Est. } \\
\text { Children } \\
\text { Aged } \\
0-6^{*}\end{array}$ & Community & $\begin{array}{c}\text { Est. } \\
\text { Children } \\
\text { Aged } \\
0-6^{*}\end{array}$ & Community & $\begin{array}{c}\text { Est. } \\
\text { Children } \\
\text { Aged } \\
0-6^{*}\end{array}$ \\
\hline 1 & $\begin{array}{l}\text { Mirabel, QC } \\
\text { (Ville) }\end{array}$ & 196 & $\begin{array}{l}\text { Chatham-Kent, ON } \\
\text { (Municipality) }\end{array}$ & 500 & $\begin{array}{l}\text { Pinehouse, SK } \\
\text { (Northern } \\
\text { Village) }\end{array}$ & 205 \\
\hline 2 & $\begin{array}{l}\text { Chilliwack, BC } \\
\text { (City) }\end{array}$ & 153 & $\begin{array}{l}\text { Guelph, ON } \\
\text { (City) }\end{array}$ & 410 & $\begin{array}{l}\text { Belleville, ON } \\
\text { (City) }\end{array}$ & 195 \\
\hline 3 & $\begin{array}{l}\text { Portage la Prairie, } \\
\text { MB } \\
\text { (City) }\end{array}$ & 147 & $\begin{array}{l}\text { Cornwall, ON } \\
\text { (City) }\end{array}$ & 368 & $\begin{array}{c}\text { Sarnia, ON } \\
\text { (City) }\end{array}$ & 155 \\
\hline 4 & $\begin{array}{l}\text { Saint-Jérôme, QC } \\
\text { (Ville) }\end{array}$ & 135 & $\begin{array}{l}\text { La Loche, SK } \\
\text { (Northern village) }\end{array}$ & 139 & $\begin{array}{l}\text { North Battleford, } \\
\text { SK } \\
\text { (City) }\end{array}$ & 154 \\
\hline 5 & $\begin{array}{l}\text { The Pas, MB } \\
\text { (Town) }\end{array}$ & 125 & $\begin{array}{l}\text { Meadow Lake, SK } \\
\text { (Town) }\end{array}$ & 128 & $\begin{array}{l}\text { Coral Harbour, } \\
\text { NU } \\
\text { (Hamlet) }\end{array}$ & 154 \\
\hline 6 & $\begin{array}{l}\text { Melfort, SK } \\
\text { (City) }\end{array}$ & 111 & $\begin{array}{l}\text { Magog, QC } \\
\text { (Ville) }\end{array}$ & 125 & $\begin{array}{c}\text { Taloyoak, NU } \\
\text { (Hamlet) }\end{array}$ & 151 \\
\hline 7 & $\begin{array}{l}\text { Kelowna, BC } \\
\text { (City) }\end{array}$ & 106 & $\begin{array}{l}\text { Leamington, ON } \\
\text { (Municipality) }\end{array}$ & 116 & $\begin{array}{l}\text { Raymond, } \mathrm{AB} \\
\text { (Town) }\end{array}$ & 141 \\
\hline 8 & $\begin{array}{l}\text { Yarmouth, NS } \\
\text { (Town) }\end{array}$ & 99 & $\begin{array}{l}\text { Medicine Hat, AB } \\
\text { (City) }\end{array}$ & 111 & $\begin{array}{l}\text { Bonnwille No. 87, } \\
\text { AB } \\
\text { (Municipal } \\
\text { District) }\end{array}$ & 139 \\
\hline 9 & $\begin{array}{l}\text { Moose Jaw, SK } \\
\text { (City) }\end{array}$ & 98 & $\begin{array}{l}\text { Fort St. John, BC } \\
\text { (City) }\end{array}$ & 109 & $\begin{array}{l}\text { Two Hills, AB } \\
\text { (Town) }\end{array}$ & 114 \\
\hline 10 & $\begin{array}{l}\text { Notre-Dame-des- } \\
\text { Bois, QC } \\
\text { (Municipalité) }\end{array}$ & 93 & $\begin{array}{l}\text { Greater Napanee, } \\
\text { ON } \\
\text { (Town) }\end{array}$ & 108 & $\begin{array}{l}\text { Division \#21, } \\
\text { Unorg, MB } \\
\text { (Unorganized) }\end{array}$ & 112 \\
\hline & TOTAL & 1,263 & & 2,114 & & 1,520 \\
\hline
\end{tabular}

* Not the community's total 0-6 population, but rather a sum of those residing in priority areas within underserved communities. Estimate of population $0-6$ is calculated as $100 \%$ of children $0-4$ and $60 \%$ of children $5-9$.

Source: Compiled by author 


\subsection{LIMITATIONS}

At many points throughout an analysis, the researcher has to make choices that will indisputably impact the results. These choices can include the selection of data sources, variables, technical GIS methodologies, data representation, definitions and exclusions. If the choices are sound, defensible and reflect the needs of the "client", then the results should produce credible evidence. Different results may be produced depending on different choices. It is important that the limitations and assumptions made by the analyst be clearly communicated to the end-user and considered when applying the evidence.

The methodology was developed with national analysis in mind. This has, as a result, impacted which dissemination areas appear as priority areas because the selection criteria was the top two quintiles of deprivation scores for all DAs across Canada. Priority areas would most likely be different if the quintile was taken for each individual province's data. Therefore, between-province analysis should be interpreted with caution. If any further interpretation is required, a provincial lens would be more appropriate when developing or modifying the methodology.

The reach results solely reflect the geographic intersection of priority areas with program delivery site catchment areas of varying distances. CAPC and CPNP offer oneon-one services including home visits which are not captured in this analysis primarily due to respecting participants' privacy. Had the home visits locations been included in the address collection, geocoding and analysis, the resulting program reach could very well have increased. However, the benefit of identifying priority areas, especially those 
without CAPC or CPNP, is that they are highly likely to be excellent target locations for home visits. In addition, the results based on geographic proximity as shown in this study are encouraging in that the program can confidently report that they reach a minimum of approximately $75 \%$ of priority areas within a $5 \mathrm{~km}$ driving distance.

Related to the ecological fallacy problem, the individuals represented within the identified priority area populations are not necessarily all deprived since the index is based on a proportion. Likewise, target population could reside outside of priority areas but in a more scattered fashion in smaller pockets across communities. One way to verify the program reach of the general population, thereby including all potentially vulnerable individuals and not just priority areas, is to conduct the spatial intersection of the CAPC and CPNP driving distance catchment areas with all DAs and calculate the proportion of all people living within and beyond the various driving distances. This verification test was an afterthought and was not conducted, but could easily be incorporated into future work.

The inherent limitation of the census data used to develop the INSPQ Deprivation Index and resulting proximity to priority areas analysis is that the census data represents the population's place of residence, on that particular census day. It is not uncommon for population groups such as recent immigrants to have temporary homes while they settle in to the community and system, or vulnerable women who may be moving in and out of shelters. In addition, the census data is based on one's residence and does not reflect places of work or activity where the majority of the population's time is spent and where they may be more likely to utilize services. 
However, Statistics Canada is an authoritative source that is, at least up until 2006 census, the best source for sociodemographic data at the block level for across Canada.

On a related matter, enumerated children in the 2006 census aged 0-6 are now 5 to 11 years old, mostly beyond the target age group of the two children's programs. At the time of the analysis, the 2011 census data was not yet available, and the 2011 deprivation index was obviously not yet produced by INSPQ. Additionally, no other data source was appropriate for identifying an updated child population at the dissemination area level. Vital Statistics' live births registry was considered since the mothers' postal code could be converted to any standard census geography. However, one immediate and major limitation of this data source is that Quebec does not participate and this would therefore leave an enormous gap in the national analysis.

The results of this analysis could be used to guide federal decision-makers, federal and regional evaluation analysts, and community planners and policy makers in making decisions about priorities for early child development programs and services, but it would be inadequate to evaluate the programs in isolation from other lines of evidence. The results are not prescriptive, but should be seen as a strong indicator for further exploration, explanation-seeking and triangulation with other lines of evidence.

\subsection{RECOMMENDATIONS}

Geographical analysis was a new approach for the case study organization's children's programs, and as such, there were many observations and lessons learned along the way that could be beneficial for other individuals and organizations who are 
considering this approach. Based on these lessons, a list of key recommendations have been identified and categorized into themes: resources, data, program data collection, and knowledge, development and exchange.

\subsubsection{Resources}

1. Program units planning any spatial analyses for the purpose of performance measurement should communicate such plans as early as possible to the corporate evaluation unit or group responsible for program evaluation. The benefit would be the avoidance of duplication of effort and cost should the corporate evaluation unit already have plans to conduct similar analyses. In addition, the evaluation unit may be able to contribute to the research questions to be answered by the spatial analysis, and may even be willing to contribute funds to such analyses as a joint research project.

2. Address geocoding could be contracted out to save time, but the requirements for geographic accuracy of addresses must be clear and the geocoding results must also be visually verified. Depending on the quality of the street address information, there could be a time and resource investment for verifying addresses (e.g. street direction), requiring collaboration and interaction between program consultants and contractor.

\subsubsection{Data}

1. The currency of deprivation index developments must be maintained since researchers who have published their local indices may be replicating and 
expanding analyses to larger geographic areas (e.g. Toronto to Canada-wide), or revising data with current or historical census for change over time.

2. Some of the census variables used in the deprivation index are based on a twenty percent sample, extracted from the census long form questionnaire. As of the 2011 census, the long form questionnaire is now part of the voluntary Canadian Household Survey, which could adversely affect analytical possibilities. Moving forward with spatial analyses in the future would require investigation of this new survey of its reliability, sample size and utility.

3. In the future, custom data tabulations could be requested and purchased from Statistics Canada so that more accurate spatial analyses can be conducted. Instead of using the census variables as is (i.e. low income cut-off (LICO), lone parent families, without high school completion, etc), a more specific variable can be tabulated that more accurately reflects the target population (i.e. females aged 15-55 who are below the LICO and who do not have high school completion and who have young children, etc). A minimum population count in the results will be required for each geographic area to maintain privacy; therefore, the number of variables included in the criteria and the level of geography will need to be considered to avoid too much data suppression.

\subsubsection{Program Data Collection}

1. Such detailed street address collection and analysis may not be required annually to determine program reach, although having this current work most certainly makes any future analysis a simpler matter of updating the addresses 
and re-running the analyses using the same processes. What this study has accomplished is a triangulation of reach with other measurements and reporting of program reach. Performance measurement tools may not necessarily collect reach data the same way, but overall their results can tell an important story.

2. When coding and entering collected program data into a database such as program addresses or province/territory, the Statistics Canada standard unique identifiers should be applied for easier and more efficient spatial analysis (e.g. the 2-digit province code: $N S=12, O N=35, B C=59, N U=62$, etc.).

3. Postal code data collection:

- When participant data is collected, an attempt should be made to collect all six postal code alpha-numeric digits for maximum flexibility in data analysis and aggregation. Forward sortation areas, the first three digits of the postal code, is insufficient for small area analysis given their usually enormous geographic size and lack of respect of census boundaries.

- If postal code data (partial or full) reported by participants is typically unreliable, investigate the reasons why data are entered erroneously, including survey clarity, language barriers, and participants' concerns about privacy. Identifying the points of resistance will lead to the appropriate action or steps necessary to mitigate risks or concerns.

- The project or participant survey should clearly identify the postal format and provide an example to impose a standard format and improve survey 
completion. Formatting on hard copy paper could be something like this:

[A-Z] [0-9] [A-Z] [0-9] [A-Z] [0-9] (e.g. K2G 8C5)

\subsubsection{Knowledge Development and Exchange}

Spatial analysis results were disseminated to the stakeholders via static maps and tables within the analyses report and presentations. The utility of static maps is limiting as they do not allow the full use of the data behind the picture. As an internal and preliminary solution, a simple and interactive desktop tool was developed with ArcExplorer Desktop software for the purpose of allowing end-users to visualize results in a simple GIS viewer, with more control of layers, zoom, map exporting and printing. Having a tool like ArcGIS Explorer on the desktops of analysts enables them to drill down to any area of interest, at any scale, to visualise results of advanced spatial analysis and to explore how such analysis results geographically overlay with the various layers of socioeconomic data relevant to the program target population. This level of interactivity with program-relevant data has the potential to increase program knowledge among analysts, program consultants, and management, and support their reporting and decision-making. Unfortunately, the thorough testing and dissemination of the end-user desktop tool and training were not possible in the timelines, but could be considered for future work.

A weakness in public access to information was identified through the research of early years programs available in each province in that most provincial government websites did not have an all-inclusive map of such program locations. As such, it would 
be difficult as a parent to locate services in nearby communities. The projects, with support from the federal government, could leverage the efforts of United Way's 2-1-1 project, which is an accessible referral program for those in crises to public health and social services. The system is currently offered in pockets of the country, but United Way is working towards a national platform. The Ontario chapter's system for case management data collection and service location will be the model for the national rollout expected in late 2012, and has a searchable map component on its website showing locations of various services ${ }^{14}$. As the CAPC and CPNP projects' funder, PHAC could encourage the CAPC/CPNP sites to register with United Way 211 as a means to increase traffic, awareness and referrals. The effectiveness of such partnership could easily be evaluated by comparing the participation rate before (baseline) and a period thereafter (progress).

\subsection{CHAPTER SUMMARY}

This chapter discussed in detail the results from multiple modules of analyses. The results of geocoded program delivery sites were presented and their distribution and type of community in which they are located was discussed. The locations of priority areas were mapped and analyzed for their containment of population aged 0 to 6. Program reach was then interpreted by various driving distances, with the driving distance methodology further justified by a comparison with the Euclidean results. The location of priority areas and their reach by the programs was the central question to be

\footnotetext{
${ }^{14} 211$ Ontario website: http://www.211ontario.ca/
} 
answered in the case study, as a means to test the central argument of this thesis. This was answered and presented through various tables and maps as visual examples of what the analysis looked like at the national, provincial, regional, community and even block level.

The data produced by the reach analysis allowed for further inquiry, and so the study pursued this by providing a gap analysis of potentially underserved communities. Quite specifically, named communities were suggested for further exploration as they demonstrated opportunity to potentially increase reach in three program reach scenarios. Working with data at the dissemination area level allowed the results to be analyzed, interpreted and presented at multiple geographic scales, drawing particular attention to obvious differences emerging from the data, and interesting connections were made that have previously not been available.

Although there are some limitations to the data and methodology, the insights obtained from this analysis can guide the programs in performance measurement, program evaluation, and planning. This chapter offered key recommendations around resources, data, data collection, and knowledge development and exchange, for organizations considering this approach. The following chapter provides a concluding discussion about the usefulness of the case study results, their impact on the discipline of performance measurement and evaluation, the study's significance to other organizations, and future work. 


\section{CHAPTER 5. CONCLUSION}

This chapter first summarizes the work presented throughout the thesis, followed by a discussion concluding the work. Lastly, the third section details the contribution of this research specifically to CAPC and CPNP, and more broadly to other programs within federal health departments.

\subsection{SUMMARY}

This thesis examined the application of GIS and spatial analysis to program performance measurement and evaluation, arguing its ability to significantly add value to existing approaches and to develop a new line of evidence. Confirmed by a thorough literature search in Chapter 2, there is very little evidence of such an application in the evaluation publications within the past two decades, despite the growing accessibility of GIS to an increasing number of disciplines. The utility of GIS in program evaluation was substantiated by an applied case study of two national children's community-based public health promotion programs funded and evaluated by a federal government agency.

Specifically, Chapter 1 introduced the need for this case study to answer two basic questions not previously answered by the programs: 1) to identify where the children aged 0 to 6 live across Canada, and, 2) to determine to what extent CAPC and CPNP are within relative proximity to this population. An equally important goal was to use GIS to improve the accuracy and validity of current performance measurement 
approaches in assessing program reach which have some shortcomings due to the potential double counting and inconsistent definitions.

Chapter 2 reviewed the literature and theoretical underpinnings that guided this research, and as discussed in Chapter 3, informed the methodology used to develop a small-area analytical approach to assess the programs' reach of the target population. The selection of the INSPQ Deprivation Index as a proxy for representing areas with the most likely concentration of the target population was justified by the findings in other Canadian public health research showing associations between areas of deprivation and multiple risk conditions reflective of the CAPC and CPNP target population.

The results presented and discussed in Chapter 4 suggest the strengths of GIS to answer the immediate research questions. As well, GIS added value to program performance measurement and evaluation through an array of geographic inquiry: scenario-building using a range of driving distances; the investigation of areas of potential program gap; verification of adequate program coverage in specific communities with the greatest number of children in areas of high deprivation; and, the description of the type of communities served or potentially underserved.

The results of the primary analysis led to these subsequent inquiries, which were permitted by the quality, availability, and national coverage of the data, as well as the chosen methodology. Lastly, using data represented at the dissemination area level allowed the results to be analyzed, interpreted and presented at multiple geographic scales (CSD, CMA), drawing particular attention to obvious differences emerging from the data, and interesting connections were made. The resulting spatial analyses through 
a GIS have proven to be much more detailed than the current method of reporting reach, lending to national, regional, city-wide and site by site analysis.

The concluding remarks of the analysis and discussion offered some key recommendations about resources, data, program data collection, and knowledge, development and exchange.

\subsection{CONCLUSION}

The central argument of this thesis is that spatial analysis can significantly improve and add value to existing approaches of measuring reach, thus contributing to program evaluation. The case study results validated the hypothesis. Developing a national approach to neighbourhood level spatial analysis of targeted public health programs has been accomplished in this case study with meaningful results. Applying a small-area analytical approach for such a large program is therefore possible, manageable and useful. The case study has illustrated that a spatial analysis approach is not only feasible for the development of program measurement in support of program evaluation, but also provides several unique advantages that could potentially enhance the evidence behind planning and policymaking. Although the results are not prescriptive, they represent a point for further exploration, explanation-seeking, and triangulation with other lines of evidence.

The goal of the author was to demonstrate the utility of bridging geographic inquiry with performance measurement and evaluation, and it is the author's hope that this thesis is valued as one contribution to the evolution of 'spatial program evaluation'. 
By narrowing this gap between geomatics and evaluation, the expectation is a strengthened approach to evidence-building and decision-making support for public health program evaluation, as well as a model on which other departments and organizations with similar information needs may build.

\subsection{SUMMARY OF CONTRIBUTIONS}

\subsubsection{Significance to CAPC and CPNP children's programs}

The results of these national spatial analyses, naturally, have the most significant impact on the CAPC and CPNP children's programs themselves. The work of Weiss and Bucuvalas (1980) on maximizing decision-makers' utilization of social science research states that decision-makers invoke three basic frames of reference for coping with and utilizing floods of information. The first is the relevance of the study to their sphere of responsibility. This case study was developed specifically to respond to the organization's performance measurement research question.

The second frame of reference is the trustworthiness of the study. Since PHAC program staff were involved in the data collection process, and consulted during the methodology design process, their support and concurrence on the quality and type of research methods had been attained.

The third frame of reference is the direction the study provides in terms of guidance for immediate action or considerations for alternative approaches to problems. The results of the analysis identifying potentially underserviced target areas 
indicate an opportunity for the program to further investigate specific communities where programming may be needed. This could be approached by seeking external validation using projects' local intelligence on the need and provision of complementary services by other ECD programs, as well as exploring creative ways to expand reach to those areas. Based on these three frames of reference, it is the author's hope that the Public Health Agency of Canada will consider utilizing the reach and potential gaps results from this case study in the program evaluation and any future strategic planning. In the case of the Public Health Agency of Canada, spatial analysis of children's programs has produced a geographic lens of information which was not previously available. Such analysis may prove to be a key knowledge piece, when the time comes for program summative evaluation as it provides an additional line of evidence and triangulation with other research findings to support overall evaluation.

Given the complexity of target population and the wide variance of services offered by program sites, such program nuances and resulting program evaluations have allegedly been challenging to communicate effectively to senior executive management in a clear and precise manner. Presenting the material with the support of a geographical context that has been built on well-defined methodologies and authoritative, standard sources like Statistics Canada census data and geographies, has the potential to increase the understanding about the program, and its validity and continued relevance.

Under the current economic pressures and the recent federal Deficit Reduction Action Plan, priority target areas identified in the analysis represent areas for continued 
investment or creative approaches to expand reach with fewer resources. The spatial analytical approach and its results potentially offer a line of evidence to support management decision-making during program strategic planning. For example, the information could be helpful during project funding solicitation in assessing which proposals would increase program reach to identified underserviced priority areas.

Lastly, further data mining is possible by linking the projects' performance measurement data to their location within the GIS. Indicators such as the number of participants, types of services offered, or funding could be spatially analysed, making greater use of the rich data source.

\subsubsection{Significance to Federal Health Departments}

Having an established approach with sound methodology, data (e.g. deprivation index) and a preliminary tool (i.e. ArcExplorer), this line of evidence is highly transferable, modifiable and applicable to other program areas within the federal public health portfolio (Public Health Agency of Canada; Health Canada), and with less time and resource investment required.

This approach is generalizable to other programs if they deliver in-person services, and target a similar population. An obvious beneficiary could be the Centre for Chronic Disease Prevention within PHAC that may have programs targeting those at risk for diabetes, for example, who have been shown to be strongly associated with areas of high deprivation.

The custom configured desktop mapping tool developed for this case study has the potential to be a preliminary baseline spatial exploratory tool for multiple program 
areas, empowering data analysts, policy analysts, program consultants and evaluators with a new lens on their programs. Information leads to knowledge; knowledge leads to informed decisions.

Indeed this analytical approach could support federal departments by using GIS to contribute to multiple objectives stated within Treasury Board's Policy on Evaluation ${ }^{15}$ : provide "information to help Ministers understand how new spending proposals fit with existing programs, identify synergies and avoid wasteful duplication" (section 3.2.b.ii); resource allocation and reallocation; and, the identification of lessons learned and best practices.

\footnotetext{
${ }^{15}$ http://www.tbs-sct.gc.ca/pol/doc-eng.aspx?evttoo=x\&section=text\&id $=15024$
} 


\title{
APPENDICES
}

\section{Appendix 1: Street Address Collection Tool}

\author{
Excel Worksheet 1: Instructions
}

\section{CAPC \& CPNP Project Site Address Collection}

\section{Purpose:}

With complete addresses for main and satellite CAPC and CPNP sites, the mapping of these locations will then be possible in a GIS (geographic information system), resulting in accurate, current, national information. The purpose of mapping CAPC/CPNP sites is two-fold. One, the mapping of the addresses will help identify gaps in service and may help inform program evaluation, especially when overlayed with a deprivation index and program participants' locations. Two, mapping of these addresses may help inform CAPC/CPNP modernization and managementrelated decision-making. Your participation in this process is very much appreciated and your regional expertise is valued.

\section{Instructions:}

Each evaluation region is to complete this spreadsheet and return it to $\mathbf{X X X X}$ by November 30 , 2010. Starting with the best or most current information available to you, the first step is to enter your province/region's project sites into the yellow worksheet called "2. PROJECT SITES COLLECTION" after validating the address. It is imperative that the addresses reflect where the program service is provided, and not where it is administered, if different. If a CAPC and CPNP project co-locate in one site, please enter each project on a separate row. Both CAPC and CPNP projects are to be entered into the one spreadsheet. Each column has an instruction and examples, and some have a drop-down list to select from. Once the site addresses are all complete, the second step is then to complete the blue worksheet called "3. FINAL QUESTIONS" where you can note any data limitation or quality issues that would need to be considered when analyzing the data.

Regional Mapping Working Group Members:

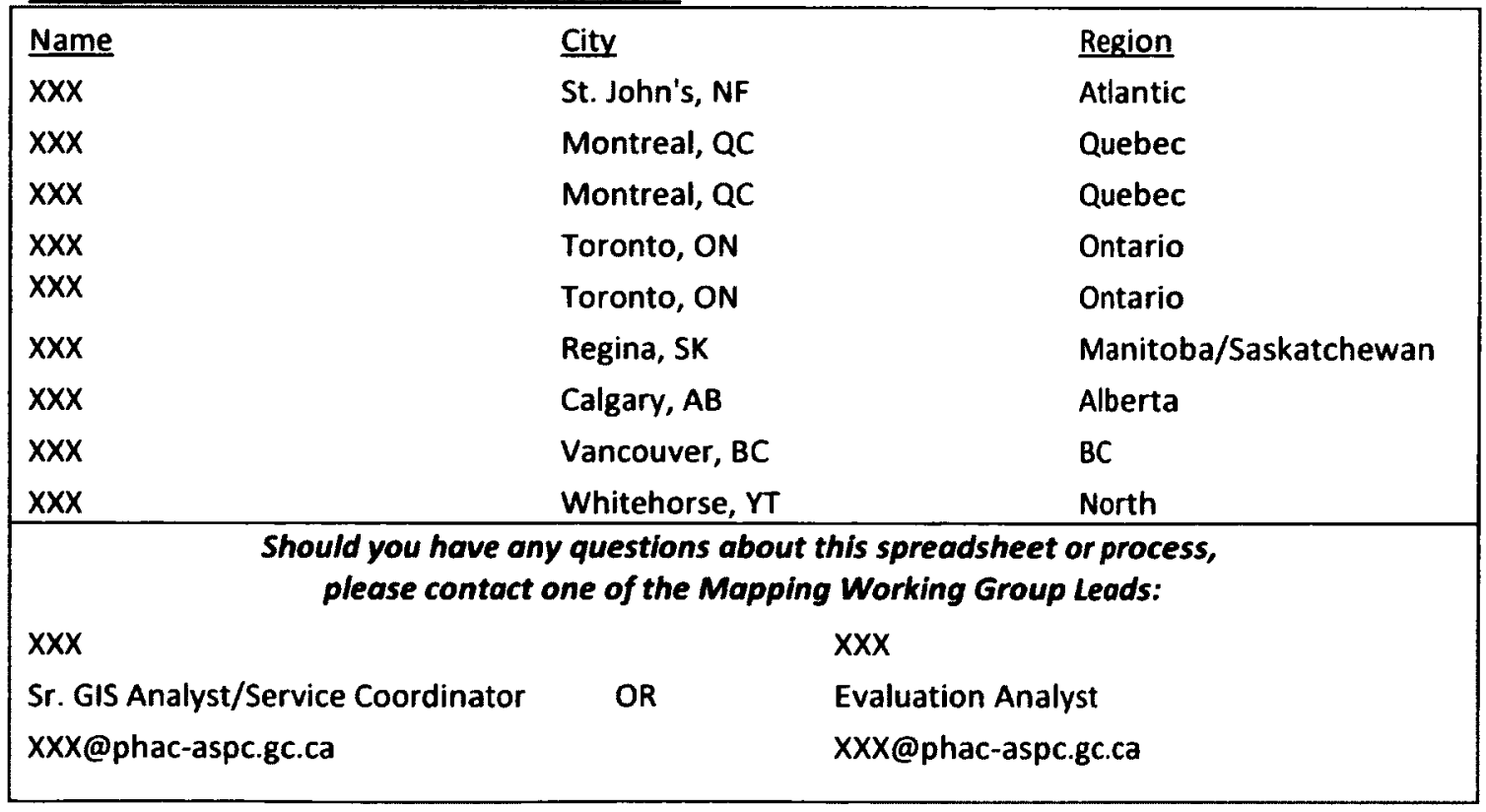


Excel Worksheet 2: Street Address Collection Template (with artificial examples and screen tips)

\begin{tabular}{|c|c|c|c|c|c|c|c|c|c|}
\hline $\begin{array}{l}\text { Project Name } \\
\text { (Host Agency or } \\
\text { Recipient) }\end{array}$ & $\begin{array}{l}\text { Project } \\
\text { Type }\end{array}$ & $\begin{array}{l}\text { Contribution } \\
\text { Agreement Project } \\
\text { Number }\end{array}$ & $\begin{array}{l}\text { Host } \\
\text { Facility }\end{array}$ & \multicolumn{2}{|c|}{$\begin{array}{l}\text { Street } \\
\text { Address }\end{array}$} & \multicolumn{2}{|c|}{$\begin{array}{l}\text { City / Town } \\
\text { / Rural Area }\end{array}$} & P rov & $\begin{array}{l}\text { Postal } \\
\text { Code }\end{array}$ \\
\hline (name) & CAPC & $x x x-x x-x x x x-x x x x-x x x$ & $\begin{array}{l}\text { (name) High } \\
\text { School. }\end{array}$ & \multicolumn{2}{|c|}{123 JonesSt. } & \multicolumn{2}{|l|}{ City name } & PR & A\#A\#A\# \\
\hline (name) & CPNP & $\begin{array}{l}x X X-X X-x X X X-X X X X- \\
x X X\end{array}$ & $\begin{array}{l}\text { (name) } \\
\text { church }\end{array}$ & \multicolumn{2}{|c|}{1 First Ave } & \multicolumn{2}{|l|}{ City name } & PR & A\#A\#A\# \\
\hline (name) & CAPC & $\begin{array}{l}X X X-X X-X X X X-X X X X- \\
X X X\end{array}$ & $\begin{array}{l}\text { (name) } \\
\text { recreation } \\
\text { facility }\end{array}$ & \multicolumn{2}{|c|}{$\begin{array}{l}2 \text { Second } \\
\text { St. }\end{array}$} & \multicolumn{2}{|l|}{ City name } & PR & A\#A\#A\# \\
\hline & & \multicolumn{3}{|c|}{$\begin{array}{l}\text { Street Address } \\
\text { Input street number, street name, street } \\
\text { type and direction (if applicable). This field } \\
\text { cannot be left blank. } \\
\text { Exclude suite numbers, floors and room } \\
\text { numbers. } \\
\text { Examples: } \\
120 \text { Colonnade Rd } \\
46 \text { St Clair Ave W } \\
89-2 \text { St E }\end{array}$} & $\begin{array}{l}\text { City } \\
\text { This f } \\
\text { cann } \\
\text { left b }\end{array}$ & $\begin{array}{l}\text { ield } \\
\text { ot be } \\
\text { lank. } \\
\text { rovince from } \\
\text { down list, } \\
\text { scroll bar if } \\
\text { This field } \\
\text { left blank. }\end{array}$ & \multicolumn{3}{|c|}{$\begin{array}{l}\text { Postal Code } \\
\text { Enter all } 6 \text { digits, using } \\
\text { capital letters and no } \\
\text { spaces. Format is letter, } \\
\text { number, letter, number, } \\
\text { letter, number ( } X 1 \times 1 \times 1 \text { ), } \\
\text { Example: K2G3NG }\end{array}$} \\
\hline
\end{tabular}




\section{Excel Worksheet 3: Submission Verification Questions}

\begin{tabular}{|l|l|l|}
\hline Follow-up Questions to Project Sites Collection & Yes/No & Comments \\
\hline $\begin{array}{l}\text { Were you able to collect 100\% of your province/region's } \\
\text { CAPC sites? }\end{array}$ & yes & \\
\hline $\begin{array}{l}\text { Were you able to collect } 100 \% \text { of your province/region's } \\
\text { CPNP sites? }\end{array}$ & yes & \\
\hline $\begin{array}{l}\text { Did you confirm that these sites are program provision } \\
\text { sites, and not program administration sites? }\end{array}$ & yes & \\
\hline
\end{tabular}

Any other comments? 


\section{Appendix 2: Geocoding Results of Site Addresses}

Step 1: Data Clean-up

Project site addresses were cleaned up prior to geocoding. Formatting was done to make the geocoding process as smooth as possible. This included, but was not limited to, abbreviating street types (e.g. "Court" to "CRT") and removing the "\#" from highway numbers (e.g. "Highway \#7" to "HWY 7"). Additionally, the removal of "th" and "st" from numeric street names such as $40^{\text {th }}$ Street or $1^{\text {st }}$ Ave drastically improved matching. For example, the Alberta address matching improved from 21/193 (11\%) match to $130 / 193(67 \%)$ match by this simple formatting.

\section{Step 2: Geocode Addresses}

The geocoding of site addresses was done by province/territory, repeating the process 13 times. As discovered in the data cleanup and geocoding processes, a few provinces and the territories tend to have unique challenges for formatting and geocoding addresses. This is further discussed for each province/territory in the section "Geocoding Challenges".

DMTI's CanMap Streetfiles v.2011.1 product was used as the address locator for geocoding. The project site addresses were stored in an Excel spreadsheet with one worksheet per province and territory. Within ESRI ArcGIS v.10, the worksheets were added and right-clicked to select the "geocode addresses" function. Selecting 'Add', the CanMap roads file for the province of choice was added. In "Advanced Geometry Options", the address locator's spatial reference was used, and high spelling sensitivity, and minimum candidate score and match score were used to produce highly accurate results $(80 \%, 80 \%, 85 \%$ respectively).

\section{Figure 1: Spatial Reference of Address Locator}

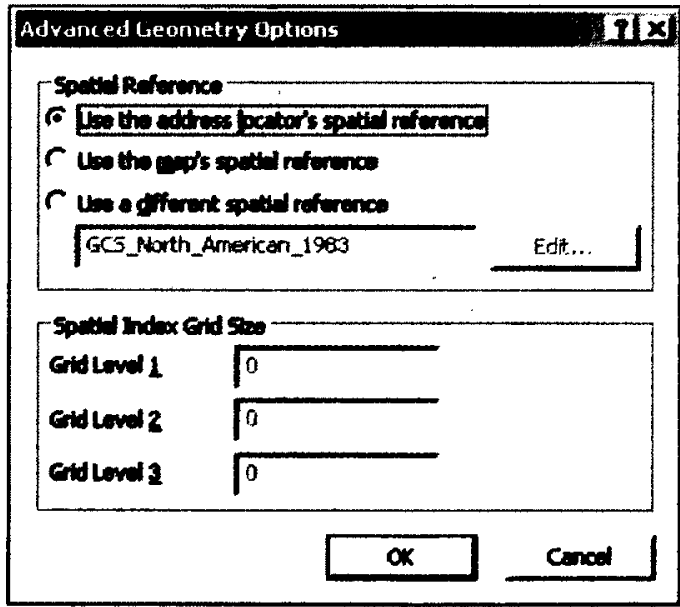

Source: ArcGIS v.10 
Figure 2: Geocoding Options

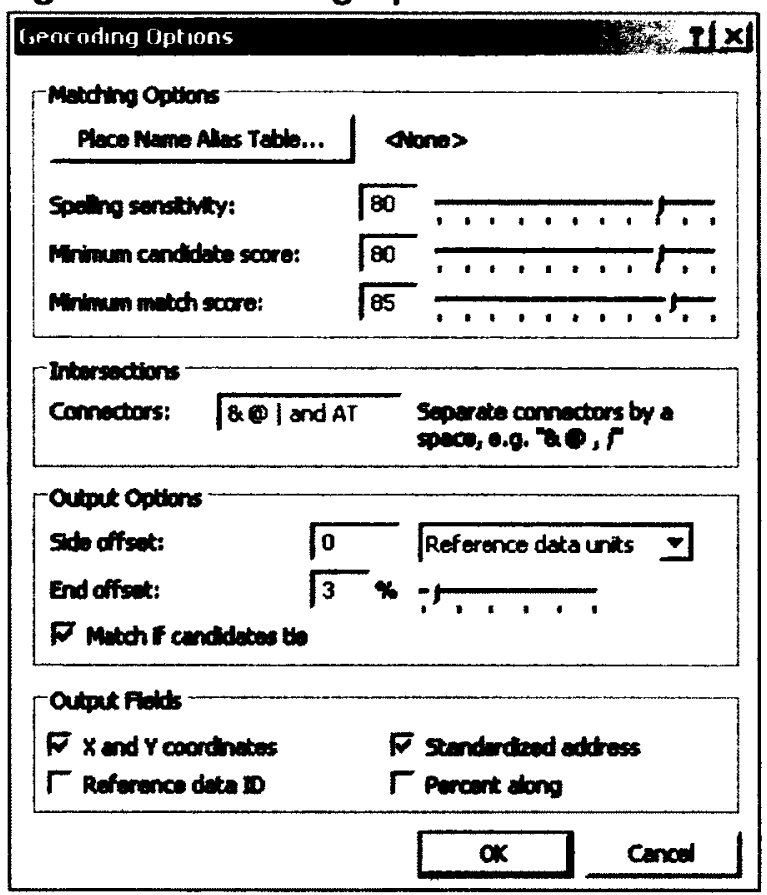

Source: ArcGIS v.10

After as much data clean-up as possible, the 960 (42\% of all addresses) remaining unmatched addresses were manually located using various investigative tools including Google Earth, Google Map, and the Canada Post Find An Address ${ }^{16}$ tool, formerly known as the Reverse Search tool.

\section{Geocoding Challenges}

Overall, unmatched addresses were re-matched by either making necessary corrections to the addresses or by identifying its location through other reference tools such as Google Map and then applying a manual point selection in CanMap. Often additional attributes in the site address table were used to verify, correct or confirm an address. One attribute that proved to be very helpful in this regard was host facility name. Since many sites are located at schools, churches, and other public facilities, their addresses can be easily found on the Internet.

Unique geocoding problems emerged for four provinces and all three territories, as further discussed herein. In the CanMap Streetfile database, Prince Edward Island community names are not used as the 'city' field, but rather lot numbers. For each CAPC and CPNP site (up to 69), its address and community name had to be searched on Google Maps. Comparing the location shown on Google Maps with the data view in ArcGIS, the location was manually identified by zooming in to same area in ArcGIS and

${ }^{16}$ http://www.canadapost.ca/cpotools/apps/fpc/personal/findAnAddress?execution=e2s1 
querying a CanMap road segment in that community to obtain the lot number. In the geocoding rematch dialogue box, the community name was replaced with the lot number, which subsequently produced excellent matches.

The French abbreviations for street type and direction often needed to be changed in the collected street address data to reflect the standard used in the CanMap product. This proved to be particularly important for Quebec, in which case manually cleaning each unmatched record with these specific standards and rematching in ArcMap produced improved results, from $30 \%$ to $63 \%$ match. However, 223 still had to be manually located. Below are such manual changes applied to Quebec site addresses.

Figure 3: Quebec Street Type Abbreviation Corrections

\begin{tabular}{|l|l|}
\hline From & To \\
\hline BLVD & BOUL \\
\hline OUEST & 0 \\
\hline AVE & AV \\
\hline CHEMIN & CH \\
\hline RT & RTE \\
\hline lière & 1 \\
\hline $2 e$ & 2 \\
\hline $3 e$ & 3 \\
\hline MONTÉE & (move this to the PreType field) \\
\hline MGR & RUE DE MONSEIGNEUR \\
\hline
\end{tabular}

Source: Compiled by author

The unmatched Ontario site addresses were much more easily geocoded by searching for the 'city' name from the collected program address data in the Statistics Canada Community Profile search engine website ${ }^{17}$ to identify its municipality or township name. For example, Buckhorn, a city name stated in the site street address dataset is found in DMTI's CanMap Streetfiles under "Galway-Cavendish and Harvey".

Within 3 hours of using this approach, geocoding unmatched addresses was more successful and produced significantly improved results (from $46 \%$ to $70 \%$ match, out of 648 site addresses). This manual search of community names to obtain the county name required a full day of effort; meanwhile another 60 unmatched addresses remained for manual location.

Many of Alberta's roads, and therefore street addresses, contain a directional identifier $(N, N E, S, S W$, etc). The resulting error of conducting $1 \mathrm{~km}$ service area between the same address of different directions could have made a negative impact on the accuracy and precision of the small area analysis. In the example below, this Calgary address would produce a location error of $2.7 \mathrm{~km}$ to $4.6 \mathrm{~km}$. Multiple site addresses in the Alberta

\footnotetext{
${ }^{17}$ http://www12.statcan.gc.ca/census-recensement/2006/dp-pd/prof/92-591/searchrecherche/frm_res.cfm?Lang=E\&SearchType=Begins\&SearchPR=01
} 
dataset had a partial directional identifier, a non-existent identifier, or no identifier at all. This required very detailed visual analysis using Google Maps to identify the possible directional identifiers that exist for each address (through Google Maps' suggested search results) and to select the most appropriate address based on additional site address table attributes including postal code and host facility name.

Figure 4: Example of Street multi-directions

$910-7^{\text {th }}$ Avenue, Calgary has 4 different directions:
NW, SW, NE, SE
Distance from each other $(\mathrm{km})$ :
\begin{tabular}{|l|l|l|l|l|}
\hline & NW & SW & NE & SE \\
\hline NW & & & & \\
\hline SW & 2.7 & & & \\
\hline NE & 4.6 & 4.3 & & \\
\hline SE & 2.9 & 2.7 & 3.1 & \\
\hline
\end{tabular}

Source: Compiled by author

For the three northern territories, the CanMap Streetfiles data product contains very few street address attributes and is missing roads. As a result, geocoding using this product produced very poor results ( 1 of 32 matched). Alternatively, the North America ArcGIS online address locator was then tested. This locator produced a $94 \%$ match for all three territories combined, although it seemed to only match by city name and produced a point in the city centroid. This was not sufficient for the purpose of this small area analysis, so these city centroids were used as a starting point for manually locating sites, with additional reference to Google Earth and Google Maps.

In summary, a total of 1,306 addresses were matched with relative ease and the remaining 960 required involved manual effort. Geocoding required the use of multiple approaches, problem solving techniques and tools, including the Canada Post reverse postal code lookup, Google Maps, Google Earth, the North America ArcGIS online address locator, CanMap Streetfile address locators, and the Statistics Canada's Community Profile search engine. The geocoding process was an incredibly lengthy exercise, demanding a disproportionate amount of effort and time compared to the other analysis components. However, having these sites geocoded will make any future or additional analysis much faster and marks a key milestone in its own for making the programs' data of greater use and value, both now and in the future. 
Appendix 3: List of Communities Potentially Not Reached by CAPC/CPNP Programs, by Province/Territory (Sorted by Number of Children)

\begin{tabular}{|c|c|c|c|c|c|c|}
\hline CSD Name & $\begin{array}{l}\text { Sum of } \\
\text { Estimated } \\
\text { Children } \\
\text { aged 0-6 }\end{array}$ & $\begin{array}{l}\text { Number of } \\
\text { Priority Areas } \\
\text { Beyond } 20 \mathrm{~km} \\
\text { from CAPC }\end{array}$ & $\begin{array}{l}\text { Number of } \\
\text { Priority Areas } \\
\text { Beyond 20km } \\
\text { from CPNP }\end{array}$ & CSD Type & Census Division Name & CMA Name \\
\hline \multicolumn{7}{|l|}{ BRTISH COLUMBIA } \\
\hline Chilliwack & 153 & 0 & 3 & City & Fraser Valley & Chilliwack \\
\hline Fort St. John & 109 & 2 & 0 & City & Peace River & Fort St. John \\
\hline Kelowna & 106 & 0 & 2 & City & Central Okanagan & Kelowna \\
\hline Williams Lake & 104 & 2 & 0 & City & Cariboo & Williams Lake \\
\hline Powell River & 64 & 2 & 0 & City & Powell River & Powell River \\
\hline Dawson Creek & 51 & 1 & 1 & City & Peace River & Dawson Creek \\
\hline Comox-Strathcona I & 44 & 1 & 1 & $\begin{array}{l}\text { Regional district electoral } \\
\text { area }\end{array}$ & Comox-Strathcona & - \\
\hline Prince Rupert & 44 & 0 & 1 & City & Skeena-Queen Charlotte & Prince Rupert \\
\hline Kaslo & 33 & 0 & 1 & Village & Central Kootenay & - \\
\hline Penticton & 33 & 0 & 1 & City & Okanagan-Similkameen & Penticton \\
\hline \multicolumn{7}{|l|}{ ALBERTA } \\
\hline Raymond & 141 & 2 & 2 & Town & Division No. 2 & - \\
\hline Bonnyville No. 87 & 139 & 2 & 2 & Municipal district & Division No. 12 & - \\
\hline Two Hills & 114 & 2 & 2 & Town & Division No. 10 & - \\
\hline Medicine Hat & 111 & 3 & 0 & City & Division No. 1 & Medicine Hat \\
\hline Whitecourt & 109 & 2 & 2 & Town & Division No. 13 & - \\
\hline Opportunity No. 17 & 102 & 1 & 1 & Municipal district & Division No. 17 & - \\
\hline Lloydminster (Part) & 86 & 0 & 1 & City & Division No. 10 & Lloydminster \\
\hline Elk Point & 61 & 1 & 1 & Town & Division No. 12 & - \\
\hline Wetaskiwin & 58 & 1 & 0 & City & Division No. 11 & Wetaskiwin \\
\hline Slave Lake & 58 & 1 & 0 & Town & Division No. 17 & - \\
\hline
\end{tabular}




\begin{tabular}{|c|c|c|c|c|c|c|}
\hline \multirow[b]{2}{*}{ CSD Name } & \multirow[b]{2}{*}{$\begin{array}{l}\text { Sum of } \\
\text { Estimated } \\
\text { Children } \\
\text { aged 0-6 }\end{array}$} & \multirow[b]{2}{*}{$\begin{array}{l}\text { Number of } \\
\text { Priority Areas } \\
\text { Beyond 20km } \\
\text { from CAPC }\end{array}$} & \multirow[b]{2}{*}{$\begin{array}{l}\text { Number of } \\
\text { Priority Areas } \\
\text { Beyond 20km } \\
\text { from CPNP }\end{array}$} & \multirow[b]{2}{*}{ CSD Type } & \multirow[b]{2}{*}{ Census Division Name } & \multirow[b]{2}{*}{ CMA Name } \\
\hline & & & & & & \\
\hline Westlock & 57 & 1 & 0 & Town & Division No. 13 & - \\
\hline Millet & 50 & 1 & 0 & Town & Division No. 11 & - \\
\hline Clyde & 44 & 1 & 0 & Village & Division No. 13 & - \\
\hline Stony Plain & 43 & 0 & 1 & Town & Division No. 11 & Edmonton \\
\hline Eckville & 38 & 1 & 1 & Town & Division No. 8 & - \\
\hline Barrhead & 38 & 1 & 1 & Town & Division No. 13 & - \\
\hline Devon & 33 & 1 & 1 & Town & Division No. 11 & Edmonton \\
\hline Airdrie & 28 & 1 & 1 & City & Division No. 6 & Calgary \\
\hline Smoky Lake County & 28 & 1 & 1 & County (municipality) & Division No. 12 & - \\
\hline Girouxville & 25 & 1 & 1 & Village & Division No. 19 & - \\
\hline Daysland & 23 & 1 & 1 & Town & Division No. 7 & - \\
\hline Wood Buffalo & 23 & 1 & 1 & Regional municipality & Division No. 16 & Wood Buffalo \\
\hline Waskatenau & 22 & 1 & 1 & Village & Division No. 12 & - \\
\hline Delia & 14 & 1 & 1 & Village & Division No. 5 & - \\
\hline Derwent & 10 & 1 & 1 & Village & Division No. 10 & - \\
\hline Minburn & 0 & 1 & 1 & Village & Division No. 10 & - \\
\hline \multicolumn{7}{|l|}{ SASKATCHEWAN } \\
\hline Pinehouse & 205 & 1 & 1 & Northern village & Division No. 18 & - \\
\hline North Battleford & 154 & 3 & 3 & City & Division No. 16 & $\begin{array}{l}\text { North } \\
\text { Battleford }\end{array}$ \\
\hline La Loche & 139 & 1 & 0 & Northern village & Division No. 18 & - \\
\hline Meadow Lake & 128 & 2 & 0 & Town & Division No. 17 & - \\
\hline Melfort & 111 & 0 & 2 & City & Division No. 14 & - \\
\hline Moose Jaw & 98 & 0 & 2 & City & Division No. 7 & Moose Jaw \\
\hline île-à-la-Crosse & 86 & 1 & 0 & Northern village & Division No. 18 & - \\
\hline
\end{tabular}




\begin{tabular}{|c|c|c|c|c|c|c|}
\hline CSD Name & $\begin{array}{l}\text { Sum of } \\
\text { Estimated } \\
\text { Children } \\
\text { aged 0-6 }\end{array}$ & $\begin{array}{l}\text { Number of } \\
\text { Priority Areas } \\
\text { Beyond 20km } \\
\text { from CAPC }\end{array}$ & $\begin{array}{l}\text { Number of } \\
\text { Priority Areas } \\
\text { Beyond 20km } \\
\text { from CPNP }\end{array}$ & CSD Type & Census Division Name & CMA Name \\
\hline Buffalo Narrows & 78 & 1 & 1 & Northern village & Division No. 18 & - \\
\hline Battleford & 59 & 1 & 1 & Town & Division No. 12 & $\begin{array}{l}\text { North } \\
\text { Battleford }\end{array}$ \\
\hline La Ronge & 59 & 1 & 0 & Town & Division No. 18 & - \\
\hline Beauval & 58 & 0 & 1 & Northern village & Division No. 18 & - \\
\hline Waldheim & 54 & 1 & 1 & Town & Division No. 15 & - \\
\hline Yorkton & 52 & 1 & 1 & City & Division No. 9 & Yorkton \\
\hline St. Louis & 46 & 1 & 1 & Village & Division No. 15 & - \\
\hline Nipawin & 45 & 1 & 1 & Town & Division No. 14 & - \\
\hline Punnichy & 42 & 1 & 1 & Village & Division No. 10 & - \\
\hline Fort Qu'Appelle & 37 & 0 & 1 & Town & Division No. 6 & - \\
\hline Stony Rapids & 35 & 0 & 1 & Northern hamlet & Division No. 19 & - \\
\hline Wilkie & 31 & 1 & 1 & Town & Division No. 13 & - \\
\hline Carievale & 28 & 1 & 1 & Village & Division No. 1 & - \\
\hline Melville & 28 & 1 & 1 & City & Division No. 5 & - \\
\hline Abernethy & 25 & 1 & 1 & Village & Division No. 6 & - \\
\hline Cole Bay & 23 & 1 & 1 & Northern village & Division No. 18 & - \\
\hline Hafford & 21 & 1 & 1 & Town & Division No. 16 & - \\
\hline Fleming & 14 & 1 & 1 & Town & Division No. 5 & - \\
\hline Bulyea & 14 & 1 & 1 & Village & Division No. 6 & - \\
\hline Quinton & 14 & 1 & 1 & Village & Division No. 10 & - \\
\hline Michel Village & 7 & 1 & 1 & Northern hamlet & Division No. 18 & - \\
\hline \multicolumn{7}{|l|}{ MANTTOBA } \\
\hline Portage la Prairie & 147 & 0 & 2 & City & Division No. 9 & $\begin{array}{l}\text { Portage la } \\
\text { Prairie }\end{array}$ \\
\hline The Pas & 125 & 0 & 1 & Town & Division No. 21 & - \\
\hline
\end{tabular}




\begin{tabular}{|c|c|c|c|c|c|c|}
\hline CSD Name & $\begin{array}{l}\text { Sum of } \\
\text { Estimated } \\
\text { Children } \\
\text { aged 0-6 }\end{array}$ & $\begin{array}{l}\text { Number of } \\
\text { Priority Areas } \\
\text { Beyond 20km } \\
\text { from CAPC }\end{array}$ & $\begin{array}{l}\text { Number of } \\
\text { Priority Areas } \\
\text { Beyond 20km } \\
\text { from CPNP }\end{array}$ & CSD Type & Census Division Name & CMA Name \\
\hline $\begin{array}{l}\text { Division No. 21, } \\
\text { Unorganized }\end{array}$ & 112 & 1 & 1 & Unorganized & Division No. 21 & - \\
\hline $\begin{array}{l}\text { Division No. } 22 \text {, } \\
\text { Unorganized }\end{array}$ & 104 & 1 & 1 & Unorganized & Division No. 22 & - \\
\hline Altona & 71 & 1 & 1 & Town & Division No. 3 & - \\
\hline Selkirk & 70 & 0 & 1 & City & Division No. 13 & - \\
\hline Dauphin & 49 & 1 & 1 & City & Division No. 17 & - \\
\hline Swan River & 49 & 1 & 1 & Town & Division No. 20 & - \\
\hline Stuartburn & 44 & 1 & 1 & Rural municipality & Division No. 1 & - \\
\hline Rapid City & 40 & 1 & 1 & Town & Division No. 15 & - \\
\hline Minitonas & 40 & 1 & 1 & Town & Division No. 20 & - \\
\hline Morden & 38 & 0 & 1 & Town & Division No. 3 & - \\
\hline Rossburn & 37 & 1 & 1 & Town & Division No. 16 & - \\
\hline Armstrong & 36 & 1 & 1 & Rural municipality & Division No. 18 & - \\
\hline \multicolumn{7}{|l|}{ ONTARIO } \\
\hline Chatham-Kent & 500 & 7 & 0 & Municipality & Chatham-Kent & Chatham-Kent \\
\hline Guelph & 410 & 5 & 0 & City & Wellington & Guelph \\
\hline Cornwall & 368 & 7 & 0 & City & $\begin{array}{l}\text { Stormont, Dundas and } \\
\text { Glengarry }\end{array}$ & Cornwall \\
\hline Belleville & 195 & 3 & 1 & City & Hastings & Belleville \\
\hline Sarnia & 155 & 2 & 2 & City & Lambton & Sarnia \\
\hline Leamington & 116 & 2 & 0 & Municipality & Essex & Leamington \\
\hline Greater Napanee & 108 & 2 & 0 & Town & Lennox and Addington & - \\
\hline East Luther Grand Valley & 73 & 1 & 1 & Township & Dufferin & - \\
\hline Orangeville & 73 & 1 & 1 & Town & Dufferin & Toronto \\
\hline Halton Hills & 61 & 1 & 0 & Town & Halton & Toronto \\
\hline
\end{tabular}




\begin{tabular}{|c|c|c|c|c|c|c|}
\hline \multirow[b]{2}{*}{ CSD Name } & \multirow[b]{2}{*}{$\begin{array}{l}\text { Sum of } \\
\text { Estimated } \\
\text { Children } \\
\text { aged 0-6 }\end{array}$} & \multirow[b]{2}{*}{$\begin{array}{l}\text { Number of } \\
\text { Priority Areas } \\
\text { Beyond 20km } \\
\text { from CAPC }\end{array}$} & \multirow[b]{2}{*}{$\begin{array}{l}\text { Number of } \\
\text { Priority Areas } \\
\text { Beyond 20km } \\
\text { from CPNP }\end{array}$} & \multirow[b]{2}{*}{ CSD Type } & \multirow[b]{2}{*}{ Census Division Name } & \multirow[b]{2}{*}{ CMA Name } \\
\hline & & & & & & \\
\hline Kingsville & 61 & 1 & 0 & Town & Essex & Leamington \\
\hline The Nation / La Nation & 56 & 1 & 0 & Municipality & Prescott and Russell & - \\
\hline West Elgin & 56 & 1 & 1 & Municipality & Elgin & - \\
\hline Amherstburg & 55 & 1 & 1 & Town & Essex & Windsor \\
\hline Petrolia & 55 & 1 & 1 & Town & Lambton & - \\
\hline Minto & 44 & 0 & 1 & Town & Wellington & - \\
\hline Burk's Falls & 40 & 1 & 1 & Village & Parry Sound & - \\
\hline $\begin{array}{l}\text { West Nipissing / Nipissing } \\
\text { Ouest }\end{array}$ & 34 & 0 & 1 & Municipality & Nipissing & - \\
\hline Norfolk County & 30 & 0 & 1 & City & Haldimand-Norfolk & Norfolk \\
\hline Greenstone & 27 & 1 & 1 & Municipality & Thunder Bay & - \\
\hline \multicolumn{7}{|l|}{ QUEBEC } \\
\hline Mirabel & 196 & 0 & 1 & Ville & Mirabel & Montréal \\
\hline Saint-Jérôme & 135 & 0 & 2 & Ville & La Rivière-du-Nord & Montréal \\
\hline Magog & 125 & 2 & 0 & Ville & Memphrémagog & Sherbrooke \\
\hline Notre-Dame-des-Bois & 93 & 0 & 1 & Municipalité & Le Granit & - \\
\hline Notre-Dame-des-Bois & 93 & 1 & 0 & Municipalité & Le Granit & - \\
\hline Stanstead & 73 & 0 & 1 & Vilie & Memphrémagog & - \\
\hline Sainte-Marie & 66 & 1 & 0 & Ville & La Nouvelle-Beauce & - \\
\hline Napierville & 66 & 1 & 0 & Village & Les Jardins-de-Napierville & - \\
\hline Kuujjuarapik & 65 & 1 & 1 & Village nordique & Nord-du-Québec & - \\
\hline Sainte-Sophie & 53 & 0 & 1 & Municipalité & La Rivière-du-Nord & - \\
\hline Pohénégamook & 52 & 1 & 1 & Ville & Témiscouata & - \\
\hline Sainte-Hélène-de-Bagot & 52 & 1 & 0 & Municipalité & Les Maskoutains & - \\
\hline Saint-Théodore-d'Acton & 51 & 1 & 0 & Paroisse (municipalité de) & Acton & - \\
\hline
\end{tabular}




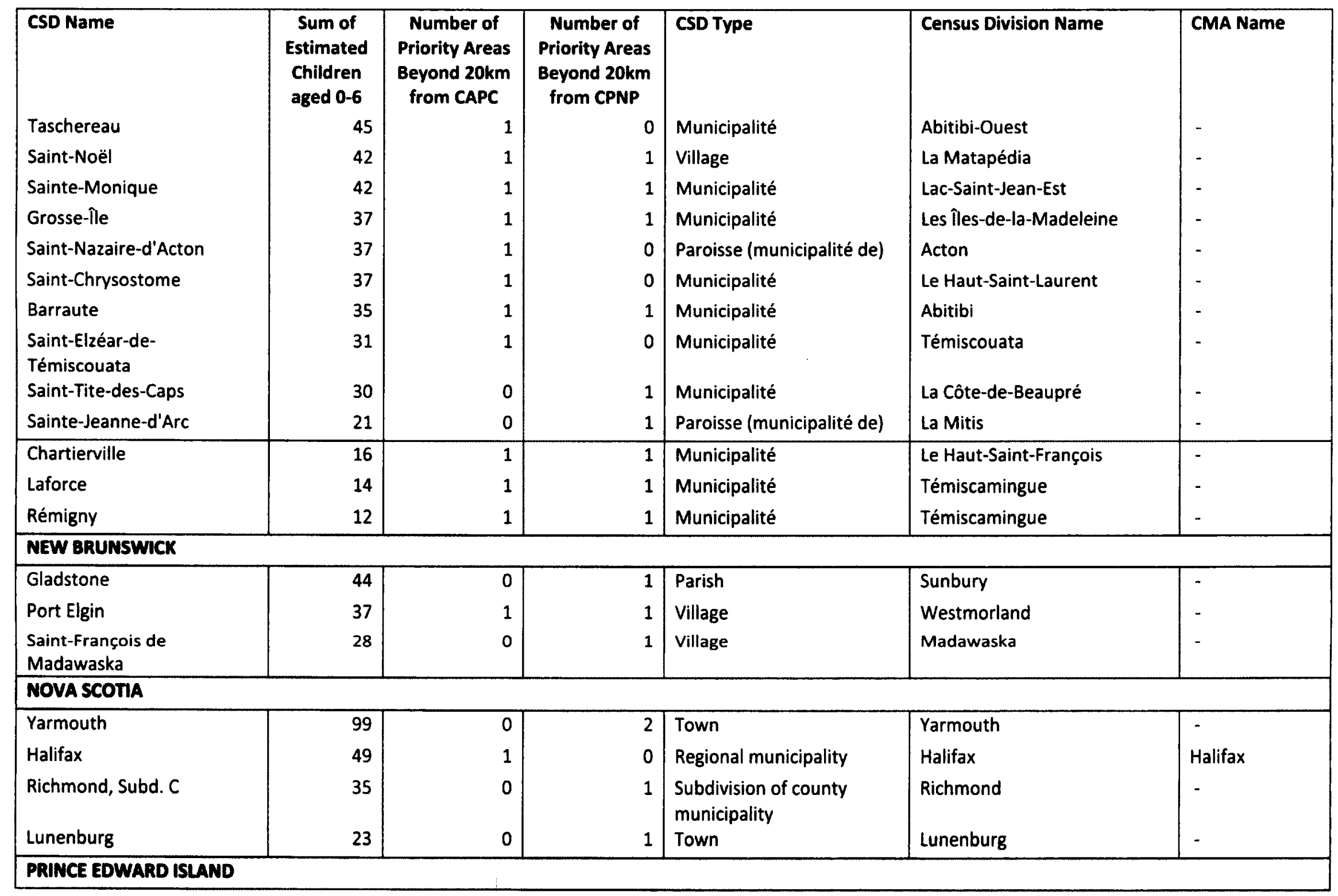




\begin{tabular}{|c|c|c|c|c|c|c|}
\hline Mount Stewart & $\begin{array}{c}\text { Sum of } \\
\text { Estimated } \\
\text { Children } \\
\text { aged 0-6 } \\
26\end{array}$ & $\begin{array}{l}\text { Number of } \\
\text { Priority Areas } \\
\text { Beyond 20km } \\
\text { from CAPC } \\
1\end{array}$ & $\begin{array}{l}\text { Number of } \\
\text { Priority Areas } \\
\text { Beyond 20km } \\
\text { from CPNP } \\
1\end{array}$ & Community & Census Division Name & CMA Name \\
\hline \multicolumn{7}{|c|}{ NEWFOUNDLAND AND LABRADOR } \\
\hline Clarenville & 47 & 1 & 1 & Town & Division No. 7 & - \\
\hline Bonavista & 28 & 1 & 1 & Town & Division No. 7 & - \\
\hline Deer Lake & 26 & 1 & 1 & Town & Division No. 5 & - \\
\hline Placentia & 25 & 1 & 1 & Town & Division No. 1 & - \\
\hline Sandringham & 12 & 1 & 1 & Town & Division No. 7 & - \\
\hline \multicolumn{7}{|c|}{ YUKON TERRITORY } \\
\hline Carmacks & 57 & 1 & 1 & Village & Yukon & - \\
\hline \multicolumn{7}{|c|}{ NORTHWEST TERRITORIES } \\
\hline Aklavik & 66 & 1 & 1 & Hamlet & Inuvik & - \\
\hline Inuvik & 59 & 1 & 0 & Town & Inuvik & - \\
\hline Tuktoyaktuk & 54 & 1 & 1 & Hamlet & Inuvik & - \\
\hline \multicolumn{7}{|l|}{ MUNAVUT } \\
\hline Coral Harbour & 154 & 1 & 1 & Hamlet & Keewatin & - \\
\hline Taloyoak & 151 & 1 & 1 & Hamlet & Kitikmeot & - \\
\hline Iqaluit & 81 & 0 & 2 & City & Baffin & - \\
\hline Qikiqtarjuaq & 60 & 1 & 1 & Hamlet & Baffin & - \\
\hline
\end{tabular}

Source: Compiled by author with Statistics Canada 2006 Census data 


\section{REFERENCES}

Aday LA, Anderson R. (1974). "A Framework for the Study of Access to Medical Care". Health Services Research. Fall, 9(3):208-220. Accessed August 26, 2012:

http://www.ncbi.nIm.nih.gov/pmc/articles/PMC1071804/pdf/hsresearch005600030.pdf

Anderton D, Oakes J and Egan K. 1997. "Environmental Equity in Superfund: Demographics of the Discovery and Prioritization of Abandoned Toxic Sites". Evaluation Review. 21(1):3-26.

Batsche $\mathrm{CJ}$ and Reader S. 2012. "Using GIS to enhance programs serving emancipated youth leaving foster care". Evaluation and Program Planning. 35(1):25-33.

Bell N, Schuurman N, Oliver S, Hayes MV. (2007). "Towards the construction of placespecific measures of deprivation: a case study from the Vancouver metropolitan area". The Canadian Geographer / Le Géographe canadien. 51(4): 444-461.

Bellefontaine T \& Wisener R. (2011). "The Evaluation of Place-Based Approaches: Questions for Further Research". Research Report for Policy Horizons Canada. June 2011. Accessed April 19, 2012:

http://www.horizons.gc.ca/doclib/2011_0074_EvaluationPB_e.pdf

Booza JC, Bridge PD, Neale AV, Schenk M. (2010). "Incorporating geographic information systems (GIS) into program evaluation: lessons from a rural medicine initiative". Journal of the American Board of Family Medicine. 23: 59-66.

Borzacchiello MT, Torrieri V and Nijkamp P. 2009. "An operational information systems architecture for assessing sustainable transportation planning: principles and design". Evaluation and Program Planning. 32(4):381-389.

Boulos MNK. 2004. "Towards evidence-based, GIS-driven national spatial health information infrastructure and surveillance services in the United Kingdom". International Journal of Health Geographics 3(1): 1-50.

Braga A, Hureau D and Papachristos A. 2011. "An Ex Post Facto Evaluation Framework for Place-Based Police Interventions". Evaluation Review. 35(6):592-626. 
Broadway MJ and Jesty G. (1998). "Are Canadian Inner Cities Becoming More Dissimilar? An Analysis of Urban Deprivation Indicators". Urban Studies. 35(9):1423-1438.

Canadian Institute for Health Information (CIHI). (2008). Reducing Gaps in Health: A Focus on Socio-Economic Status in Urban Canada (Ottawa, Ont.: CIHI).

Centre for Disease Control (2011). "Program Evaluation Tip Sheet: Reach and Impact". National Center for Chronic Disease Prevention and Health Promotion, Division for Heart Disease and Stroke Prevention. August 2011. Accessed April 12, 2012:

http://www.cdc.gov/DHDSP/programs/nhdsp_program/docs/Reach_Impact_Tip_Sheet.pdf

Commission on Social Determinants of Health (CSDH). 2008. "Closing the gap in a generation: health equity through action on the social determinants of health". Final Report of the Commission on Social Determinants of Health. Geneva, World Health Organization.

Craun S and Freisthler B. 2008. "Using Tax Parcels to Select a Location-Based Sample: An Illustration That Examines Residents' Awareness of Sex Offenders in Neighbourhoods". Evaluation Review. 32(4):315-334.

Cronbach $\sqcup$, Ambron SR, Dornbusch SM, Hess RD, Hornik RC, Phillips DC, Walker DF, Weiner SS. (1980). Toward Reform of Program Evaluation. San Fransisco, CA: JosseyBass.

Evans RG and Stoddart GL. 1990. "Producing Health, Consuming Health Care". Social Science and Medicine 31(12): 1347-63.

Eyles J and Woods KJ. 1983. The Social Geography of Medicine of Health. New York: St. Martin's Press.

Favaro P, Lam T and Durocher L. (2008). Social Risk Index: Elementary and Secondary Schools. Peel District School Board.

Friis RH and Sellers TA. 2009. Epidemiology for Public Health Practice. Fourth Edition. Sudbury, Mass.: Jones and Bartlett Publishers.

Frohlich N \& Mustard C. (1996). "A Regional Comparison of Socioeconomic and Health Indices in a Canadian Province". Social Science \& Medicine. 42:1273-1281. 
Gatrell AC. 2002. Geographies of Health: An Introduction. UK: Blackwell Publishers Ltd.

Gatrell A and Löytönen M, eds. 1998. GIS and Health. London: Taylor \& Francis Ltd.

Glasgow RE, Vogt TM, Boles SM. (1999). "Evaluating the public health impact of health promotion interventions: the RE-AIM framework." American Journal of Public Health. 1999 September; 89(9): 1322-1327.

Goddard M, Smith P. (2001). "Equity of access to health care services:

Theory and evidence from the UK". Social Science \& Medicine. 53(9):1149-1162.

Goodchild MF. (1992). Analysis. In RF Abler, MG Marcus, JM Olson (eds.), Geographer's Inner Worlds: Pervasive Themes in Contemporary American Geography. New Brunswick, N.J.: Rutgers University Press. 138-162.

Greene J and McClintock C. (1985). "Triangulation in Evaluation". Evaluation Review. 9(5):523-545.

Greene JC. (2001). "Evaluation Extrapolations". American Journal of Evaluation. 22:397402.

Hashemi SM and Hedjazi Y. (2011). "Factors affecting members' evaluation of agribusiness ventures' effectiveness". Evaluation and Program Planning. 34(1):51-59.

Hertzman C and Bertrand J. (2007). "Children in poverty and the use of early development instrument mapping to improve their worlds". Paediatric Child Health. 12(8): 687-692.

Holian J. (1996). "Client and Birth Record Linkage: A Method, Biases, and Lessons". American Journal of Evaluation. 17:227-235.

Irwin LG, Arjumand Siddiqi A, Hertzman C. (2007). "Early child development: a powerful equalizer". Final Report for the WHO Commission on the Social determinants of Health. Geneva: World Health Organization. Accessed April 12, 2012:

http://factsforlife.org/pdf/a91213.pdf

Jacobon C, Carter RW, Hockings M and Kelman J. (2011). "Maximizing Conservation Evaluation Utilization". Evaluation. 17(1):53-71. 
Jaeger E, Shlay A and Weinraub M. (2000). "Child Care Improvement on a Shoestring: Evaluating a Low-Cost Approach to Improving the Availability of Quality Child Care". Evaluation Review. 24(5):484-515.

Jones K and Moon G. (1987). Health, Disease and Society: a critical medical geography. London: Routledge \& Kegan Paul Ltd.

Koschinsky J. (2012). "The case for spatial analysis in evaluation to reduce health inequities". Evaluation and Program Planning, doi:10.1016/j.evalprogplan.2012.03.004 In Press, Corrected Proof. Last accessed September 14, 2012.

Krepicz M. (2010). GIS for Neighbourhood Social Planning. Presentation for GeoTec 2010.

Lalonde M. 1974. A New Perspective on the Health of Canadians: A Working Document. Last accessed September 6, 2012: http://www.phac-aspc.gc.ca/ph-sp/pdf/perspecteng.pdf.

Langlois A \& Kitchen P. (2001). "Identifying and Measuring Dimensions of Urban Deprivation in Montreal: An Analysis of the 1996 Census Data”. Urban Studies. January, 38(1): 119-139.

Last JM, ed. (2001). A Dictionary of Epidemiology, $4^{\text {th }}$ ed. New York: Oxford University Press.

Maheswaran R and Craglia M. (2004). "Introduction and Overview" in GIS in Public Health Practice. Edited by Maheswaran, Ravie and Massimo Craglia. Boa Raton, Florida: CRC Press.

Martin D, Wrigley H, Barnett S, Roderick P. (2002). "Increasing the sophistication of access measurement in a rural healthcare study." Health \& Place. 8:3-13.

Matern R, Mendelson M and Oliphant M. (2009). Developing a Deprivation Index: The Research Process. Daily Bread Food Bank and the Caledon Institute of Social Policy.

Matheson F, Moineddin R, Dunn JR, Creatore MI, Gozdyra P \& Glazier RH. (2006). "Urban neighbourhoods, chronic stress, gender and depression". Social Science and Medicine. 63:2604-2616. 
Matheson F, Moineddin R \& Glazier RH. (2008). "The weight of place: A multilevel analysis of gender, neighborhood material deprivation, and body mass index among Canadian adults". Social Science and Medicine. 66:675-690.

McKenzie, R., Naccarella, L., Stewart, A., \& Thompson, C. (2007). "Targeting what matters in health promotion evaluation: Using the RE-AIM approach to identify success in real-world settings". Evaluation Journal of Australasia. 7(1): 19-26.

McLafferty S, Freeman VL, Barrett RE, Luo L \& Shockley A. (2012). "Spatial error in geocoding physician location data from the AMA Physician Masterfile: Implications for spatial accessibility analysis." Spatial and Spatio-temporal Epidemiology. April, 3(1): 31 38.

McLeod, Kari S. (1998). Melting Snow: A Re-Examination of Dr. John Snow, His Dot Map, and the 1854 Broad Street Cholera Outbreak. MA Thesis, Department of Geography, Carleton University.

McMurchy D \& Palmer R. (2012). The Community Action Program for Children (CAPC) National Outcomes Assessment. Technical report. Prepared for the Public Health Agency of Canada.

Minister of Supply and Services Canada. (1994). Strategies for Population Health: Investing in the Health of Canadians. Prepared by the Federal, Provincial and Territorial Advisory Committee on Population Health. For the Meeting of the Ministers of Health, Halifax, Nova Scotia. September 14-15, 1994. Last accessed September 6, 2012: http://www.phac-aspc.gc.ca/ph-sp/pdf/strateg-eng.pdf

Mustard JF (2002). Chapter 2: Early Child Development and the Brain - the Base for Health, Learning, and Behaviour Throughout Life. From: From Early Child Development to Human Development: Investing in Our Children's Future. Ed: Mary Eming Young. World Bank: Washington, DC. Online Book. http://www.questia.com/PM.qst?a=o\&d=116203105

Myers J, Bernstein M, Morin SF and Reyes M. (2007). "Targeting HIV clinical training with maps: Lessons from the Pacific AIDS Education and Training Center". Evaluation and the Health Professions. 30(4):322-338.

Nunn S and Newby W. (2011). "The Geography of Deterrence: Exploring the Small Area Effects of Sobriety Checkpoints on Alcohol-Impaired Collision Rates Within a City". Evaluation Review. 35(4):354-378. 
Nutley SN, Walter I \& Davies HTO. (2007). Using Evidence: How Research Can Inform Public Services, Bristol: The Policy Press.

Pampalon R \& Raymond G. (2000). "A Deprivation Index for Health and Welfare Planning in Quebec". Chronic Diseases in Canada. 21:104-113.

Pampalon R \& Raymond G. (2003). "Indice de défavorisation matérielle et sociale : son application au secteur de la santé et du bien-être". Santé, Société et Solidarité. 1:191208. Accessed June 4, 2012 :

http://www.persee.fr/web/revues/home/prescript/article/oss_16348176_2003_num_2_1_932

Pickles J. (1997). "Tool or Science? GIS, Technoscience, and the Theoretical Turn". Annals of the Association of American Geographers, 87(2):363-372

Predy GN, Edwards J, Fraser-Lee N, Ladd B, Moore K, Lightfoot P \& Spinola C. (2008). Poverty and health in Edmonton. Edmonton, Alberta: Public Health Division, Alberta Health Services (Edmonton Area); November.

Public Health Agency of Canada (2006a). "Integrated National Evaluation Tool"

Public Health Agency of Canada (2006b). "National Program Profile performance measurement data collection tool"

Public Health Agency of Canada. (2006c). What is the Population Health Approach? http://www.phac-aspc.gc.ca/ph-sp/phdd/approach/approach.htmlthealth (last accessed April 10, 2006).

Public Health Agency of Canada (2010a). Promotion of Population Health Grant and Contribution Programs: Summary of Program Evaluations, 2004-2009. Accessed April 17, 2012: http://www.phac-aspc.gc.ca/about_apropos/reports/2008-09/pphgcp-pscpsp/03rel-eng.php

Public Health Agency of Canada (2010b). Summative Evaluation of the Canada Prenatal Nutrition Program 2004-2009. Accessed April 12, 2012: http://www.phacaspc.gc.ca/about_apropos/evaluation/reports-rapports/2009-2010/cpnppcnp/overview-ve-eng.php\#a1 
Public Health Agency of Canada (2010c). Summative Evaluation of the Community Action Program for Children 2004-2009. Accessed April 12, 2012:

http://www.phac-aspc.gc.ca/about_apropos/evaluation/reports-rapports/2009-

2010/capc-pace/index-eng.php

Renger R, Cimetta A, Pettygrove S, Rogan S. (2002). "Geographic information systems (GIS) as an evaluation tool". American Journal of Evaluation. 23: 469-79.

Renger R, Passons O and Cimetta A. 2003. "Evaluating Housing Revitalization Projects: Critical Lessons for all Evaluators". American Journal of Evaluation. 24:51-64.

Rossi PH, Lipsey MW, Freeman HE. (2004). Evaluation: A systematic approach. Seventh Edition. Thousand Oaks, CA: Sage.

Schuurman N. 2000. "Trouble in the Heartland: GIS and its Critics in the 1990s". Progress in Human Geography. 24(4):569-590.

Sheppard E. 2001. "Quantitative geography: representations, practices, and possibilities". Environment and Planning D: Society and Space. 19:535-554.

Sidebotham P, Heron J, Golding J; ALSPAC study team. (2002). "Child Maltreatment in the "Children of the Nineties": deprivation, class and social networks in a UK sample". Child Abuse and Neglect. December, 26(12):1243-59. Accessed June 4, 2012: http://www.ncbi.nlm.nih.gov/pubmed/12464299

Smith NL (1979). "Techniques for the Analysis of Geographic Data in Evaluation". Journal of Evaluation and Program Planning. 2:119-126.

Suggett B. \&Larsen P. (2000). "Prenatal education class attendance with additional insights provided by a geographic information system". Canadian Journal of Program Evaluation Special Issue, 177-183.

Taylor DRF. (2005). "The Theory and Practice of Cybercartography: An Introduction" in Cybercartography - Theory and Practice. Edited by D.R. Fraser Taylor.

Terashima M. (2009). Mapping Social Determinants of Health. Dalhousie University, Community Health \& Epidemiology. Presentation for NCCPH Summer Institute 2009. http://www.si2009.ca/docs/EN_Terashima_NCCDH_July6_MappingFinal.pdf 
Townsend, P. (1987). “Deprivation”. Journal of Social Policy. 16:125-146.

Treasury Board of Canada Secretariat. (2011). "2010 Annual Report on the Health of the Evaluation Function". Accessed April 11, 2012:

http://www.tbs-sct.gc.ca/report/orp/2011/arhef-raefe01-eng.asp

Weiss CH \& Bucuvalas MJ (1980). "Truth Tests and Utility Tests: Decision-Makers'

Frames of Reference for Social Science Research". American Sociological Review. April, 45(2):302-313.

Wilkinson P, Grundy C, Landon M and Stevenson S. 1998. "GIS in Public Health" in GIS and Health. Edited by Gatrell, Anthony and Markku Löytönen. London: Taylor \& Francis Ltd.

Young TK. 1998. Population Health: Concepts and Methods. New York: Oxford University Press. 